PNL- 4878

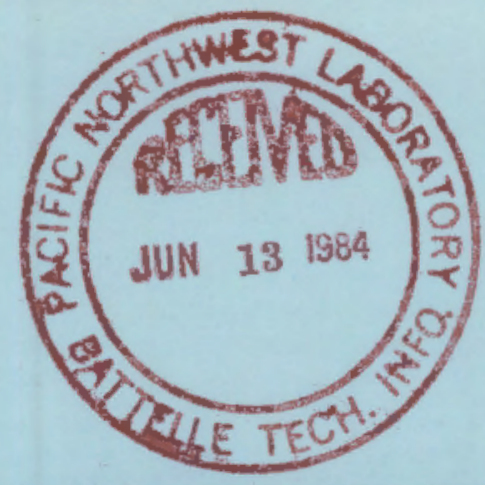

1 -

NUREG/CR-3533

PNL-4878

RAE-18-5

\title{
Radon Attenuation Handbook for Uranium Mill Tailings Cover Design
}

Prepared by V. C. Rogers, K. K. Nielson, RAE

D. R. Kalkwarf/PNL

Rogers \& Associates Engineering Corporation

Pacific Northwest Laboratory

Prepared for

U.S. Nuclear Regulatory

Commission 
This report was prepared as an account of work sponsored by an agency of the United States Government. Neither the United States Government nor any agency thereof, or any of their employees, makes any warranty, expressed or implied, or assumes any legal liability of responsibility for any third party's use, or the results of such use, of any information, apparatus, product or process disclosed in this report, or represents that its use by such third party would not infringe privately owned rights.

\section{NOTICE}

Availability of Reference Materials Cited in NRC Publications

Most documents cited in NRC publications will be available from one of the following sources:

1. The NRC Public Document Room, 1717 H Street, N.W. Washington, DC 20555

2. The NRC/GPO Sales Program, U.S. Nuclear Regulatory Commission, Washington, DC 20555

3. The National Technical Information Service, Springfield, VA 22161

Although the listing that follows represents the majority of documents cited in NRC publications, it is not intended to be exhaustive.

Feferenced documents available for inspection and copying for a fee from the NRC Public Document foom include NRC correspondence and internal NRC memoranda; NRC Office of Inspection and Enforcement bulietins, circulars, information notices, inspection and investigation notices; Licensee Event Reports; vendor reports and correspondence; Commission papers; and applicant and licensee documents and correspondence.

The following documents in the NUREG series are available for purchase from the NRC/GPO Sales Program: formal NRC staff and contractor reports, NAC-sponsored conference proceedings, and NRC booklets and brochures. Also available are Regulatory Guides, NRC regulations in the Code of Federal Regulations, and Nuclear Regulatory Commission Issuances.

Documents available from the National Technical Information Service include NUREG series reports and technical reports prepared by other federal agencies and reports prepared by the Atomic Energy Commission, forerunner agency to the Nuclear Regulatory Commission.

Documents available from public and special technical libraries include all open literature items, such as books, journal and periodical articles, and transactions. Federal Register notices, federal and state legislation, and congressional reports can usually be obtained from these libraries.

Documents such as theses, dissertations, foreign reports and translations, and non-NRC conference proceedings are available for purchase from the organization sponsoring the publication cited.

Single copies of NRC draft reports are available free, to the extent of supply, upon written request to the Division of Technical Information and Document Control, U.S. Nuclear Regulatory Commission, Washington, DC 20555.

Copies of industry codes and standards used in a substantive manner in the NAC regulatory process are maintained at the NRC Library, 7920 Norfolk Avenue, Bethesda, Maryland, and are available there for reference use by the public. Codes and standards are usually copyrighted and may be purchased from the originating organization or, if they are American National Standards, from the American National Standards Institute, 1430 Broadway, New York, NY 10018. 
NUREG/CR-3533

PNL-4878

RAE-18-5

RU

\section{Radon Attenuation Handbook for Uranium Mill Tailings Cover Design}

Manuscript Completed: February 1984

Date Published: April 1984

\section{Prepared by}

V. C. Rogers, K. K. Nielson, Rogers and Associates Engineering Corporation

D. R. Kalkwarf, Pacific Northwest Laboratory

Rogers and Associates Engineering Corporation

Salt Lake City, UT 84110

Under Contract to:

Pacific Northwest Laboratory

Richland, WA 99352

\section{Prepared for}

Division of Health, Siting and Waste Management

Office of Nuclear Regulatory Research

U.S. Nuclear Regulatory Commission

Washington, D.C. 20555

NRC FIN B2269 



\section{ABSTRACT}

This handbook has been prepared to facilitate the design of earthen covers to control radon emission from uranium mill tailings. Radon emissions from bare and covered uranium mill tailings can be estimated from equations based on diffusion theory. Basic equations are presented for calculating surface radon fluxes from covered tailings, or alternately, the cover thicknesses required to satisfy a given radon flux criterion. Also described is a computer code, RAECOM, for calculating cover thicknesses and surface fluxes. Methods are also described for measuring diffusion coefficients for radon, or for estimating them from empirical correlations. Since long-term soil moisture content is a critical parameter in determining the value of the diffusion coefficient, methods are given for estimating the long-term moisture contents of soils. The effects of cover defects or advection are also discussed and guidelines are given for determining if they are significant. For most practical cases, advection and cover defect effects on radon flux can be neglected. Several examples are given to demonstrate cover design calculations, and an extensive list of references is included. 

ABSTRACT ............................. i

EXECUTIVE SUMMARY .................. vii

1 INTRODUCTION ................... 1-1

1.1 Organization of Handbook ......... 1-1

1.2 Background and Previous Work ......... 1-2

2 DETERMINING RADON ATTENUATION THROUGH COVER MATERIALS 2-1

2.1 Radon Diffusion Equation ......... 2-1

2.2 Flux From Bare Tailings ......... 2-2

2.3 Flux From Covered Tailings ........ 2-2

2.4 Cover Thickness From Flux Criterion . . . . . 2-4

2.5 Examples of Surface Flux and Cover Thickness Determinations ............ 2-6

2.6 Multiregion Systems .......... 2-11

2.6.1 The RAECOM Computer Code ...... 2-11

2.6.2 Approximate Expressions ........ 2-11

2.6.3 Examples of Multiregion Calculations . . 2-14

2.7 Cover Source Considerations ....... 2-16

3 MEASUREMENT OF THE RADON DIFFUSION COEFFICIENT $\ldots$. 3-1

3.1 Laboratory Measurements . . . . . . . . 3-1

3.1.1 Bare Flux and Covered Flux ...... 3-1

3.1.2 Bare Flux and Covered Source Concentration 3-2

3.1.3 Transient Radon Concentration Above A Cover 3-2

3.1.4 Other Laboratory Methods of Measuring D . 3-4

3.2 Field Measurements .......... 3- . 3-4

3.3 Sensitivity Analysis ........ 3-5

3.4 Values of Measured Diffusion Coefficient . . . 3-5 
Table of Contents (Continued)

Chapter

$\underline{\text { Page }}$

4.4 Estimates of The Long-Term Moisture Content of Soils 4-6

4.5 Compaction Effects on Diffusion Coeficients . 4-7

4.6 Summary ................ 4-8

5

OTHER FACTORS INFLUENCING RADON MIGRATION .... 5-1

5.1 Radon Source Term ........... 5-1 5.2 Source Term Impacts on Reclamation Design ... 5-1 5.3 Long-Term Integrity of Tailings Covers .... 5-3 5.4 Radon Transport By Advection ....... 5-7

6 SUMMARY AND APPLICATION ................. 6-1

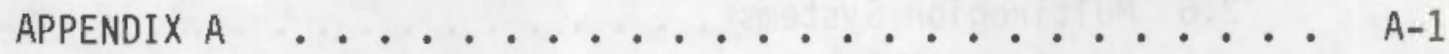

APPENDIX B ...................... B-1

REFERENCES $\ldots \ldots \ldots \ldots \ldots \ldots \ldots$ R-1 


\section{List of Figures}

Figure No.

Page

ES-1 Comparison of Measured Radon Diffusion Coefficients With A Simple Correlation Function Assuming Different Porosities .............. $x$

238U Decay Scheme ............. 1- . . . .

2 Normalized Flux From Bare Tailings as a Function of Tailings Thickness and Diffusion Coefficient ... 2-3

3 Cover Surface Radon Flux For Various Thicknesses and Parameters ............. 2-5

4 Nomograph For Estimating Necessary Cover Thickness For Radon Attenuation........ 2-7

Effect of Soil Thickness on Surface Radon Flux . . 2-8

Major Components of RAECOM Model . . . . . 2-12

Parameters For a Multilayer Cover System . . . . 2-13

8 Transient Alpha Activity Curves For Measuring Radon Diffusion Coefficients ......... 3-3

9 Relative Uncertainties For Four Methods of Determining the Diffusion Coefficient. Each Curve Assumes A 10\% Uncertainty In Individual Radon Measurements . . . 3-6

10 Comparison of Measured Radon Diffusion Coefficients With A Simple Correlation Function Assuming Different Porosities

11 Reference Volume of Unsaturated Porous Material . 4-2

12 Comparison of Radon Diffusion Coefficients and Model Calculation for Riverton, Wyoming Soil .... 4-3

13 Particle Size Distribution Effects On D .... 4-5

14 Compaction Effects On D For A Well Graded Soil ... 4-9

15 Radon Emanating Coefficients For Tailings Samples . 5-2

16 Cover Efficiency For Sandy Tailings ... . . . 5-4

17 Loss In Radon Attenuation Effectiveness . . . . 5-6

18 Estimation of the Ratios $v_{0} / v_{d}$ and $J_{d} / J_{a}$ From The Cyclic Radon Flux Ratio K......... 5-9 


\section{List of Tables}

Table No.

Page

ES-1 Procedural Checklist For Calculating Adequate Cover Thickness ........................... xiv

1 Rules of Thumb For Estimating Cover Thicknesses - 2-10.

2 RAECOM Calculation of Multiregion Example ... 2-17

3 Measured Radon Diffusion Coefficients For Earthen Materials ................... 3-9

4 Key Parameters for Source Calculation Example . . 5-5

5 Procedural Checklist For Calculating Adequate Cover Thickness ............. 6-5 


\section{EXECUTIVE SUMMARY}

\section{ES.1 INTRODUCTION}

This handbook has been prepared to facilitate the design of earthen covers to control radon emission from uranium mill tailings. It contains specific procedures for designing tailings covers for adequate radon attenuation. The procedures are presented so that the design analysis can be performed with either hand calculators or with more complex computer models. Both methods give sufficient accuracy in the required cover thickness for most practical applications. The handbook also contains a greatly expanded data base for estimating diffusion coefficients based upon soil type, compaction and moisture content.

The handbook addresses the following main topics important in evaluating the effectiveness of cover designs for radon attenuation.

1. Concise procedures for calculating cover thicknesses required to satisfy the design criterion using both exact and approximate expressions.

2. Experimental techniques used to measure the radon diffusion coefficients for cover materials.

3. Procedures and a data base for estimating diffusion coefficients for cover materials for use when specific measurements on the material are not available.

In addition, the handbook contains supporting information in the following areas:

1. An identification of other key references relating to radon transport through materials. This also includes recent field verification of both the calculational procedures and the laboratory measurements.

2. A discussion of the characteristics of the radon source term and its influence on cover design.

3. The mathematical development of the procedures and a listing of the RAECOM computer program and input data format.

Radon does not combine readily with other elements because it is a chemically inert gas. The principal isotope of radon, $222 \mathrm{Rn}$, is generated from the radioactive decay of $226 \mathrm{Ra}$ and is a decay daughter in the $238 \mathrm{U}$ decay series. The half-life of radon is 3.8 days, allowing the radon 
to migrate considerable distances before decaying. Furthermore, the generation of $222 \mathrm{Rn}$ continues at its current rate for many thousands of years due to the relatively long half-lives of ${ }^{226} \mathrm{Ra}$, and its parent, ${ }^{230} \mathrm{Th}$, which are both present in the tailings.

The calculation of the thicknesses of cover materials required to attenuate radon flux to near-background levels is generally based upon diffusion theory. The effectiveness of a particular cover material in attenuating radon release depends upon that material's ability to restrict the diffusion long enough that the radon decays to a solid daughter and becomes trapped before it completely penetrates the cover. The parameter that characterizes this radon movement in the soil is called the diffusion coefficient.

\section{ES.2 DETERMINING RADON ATTENUATION THROUGH COVER MATERIALS}

The thickness of cover material required for uranium-mill tailings reclamation is usually determined by a radon flux or concentration criterion which must be satisfied. The general approach used in estimating the required thickness of a cover can be divided into two phases. First, the characteristic parameters of the tailings and cover must be measured or estimated. These include the radon diffusion coefficients, porosities and moistures of the tailings and cover, and the radium content and emanating power of the tailings. Second the thickness of cover needed to achieve a prescribed radon flux is determined by iteratively calculating radon fluxes for various cover thicknesses until the thickness giving the prescribed flux is found. Alternatively, an approximate expression can be used to calculate the cover thickness directly. The diffusion coefficient for radon in the total pore space of the soil is designated by the symbol $D$, consistent with recent reports on radon movement. A second parameter, the effective bulk diffusion coefficient of the soil, is of ten designated $\mathrm{D}_{\mathrm{e}}$, and has sometimes been confused with $\mathrm{D}$ due to varying symbols and nomenclature used in the literature. The two are related by $D=D_{e} / p$, where $p$ is the total soil porosity.

Radon emissions from bare and covered uranium mill tailings are estimated from equations based on diffusion theory. Basic equations are presented for calculating surface radon fluxes from covered tailings, or alternately, the cover thicknesses required to satisfy a given radon flux criterion. Also described is a computer code, RAECOM, for calculating cover thicknesses and surface fluxes.

\section{ES.3 MEASUREMENT OF THE RADON DIFFUSION COEFFICIENT}

The degree of radon flux reduction provided by a tailings cover depends on the time required for the radon to diffuse through the cover, and thus to partially decay in it. Therefore, the diffusion coefficient of the soil is of central importance to determine the required cover thickness to achieve a given radon flux reduction. It is therefore advantageous to 
know as accurately as possible the $D$ of the candidate cover material. The diffusion coefficient is most accurately determined by direct measurement. The measurable quantities in determining $D$ are the radon flux and the radon concentration. The $D$ can be calculated from any combination of two measurements of flux and concentration which directly involve the source and the cover.

The three most common pairs of measurements to determine $D$ are: a) the source flux and the flux through the cover; b) the source flux and the equilibrium concentration at the bottom of the cover; and c) the timedependent concentration at the bottom of the cover and at the top of the cover within a sealed system. Variations on these methods have also been used. Radon diffusion coefficients can be measured either in the laboratory or in the field. Field measurements offer the advantage of exposure to actual wind, sun, rain and other significant environmental parameters which may affect the soil moisture content and its diffusion coefficient. However higher variability complicates the interpretation of field data. Laboratory measurements of $D$ provide better control over the soil and diffusion conditions. The expense of testing soils in the laboratory is also generally less than for field tests, as are the time requirements for the tests.

A diffusion coefficient data base, containing nearly 200 elements, has been assembled. A representative sample of the data is shown in Figure ES-1. The data were mostly measured by the time-dependent technique (method c), but also include many steady-state and some field measurements. The diffusion coefficients are relatively constant at absolute dryness, averaging $0.061+0.006 \mathrm{~cm}^{2} / \mathrm{s}$ for the dry soils tested. As illustrated, increasing mo isture causes lower diffusion coefficients.

The variation in diffusion coefficients at intermediate moistures can be largely attributed to varying pore size distributions; however, the variation at high moistures $(m=0.9-1.0)$ cannot. Instead, this variation results from the very steep variation in diffusion coefficients with moisture as $m$ approaches unity. This causes large apparent errors in diffusion coefficients to result from relatively small errors in sample moisture content, density, or specific gravity estimates from which the saturation, $m$, is estimated. The large variation near saturation in Figure ES-1 is therefore attributed to uncertainties in the degree of moisture saturation of the soil samples.

Other soil properties besides soil moisture may have an influence on $D$. One parameter, the percent passing a 200 mesh sieve, is a convenient way to classify soils. It is important that the highest practical compaction be achieved for earthen covers over the tailings so that maximum radon attenuation is obtained; thus, pertinent engineering specifications should usually call for compactions of at least 90 percent of standard Proctor compaction. 


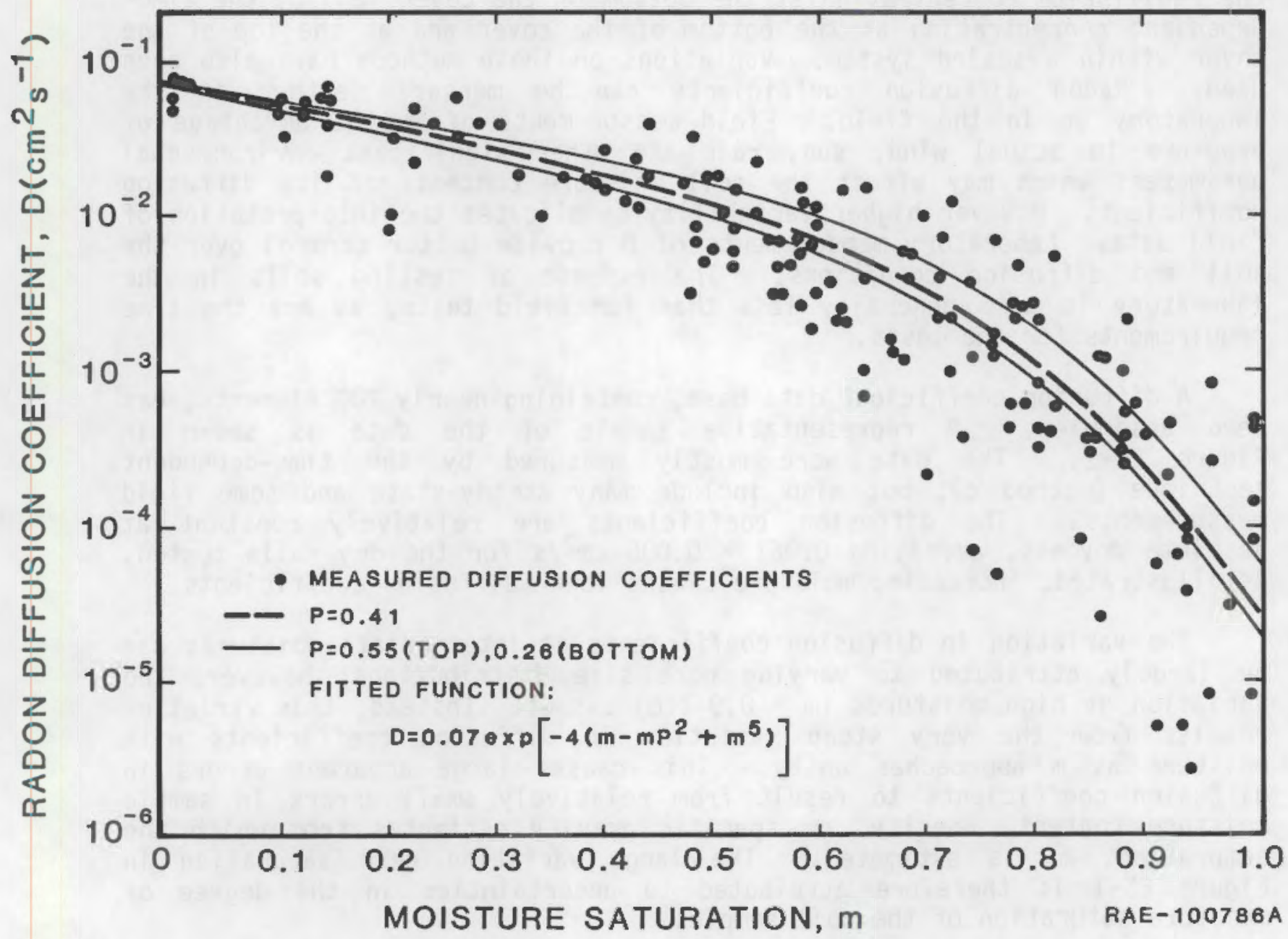

FIGURE ES-1. COMPARISON OF MEASURED RADON DIFFUSION COEFFICIENTS WITH A SIMPLE CORRELATION FUNCTION ASSUMING DIFFERENT POROSITIES. 


\section{ES.4 ESTIMATING DIFFUSION COEFFICIENTS}

It is often desirable to estimate the diffusion coefficient of materials under varying conditions for which measured values are not available. This can be done with either complex models based upon physical characteristics of the soil, or upon empirical correlations based upon measured values of $D$. So $i l$ moisture and compaction are important factors in the value of $D$ for a given soil.

Recently, a theoretical model has been developed for estimating radon diffusion coefficients without relying on fitted parameters to radon diffusion data. The formalism considers the detailed composition of the pore fluid as well as a statistical definition of the pore structure of the material. The pore fluid is modeled as a two-phase mixture of air and water, with radon diffusion occurring in both phases, and with radon exchange occurring between the air and water. The pore structure is modeled from the measured pore size distribution of the soil, and is described by the weighted average of all combinations of single and composite pores. The soil parameters required to estimate a radon diffusion coefficient are thus the moisture, the packing density and the pore size distribution.

Agreement between the model calculations and measured $D$ values is generally within the experimental uncertainties in the data. The pore size distribution needed for the calculations can be obtained either from water drainage curves or from particle size distributions.

Empirical correlations for estimating $D$ have the advantage of being simple and easy to use, with a minimal amount of information needed. The recommended correlation using the fraction of saturation, $m$, is:

$$
D=0.07 \exp \left[-4\left(m-m p^{2}+m^{5}\right)\right]
$$

and is plotted in Figure ES-1.

The correlation shown in Figure ES-1 has a geometric standard deviation of 2.0. However, individual estimates for a particular soil at a given moisture may be uncertain by as much as an order of magnitude, especially for higher values of $m$.

The moisture content of earthen materials has been shown to markedly affect their properties for radon gas diffusion, salt and radionuclide transport, physical stability, and support of vegetation. Because of these effects, the moisture contents in covers for uranium mill tailings are of particular interest for proper containment and stabilization of the tailings and their decay products. Since tailings containment systems must function for very long time periods, the long-term equilibrium moisture characteristics are of particular interest. 
There presently exist several complex models for calculating equilibrium soil moistures. However, considerable detailed meteorological, hydrological and geophysical data are needed as input to these models and a detailed discussion of the models is beyond the scope of this handbook. There are several empirical and semi-empirical approaches that give a satisfactory estimate of the long-term moisture. One simple engineering correlation is:

$$
m_{r}=\left[0.124 p^{\frac{1}{2}}-0.0012 E-0.04+0.156 f_{c m}\right] \text {, }
$$

where

$$
\begin{aligned}
& m_{r}= \begin{array}{l}
\text { residual soil moisture in soil overlying a deep aquifer } \\
\text { (fraction of saturation) }
\end{array} \\
& P= \text { annual precipitation }(\text { in) } \\
& E=\text { annual lake evaporation (in) } \\
& f_{C m}=\text { soil fraction passing a No. } 200 \text { mesh sieve }
\end{aligned}
$$

\section{ES.5 OTHER FACTORS INFLUENCING RADON MIGRATION}

Three other factors influencing radon migration warrant consideration. They are the source term (of the tailings), the effects of defects in the cover, and the effects of advective radon transport.

Characterization of the source term is an important step in performing the design analysis of an adequate cover system. The key parameters defining the source term are the radium concentration, the dry bulk density, the emanation coefficient, and the diffusion coefficient. The utilization of source term information can have beneficial impacts on remedial action design concepts. For example, the sand component of tailings can be effective as a bottom layer of a tailings cover.

An effective cover may be placed initially over the tailings. However, there are many mechanisms that can disrupt a cover, and, because radon generally takes the path of least resistance, these mechanisms can render a significant part of the cover less effective in attenuating radon. Several techniques are available for promoting or maintaining cover integrity. If cracks develop, the percentage loss of cover effectiveness in the crack depth zone is approximately equal to twelve times the percent of the surface area disrupted by cracks.

Over the last several years there has been growing evidence presented to suggest enhanced, advective transport of radon in the environment. 
However, most advective transport is cyclic in direction and velocity, minimizing long-term effects on net radon releases. Advection is generally not an important effect for semi-arid regions. However, it may be more prominant in humid areas because the diffusion coefficients are generally smaller.

\section{ES.6 SUMMARY AND APPLICATION}

The radon releases from bare and covered tailings can be estimated using diffusion theory, if appropriate diffusion coefficients are used. The procedures for calculating the thickness of an adequate cover system are straight-forward and the calculations can be performed by hand or by computer programs such as the RAECOM code. A procedural checklist for the hand calculations is given in Table ES-1.

As shown in the table, Step 1 is the calculation of all source parameters. Step 2 is the calculation of the cover parameters. These parameters are input to RAECOM for a determination of the required cover thickness and surface flux. If a hand calculation is performed, Step 3 is the calculation of cover attenuation parameters and bare tailings flux. In Step 4, the required cover thickness is calculated. If the system consists of a multilayer cover, the surface flux from the first layer is calculated in Step 4 and the diffusion coefficient for the effective source term is calculated in Step 5. Repeat steps 4 and 5 until the top layer is calculated. 


\section{TABLE ES-1}

PROCEDURAL. CHECKLIST FOR CALCULATING ADEQUATE COVER THICKNESS

Step

1. Determine Source Term Parameters, $R, E, \rho_{t}, p_{t}, a_{t}$

Def au It values, $R=2,812 \mathrm{G}$

$\rho_{\mathrm{t}}=1.5, \mathrm{D}_{\mathrm{t}}=0.35, \mathrm{~g}_{\mathrm{t}}=2$

2. Determine Cover Material Parameters, $D_{C}, P_{C}, \rho_{C}$

Default values, $P_{C}=0.35$, $g_{c}=2.7$

3. Calculate Cover Attenuation Parameters and Calculate or Estimate Bare Tailings Flux

4. Calculate Surface Flux or Cover Thickness

\footnotetext{
5. For Multiple Layer Cover, Calculate Effective Source $\mathrm{O}_{\mathrm{sm}}$
}

6. Repeat For Multiple Layer Covers

$$
\begin{aligned}
& m_{t}=10^{-2} M_{t}\left[\frac{1}{\rho_{t}}-\frac{1}{g_{t}}\right]^{-1} \\
& D_{t}=0.07 \exp \left[-4\left(m-m p^{2}+m^{5}\right)\right] \\
& a_{t}=p_{t}^{2} D_{t}\left[1-0.74 m_{t}\right]^{2} \\
& m_{c}=10^{-2} M_{c}\left[\frac{1}{\rho_{c}}-\frac{1}{g_{c}}\right]^{-1} \\
& D_{c}=0.07 \exp \left[-4\left(m-m p_{c}^{2}+m^{5}\right)\right] \\
& J_{t}=R \rho_{t} E\left(\lambda D_{t}\right)^{\frac{1}{2}} \\
& D_{c}=\left(\lambda / D_{c}\right)^{\frac{1}{2}} \\
& a_{c}=P_{c}^{2} D_{c}\left[1-0.74 m_{c}\right]^{2}
\end{aligned}
$$

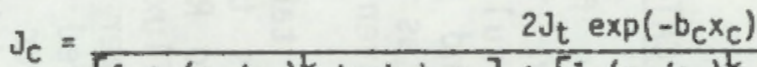

$$
x_{c}=\frac{1}{b_{c}} \ln \left[\frac{2 J_{t} / J_{c}}{\left(1+\sqrt{\left.a_{t} / a_{c}\right)} \tanh b_{t} x_{t}\right)+\left(1-\sqrt{\left.a_{t} / a_{c}\right)} \tanh b_{t} x_{t}\right)\left(J_{c} / J_{t}\right)^{2}}\right]
$$

Calculate Item 4 for the first cover layer, then calculate Item 5 for the second cover layer, then calculate Item 4 for the second cover layer, and so on until Item 4 is calculated for the top layer 


\section{INTRODUCTION}

Radon emissions from uranium-mill tailings have long been recognized as a major potential health hazard. During the milling of uranium ore, the ore is crushed to facilitate processing and a negligible fraction of radium, the parent of radon, is removed. Consequently, the accessibility of radon to the environment is generally increased.

An important feature of any uranium-mill tailings management program is the proper long-term stabilization of the tailings to adequately reduce radon emissions. The generally accepted means of achieving stabilization is to cover the tailings with earthen materials. Hence, it is important to accurately determine the radon-attenuating properties of cover materials and cover systems. Radon migration through earthen materials is a complex process in which the pore space and the air and moisture in it greatly influence the effectiveness of the cover material in attenuating radon. This handbook provides the basis, the methodology, and the standardized procedures for calculating the radon attenuation provided by cover systems placed over uranium mill tailings impoundments. It is an update of an earlier handbook $(1)$ and as such contains significant new information on estimating and measuring diffusion coefficients. It also incorporates the results of recent research efforts, particularly in the areas of the physical description of the diffusion coefficient, the effects of cracking and other defects and the effects of advective radon transport caused by moisture evaporation or barometric pressure variations.

The handbook contains specific procedures for designing tailings covers for adequate radon attenuation. The procedures are presented so that the design analysis can be performed with either hand calculators or with more complex computer models. Both methods give sufficient accuracy in the required cover thickness for most practical applications. The handbook also contains a greatly expanded data base for estimating diffusion coefficients based upon soil type, compaction and moisture content.

\subsection{ORGANIZATION OF HANDBOOK}

This handbook addresses the following main topics important in evaluating the effectiveness of cover designs for radon attenuation.

1. Concise procedures for calculating cover thicknesses required to satisfy the design criterion using both exact and approximate expressions.

2. Experimental techniques used to measure the radon diffusion coefficients for cover materials.

3. Procedures and a data base for estimating diffusion coefficients for cover materials for use when specific measurements on the material are not available. 
In addition, the handbook contains supporting information in the following areas:

1. An identification of other key references relating to radon transport through materials. This also includes recent field verification of both the calculational procedures and the laboratory measurements.

2. A discussion of the characteristics of the radon source term and its influence on cover design.

3. The mathematical development of the procedures and a listing of the RAECOM computer program and input data format.

A background review of early and recent relevant literature is presented in the following section of this chapter. Specific quantitative results from the recent literature are presented as appropriate to the technical development in later chapters. Chapter 2 contains the procedures for calculating the required cover thicknesses, along with several illustrations and examples. The methods for measuring diffusion coefficients are presented in Chapter 3, along with a comprehensive data base for a variety of soil types. The methods for estimating the cover diffusion coefficients are given in Chapter 4. Chapter 5 contains a discussion of the effects of advection, cover defects and source term variations. The surmary in Chapter 6 contains a checklist of the cover design procedures. The mathematical development and computer code information are given in Appendices of the handbook.

\subsection{BACKGROUND AND PREVIOUS WORK}

Radon does not combine readily with other elements because it is a chemically inert gas. The principal isotope of radon, ${ }^{222} \mathrm{Rn}$, is generated from the radioactive decay of $226 \mathrm{Ra}$ and is a decay daughter in the $238 \mathrm{U}$ decay series as shown in Figure 1. The half-life of radon, $T_{3}$, is 3.8 days which allows the radon to migrate considerable distances before decaying. Furthermore, the generation of $222 \mathrm{Rn}$ continues at its current rate for many thousands of years due to the relatively long half-lives of ${ }^{226} \mathrm{Ra}$, and its parent, ${ }^{230} \mathrm{Th}$, which are both present in the tailings.

The calculation of the thicknesses of cover materials required to attenuate radon flux to near-background levels is generally based upon diffusion theory. The effectiveness of a particular cover material in attenuating radon release depends upon that material's ability to restrict the diffusion long enough that the radon decays to a solid daughter and becomes trapped before it completely penetrates the cover. The parameter that characterizes this radon movement in the soil is called the diffusion coefficient. 


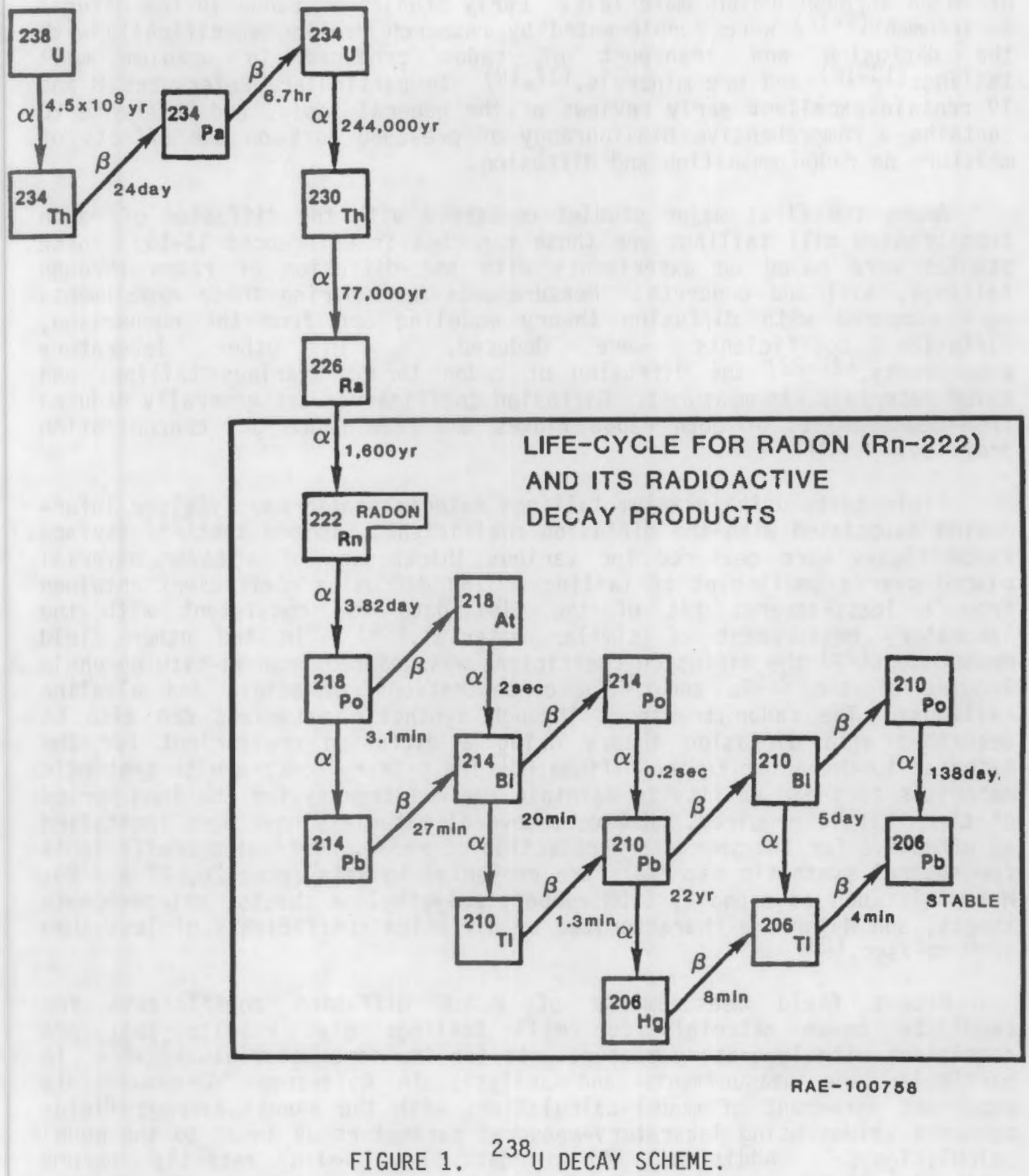


Researchers have long been interested in the diffusion and transport of radon through porous materials. Early studies of radon in the natural environment (2-12) were supplemented by research dealing specifically with the diffusion and transport of radon produced in uranium mill tailings $(13-16)$ and ore minerals. $(17,18)$ In particular, References 8 and 19 contain excellent early reviews of the general topic, and Reference 20 contains a comprehensive bibliography of pre-1980 work on the effects of moisture on radon emanation and diffusion.

Among the first major studies concerned with the diffusion of radon from uranium mill tailings are those reported in References 13-16. These studies were based on experiments with the diffusion of radon through tailings, soil and concrete. Measurements made during these experiments were compared with diffusion theory modeling and from the comparison, diffusion coefficients were deduced. In other laboratory experiments, (21-23) the diffusion of radon through various tailings and cover materials was measured. Diffusion coefficients are generally deduced from measurements of both radon fluxes and from radon gas concentration profiles. $(24-35)$

Field tests using uranium tailings materials also have yielded information associated with the diffusion coefficient. In one test (24) surface radon fluxes were measured for various thicknesses of a cover material placed over a small plot of tailings. The diffusion coefficient obtained from a least-squares fit of the flux data was consistent with the laboratory measurement of similar material.(24) In the other field measurement (25) the diffusion coefficient was deduced from in-situ borehole logging of the $226 \mathrm{Ra}$ and $222 \mathrm{Rn}$ concentrations in acidic and alkaline tailings. The radon transport through synthetic materials can also be described with diffusion theory using a diffusion coefficient for the material to characterize the diffusion. The primary concern with synthetic materials is their ability to maintain their integrity for the long period of time that is required. However, several materials have been identified as effective for the short-term reduction of radon. Diffusion coefficients for several synthetic materials are presented in References 26, 27 and 28 . Materials such as asphalt, EPDM rubber, polyethylene sheets, polycarbonate sheets, and Mylar are characterized by diffusion coefficients of less than $10^{-6} \mathrm{~cm}^{2} / \mathrm{sec} .(26)$

Recent field measurements of radon diffusion coefficients for candidate cover materials for mill tailings give results that are consistent with laboratory measurements for the same materials. $(36,37)$ In particular the measurements and analysis in Reference 36 demonstrate excellent agreement of model calculations with the annual average fieldmeasured values using laboratory-measured parameters as input to the model calculations, Additional field data have also recently become available(38) for comparison with laboratory measurements and calculational models.

Other recent efforts have focused upon methods for calculating or estimating radon diffusion coefficients with techniques ranging from simple correlations $(22,23,39)$ to complex models. $(40,41)$ Considerable success has been achieved with both the correlations and the models. 
Advective effects have recently been investigated.(42) The long-term effect of advection on the surface radon flux is generally much smaller than are uncertainties in predicting the flux. This same conclusion applies to cover defects such as cracking. (43-45) Therefore, in general, simple diffusion theory adquately describes the long-term radon transport through uranium mill tailings and earthen cover systems. 



\section{DETERMINING RADON ATTENUATION THROUGH COVER MATERIALS}

The thickness of cover material required for uranium-mill tailings reclamation is usually determined by a radon flux or concentration criterion which must be satisfied. The general approach used in estimating the required thickness of a cover can be divided into two phases. First, the characteristic parameters of the tailings and cover must be measured or estimated. These include the radon diffusion coefficients, porosities and moistures of the tailings and cover, and the radium content and emanating power of the tailings. Second the thickness of cover needed to achieve a prescribed radon flux is determined by iteratively calculating radon fluxes for various cover thicknesses until the thickness giving the prescribed flux is found. Alternatively, an approximate expression can be used to calculate the cover thickness directly.

In the following equations and throughout this handbook, the diffusion coefficient for radon in the total pore space of the soil is designated by the symbol $\mathrm{D}$, consistent with recent reports on radon movement. A second parameter, the effective bulk diffusion coefficient of the soil, is often designated $D_{e}$, and has sometimes been confused with $D$ due to varying symbols and nomenclature used in the literature. The two are related by $D=D_{e} / p$, where $p$ is the total soil porosity. Identjfal nomenclature but different symbols were used in the earlier handbook 1 ) and in the NRC's Generic Environmental Impact Statement on Uranium Milling (Appendix P). The symbol $\mathrm{D}$ in those reports corresponds to $\mathrm{D}_{\mathrm{e}}$ in this handbook.

\subsection{RADON DIFFUSION EQUATION}

The one-dimensional steady-state radon diffusion equation is:

$$
D \frac{d^{2} C}{d x^{2}}-\lambda C+R \rho \lambda E / p=0,
$$

where

$$
\begin{aligned}
& C=\text { radon concentration in the total pore space }\left(\mathrm{pCi} \mathrm{cm}^{-3}\right) \\
& D=\begin{array}{l}
\text { diffusion coefficient for radon in the total pore space } \\
\left(\mathrm{cm}^{2} \mathrm{~s}^{-1}\right)
\end{array} \\
& \lambda=\text { decay constant of radon }\left(2.1 \times 10^{-6} \mathrm{~s}^{-1}\right) \\
& \left.R=\text { specific activity of radium in the soil ( } \mathrm{pCi} \mathrm{g}^{-1}\right) \\
& \rho=\text { dry bulk density of the soil }\left(\mathrm{g} \mathrm{cm}^{-3}\right) \\
& E=\text { radon emanation coefficient (dimensionless) } \\
& \mathrm{P}=\text { total porosity of the soil (dimensionless) }
\end{aligned}
$$


The radon flux from the bulk soil material is related to the radon concentration in its pore space by Fick's Law:

$$
J=-10^{4} \text { Dp } \frac{d C}{d x} \text {, }
$$

where

$$
\begin{aligned}
J & =\text { bulk radon flux }\left(\mathrm{pCi} \mathrm{m}-2 \mathrm{~s}^{-1}\right) \\
10^{4} & =\text { factor to convert units from } \mathrm{pCi} \mathrm{cm}^{-2} \mathrm{~s}^{-1} \text { to } \mathrm{pCi} \mathrm{m} \mathrm{m}^{-2} \mathrm{~s}^{-1}
\end{aligned}
$$

Appendix A contains the mathematical basis for Equation 1 as well as for the solutions used in this handbook. The solutions of interest are for bare tailings, tailings covered with homogeneous material, and a generalized multiregion problem with many tailings and cover layers.

\subsection{FLUX FROM BARE TAILINGS}

The solution of Equations 1 and 2 for the flux from a bare, homogeneous tailings pile is:

$$
J_{t}=10^{4} R \rho E \sqrt{\lambda D_{t}} \tanh \sqrt{\frac{\lambda}{D_{t}}} x_{t},
$$

where

$$
\begin{aligned}
& \mathrm{J}_{\mathrm{t}}=\text { radon flux from the tailings surface }\left(\mathrm{pCi} \mathrm{m} \mathrm{m}^{-2} \mathrm{~s}^{-1}\right) \\
& x_{t}=\text { thickness of tailings }(\mathrm{cm})
\end{aligned}
$$

The subscript " $t$ " refers to the tailings region. A graph of $J_{t} / R E$ is given in Figure 2 as a function of $x_{t}$, illustrating the limitation on the radon flux imposed by radon decay, particularly for low diffusion coefficients. As illustrated, most of the radon comes from the surface layers of tailings; hence there is an advantage in consolidating tailings into smaller, thicker piles.

\subsection{FLUX FROM COVERED TAILINGS}

The exact solution from diffusion theory to the two-region, tailingscover problem is:

$$
J_{c}=\frac{2 J_{t} e^{-b_{c} x_{c}}}{\left[1+\sqrt{a_{t} / a_{c}} \tanh \left(b_{t} x_{t}\right)\right]+\left[1-\sqrt{a_{t} / a_{c}} \tanh \left(b_{t} x_{t}\right)\right] e^{-2 b_{c} x_{c}}}
$$




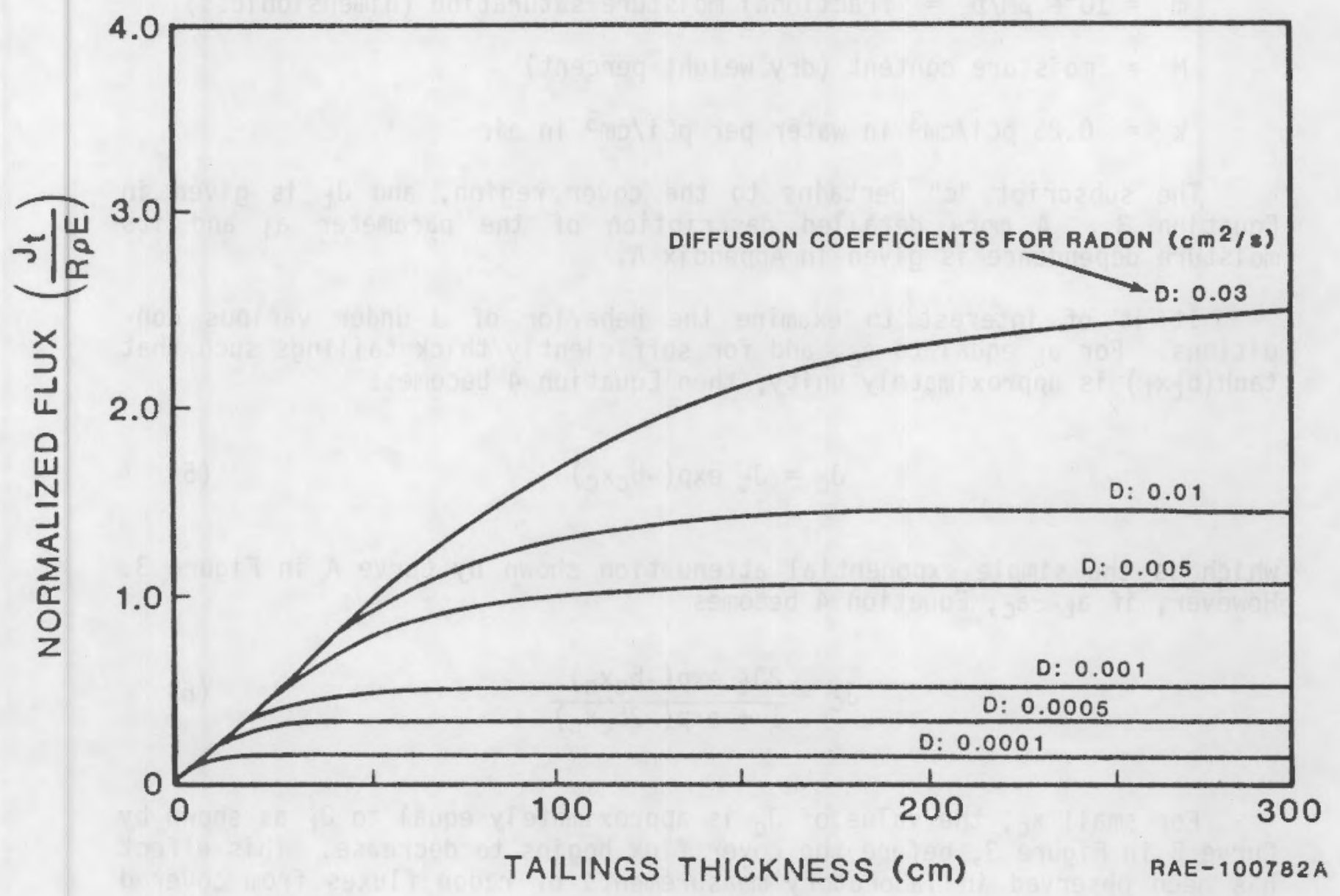

FIGURE 2. NORMALIZED FLUX FROM BARE TAILINGS AS A FUNCTION OF TAILINGS THICKNESS AND DIFFUSION COEFFICIENT. 
where

$$
\begin{aligned}
b_{i} & =\sqrt{\lambda / D_{i}}(i=c \text { or } t)\left(\mathrm{cm}^{-1}\right) \\
a_{i} & =p_{i}^{2} D_{i}\left[1-(1-k) m_{i}\right]^{2}\left(\mathrm{~cm}^{2} \mathrm{~s}^{-1}\right) \\
m & =10^{-2} \rho M / p=\text { fractional moisture saturation (dimensionless) } \\
M & =\text { moisture content (dry weight percent) } \\
k & =0.26 \mathrm{pCi} / \mathrm{cm}^{3} \text { in water per } \mathrm{pCi} / \mathrm{cm}^{3} \text { in air }
\end{aligned}
$$

The subscript "c" pertains to the cover region, and $J_{t}$ is given in Equation 3. A more detailed description of the parameter $a_{i}$ and its moisture dependence is given in Appendix A.

It is of interest to examine the behavior of $J$ under various conditions. For at equal to $a_{c}$, and for sufficiently thick tailings such that $\tanh \left(b_{t} x_{t}\right)$ is approximately unity, then Equation 4 becomes:

$$
J_{c}=J_{t} \exp \left(-b_{c} x_{c}\right)
$$

which is the simple exponential attenuation shown by Curve $A$ in Figure 3 . However, if $a_{t} \ll a_{c}$, Equation 4 becomes

$$
J_{c}=\frac{2 J_{t} \exp \left(-b_{c} x_{c}\right)}{1+\exp \left(-2 b_{c} x_{c}\right)}
$$

For small $x_{C}$, the value of $J_{C}$ is approximately equal to $J_{t}$ as shown by Curve $B$ in Figure 3 , before the cover flux begins to decrease. This effect has been observed in laboratory measurements of radon fluxes from covered tailings.(22) For large $x_{C}$, Equation 6 becomes:

$$
J_{c}\left(x_{C} \text { large }\right)=2 J_{t} \exp \left(-b_{c} x_{c}\right),
$$

so that $\mathrm{J}_{\mathrm{C}}$ decreases exponentially in the same manner as in Equation 5 but retains twice the magnitude which is shown by Curve $B$ in Figure 3 . This is also observable (22) in laboratory measurements.

\subsection{COVER THICKNESS FROM FLUX CRITERION}

The value of $x_{c}$ required to achieve a specified flux can be obtained by rearranging Equation 4, assuming the tailings are more than $100 \mathrm{~cm}$ thick, and approximating $\exp \left(-2 b_{c} x_{c}\right)$ by $\left(J_{c} / J_{t}\right)^{2}$. The result is: 


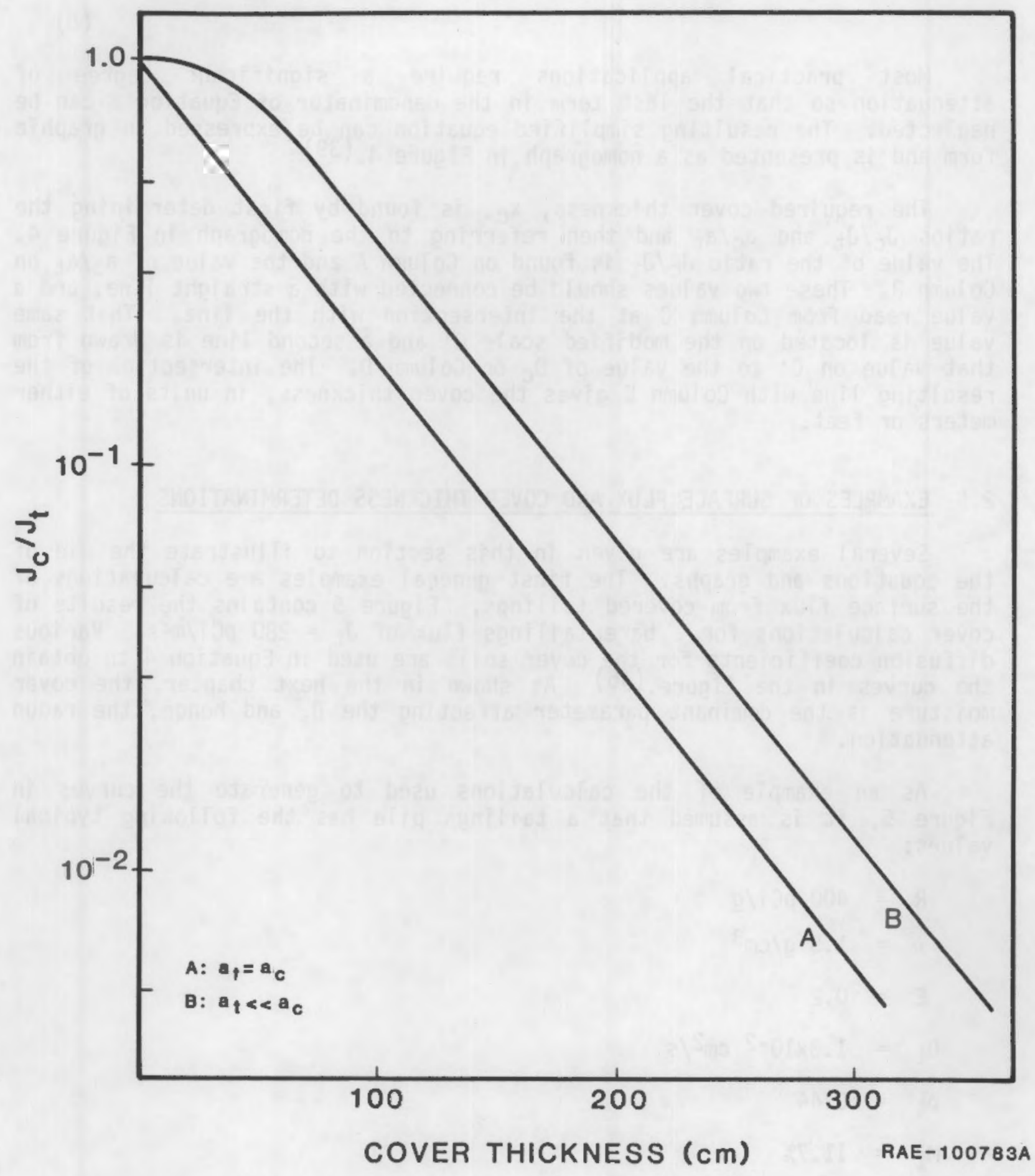

FIGURE 3. COVER SURFACE RADON FLUX FOR VARIOUS THICKNESSESS AND PARAMETERS. 


$$
x_{c}=\sqrt{\frac{D_{c}}{\lambda}} \ln \left[\frac{2 J_{t} / J_{c}}{\left(1+\sqrt{a_{t} / a_{c}} \tanh b_{t} x_{t}\right)+\left(1-\sqrt{a_{t} / a_{c}} \tanh b_{t} x_{t}\right)\left(J_{c} / J_{t}\right)^{2}}\right]
$$

Most practical applications require a significant degree of attenuation so that the last term in the denominator of Equation 8 can be neglected. The resulting simplified equation can be expressed in graphic form and is presented as a nomograph in Figure $4 .(39)$

The required cover thickness, $x_{c}$, is found by first determining the ratios $J_{c} / J_{t}$ and $a_{c} / a_{t}$ and then referring to the nomograph in Figure 4. The value of the ratio $\mathrm{J}_{\mathrm{C}} / \mathrm{J}_{t}$ is found on Column $A$ and the value of $\mathrm{a}_{\mathrm{c}} / \mathrm{a}_{t}$ on Column B. These two values should be connected with a straight line, and a value read from Column $C$ at the intersection with the line. That same value is located on the modified scale $C^{\prime}$ and a second line is drawn from that value on $\mathrm{C}^{\prime}$ to the value of $\mathrm{D}_{C}$ on Column $\mathrm{D}$. The intersection of the resulting line with Column $E$ gives the cover thickness, in units of either meters or feet.

\subsection{EXAMPLES OF SURFACE FLUX AND COVER THICKNESS DETERMINATIONS}

Several examples are given in this section to illustrate the use of the equations and graphs. The first general examples are calculations of the surface flux from covered tailings. Figure 5 contains the results of cover calculations for a bare tailings flux of $\mathrm{J}_{t}=280 \mathrm{pCi} / \mathrm{m}^{2} \mathrm{~s}$. Various diffusion coefficients for the cover soils are used in Equation 4 to obtain the curves in the figure. (46) As shown in the next chapter, the cover moisture is the dominant parameter affecting the $\mathrm{D}$, and hence, the radon attenuation.

As an example of the calculations used to generate the curves in Figure 5, it is assumed that a tailings pile has the following typical values:

$$
\begin{aligned}
R & =400 \mathrm{pCi} / \mathrm{g} \\
\rho & =1.5 \mathrm{~g} / \mathrm{cm}^{3} \\
\mathrm{E} & =0.2 \\
\mathrm{D}_{t} & =1.3 \times 10^{-2} \mathrm{~cm}^{2} / \mathrm{s} \\
\mathrm{p}_{t} & =0.44 \\
M_{t} & =11.7 \% \\
\mathrm{x}_{t} & =300 \mathrm{~cm}
\end{aligned}
$$

The radon flux from the surface of the uncovered tailings is calculated from Equation 3: 


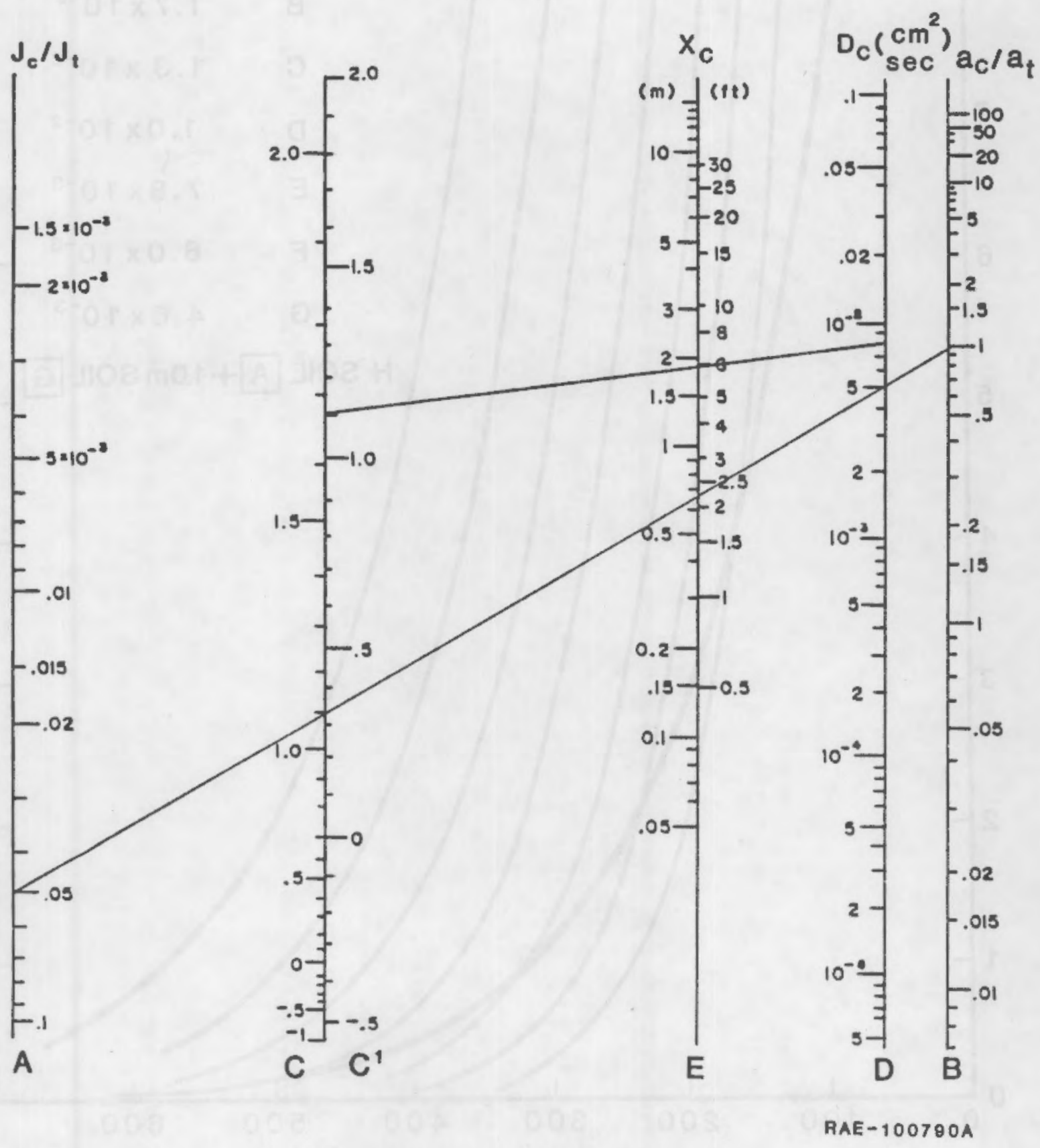

FIGURE 4. NOMOGRAPH FOR ESTIMATING NECESSARY COVER THICKNESS FOR RADON ATTENUATION. 


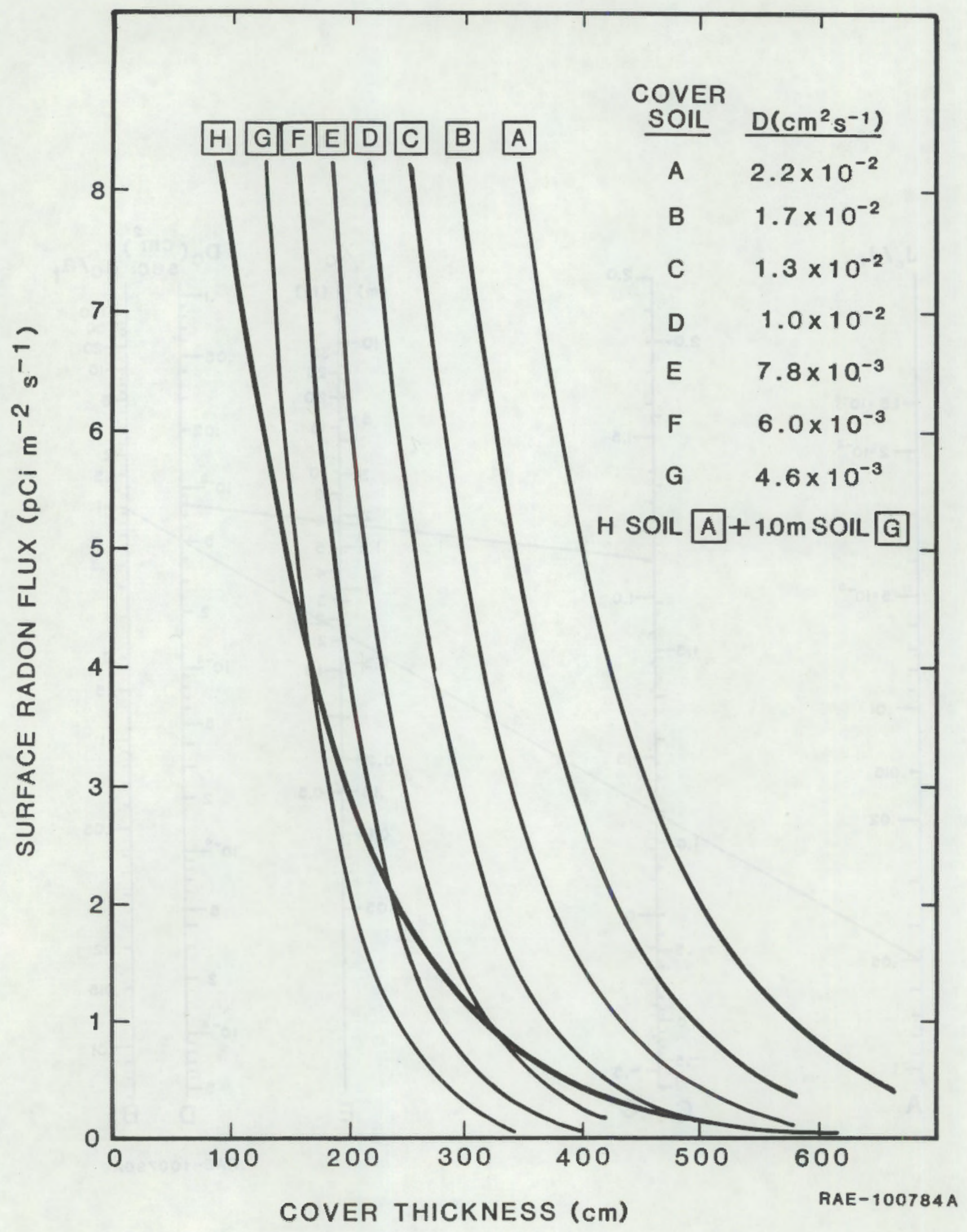

FIGURE 5. EFFECT OF SOIL THICKNESS ON SURFACE RADON FLUX. 


$$
\begin{aligned}
\mathrm{Jt} & =\left(10^{4} \mathrm{~cm}^{2} / \mathrm{m}^{2}\right)(400)(1.5)(0.2)\left[\left(2.1 \times 10^{-6}\right)(0.013)\right]^{\frac{1}{2}} \tanh (3.8) \\
& =198 \mathrm{pCi} / \mathrm{m}^{2} \mathrm{~s}
\end{aligned}
$$

Cover material is available which can be compacted to have the following properties:

$$
\begin{aligned}
& D_{C}=7.8 \times 10^{-3} \mathrm{~cm}^{2} / \mathrm{s} \\
& P_{C}=0.3 \\
& M_{C}=6.3 \%
\end{aligned}
$$

Furthermore, it is assumed that $m_{c}=m_{t}$.

The flux attenuation with two meters of cover material is calculated from Equation 4:

$$
\begin{aligned}
& J_{C}=\frac{2(198)\left(3.76 \times 10^{-2}\right)}{2.893-0.001} \\
& J_{C}=5.1 p C i m^{-2} s^{-1}
\end{aligned}
$$

If a greater flux is acceptable, the same calculation can be repeated with smaller cover thicknesses, or the required thickness can be directly calculated from Eguation 8. For example, what cover thickness would yield a $J_{\mathrm{C}}$ of $20 \mathrm{pCi} \mathrm{m}-\mathrm{S}_{\mathrm{s}}-1$ ? This is determined from Equation 8 as:

$$
\begin{aligned}
& x_{C}=61 \ln \left[\frac{19.8}{2.893-.009}\right] \\
& x_{C}=118 \mathrm{~cm}
\end{aligned}
$$

As an example of the use of the nomograph in Figure 4, a different system with the following parameters is considered:

$$
\begin{aligned}
& J_{t}=400 \mathrm{pCi} / \mathrm{m}^{2} \mathrm{~s} \\
& J_{c}=20 \mathrm{pCi} / \mathrm{m}^{2} \mathrm{~s} \\
& \mathrm{p}_{\mathrm{c}}=\mathrm{p}_{\mathrm{t}}=0.30 \\
& \mathrm{~m}_{\mathrm{c}}=\mathrm{m}_{\mathrm{t}}=0.30 \\
& D_{\mathrm{C}}=\mathrm{D}_{\mathrm{t}}=0.008 \mathrm{~cm}^{2} / \mathrm{s}
\end{aligned}
$$


These values give a $J_{C} / J_{t}$ of 0.05 , located on Column $A$ and $a_{C} / a_{t}$ of 1 , located on Column B. An intermediate parameter value of 1.1 is read from Column C. The same value is located on the modified scale on Column C'. This value is then used with the diffusion coefficient of the cover, located on Column $D$ to obtain the cover thickness from Column E. For example the cover thickness needed to attenuate the radon flux to $20 \mathrm{pCi} / \mathrm{m}^{2} \mathrm{~s}$ is about $1.8 \mathrm{~m}(5.9 \mathrm{ft})$. Use of Equation 8 yields a cover thickness of $1.85 \mathrm{~m}$.

An even simpler way to use the nomograph is to substitute the value of $D_{c} / D_{t}$ for $a_{c} / a_{t}$; i.e., the quantity $p(1-0.74 \mathrm{~m})$ is assumed to be the same for the tailings and the cover. To account for the variations in the ratio of $p(1-0.74 \mathrm{~m})$ for the cover to the tailings, the rule of thumb may be used that the cover thickness decreases by $0.1 \mathrm{~m}$ for every 0.2 decrease in this ratio.(39) The diffusion coefficient for the tailings also has only a secondary effect on $x_{C}$, so that, as an additional rule of thumb, $x_{c}$ changes by $0.1 \mathrm{~m}$ for every factor of two change in $D_{t}$. The direction of the change is determined from the following: If $D_{t}$ is increased by a factor of 2 , but $J_{t}$ is known from direct measurement so that it is unaffected by the change, then $x_{c}$ decreases by $0.1 \mathrm{~m}$. On the other hand, if $\mathrm{J}_{t}$ is calculated from other parameters, one of these parameters being $0_{t}$, then $J_{t}$ also varies with $D_{t}$, so that the resulting effect is that $x_{c}$ increases by $0.1 \mathrm{~m}$ for every factor of two increase in $D_{t}$. These rules of thumb are summarized in Table 1. With these rules of thumb, the cover thickness can be obtained from the nomograph using a value of unity for the ratio $a_{c} / a_{t}$, and then modifying $x_{c}$ accordingly. For example, if $D_{t}$ equals $0.002 \mathrm{~cm}^{2} / \mathrm{s}$ instead of 0.008 as given above, and the value for $\mathrm{J}_{t}$ is a measured value that does not change, then the $x_{c}$ of $1.8 \mathrm{~m}$ is increased by $0.2 \mathrm{~m}$ to a value of $2.0 \mathrm{~m}$, because the $D_{t}$ is reduced by a factor of four. Furthermore, if $\mathrm{PC}_{\mathrm{C}}$ were equal to 0.25 instead of 0.3 , then the porosity ratio decreases by about 0.2 , so that $x_{c}$ is decreased from $2.0 \mathrm{~m}$ to $1.9 \mathrm{~m}$. If in the original example $J_{t}$ were based upon a calculated value instead of a measured value so that $a$ change in $D_{t}$ affects value of $J_{t}$, then a reduction in $D_{t}$ by a factor of four would yield a reduction in the cover thickness of $0.2 \mathrm{~m}$, from $1.8 \mathrm{~m}$ to $1.6 \mathrm{~m}$.

TABLE 1

\section{RULES OF THUMB FOR ESTIMATING COVER THICKNESSES}

Parameter Change

$\frac{P_{c}\left(1-0.74 m_{c}\right)}{P_{t}\left(1-0.74 m_{t}\right)}$

( $J_{t} \begin{gathered}D_{t} \\ \text { unchanged) }\end{gathered}$
Change In

Parameter value

0.2 decrease

factor of 2 increase

factor of 2 increase
Resulting Changes

In Cover Thickness

$0.1 \mathrm{~m}$ decrease

$0.1 \mathrm{~m}$ decrease

$0.1 \mathrm{~m}$ increase 


\subsection{MULTIREGION SYSTEMS}

The mathematical solutions for multi-layer covers involving three(13) and four $(59)$ region systems have been presented previously. A general multiregion system must be solved by computer using matrix formulations of the diffusion equations; however, approximate analytical solutions are also available.

\subsubsection{The RAECOM Computer Code}

RAECOM (acronym for Radon Attenuation Effectiveness and Cover optimization with Moisture effects) is a FORTRAN computer program which determines the radon fluxes and concentrations in a multilayer uranium tailings and cover system and then optimizes the thickness of a specified cover layer to satisfy given constraints on the maximum radon flux. (48)

A logic flow diagram for the code is shown in Figure 6. First, the $D$ 's are calculated from a correlation if they are not input directly. Then the migration of radon is determined for the specified cover characteristics and the radon concentrations (C), and the radon fluxes (J) are calculated. The cover optimization is performed yielding adjusted values $(x)$ for the layer thicknesses. The radon migration calculations are then repeated for each $\mathrm{J}$ and $\mathrm{C}$ with the adjusted cover layer thicknesses, and the resulting surface flux, $J_{C}$, is tested against the specified criterion, $\mathrm{J}_{\mathrm{crit}}$. If this criterion is satisfied, the code proceeds to final output. If the flux criterion is not satisfied, appropriate layer thicknesses are adjusted within the specified constraints, radon migration calculations are repeated, and the surface radon flux is again tested against the flux criterion. This process is repeated until all criteria are satisfied. The code then prints out all radon attenuation data. The input data format and code listing are given in Appendix B.

\subsubsection{Approximate Expressions}

When it is necessary to estimate the radon flux from a multilayer system or to determine a cover layer thickness without resorting to a computer calculation, approximate analytical expressions may be used. - The expressions presented in this section can be used for that purpose.

The procedure for multilayer systems utilizes a sequential application of Equations 4 or 8 to each cover layer. The procedure treats the cover layer in question as a single cover system with a modified source layer accounting for the tailings and all cover layers beneath the layer in question. In order to apply Equation 8 to the layer in question, an estimate must be made of the radon flux from the previous layer, $J_{t}$, and the diffusion coefficient of the source, $D_{t}$. Following are the steps in this procedure utilizing the cover system configuration shown in Figure 7 : 


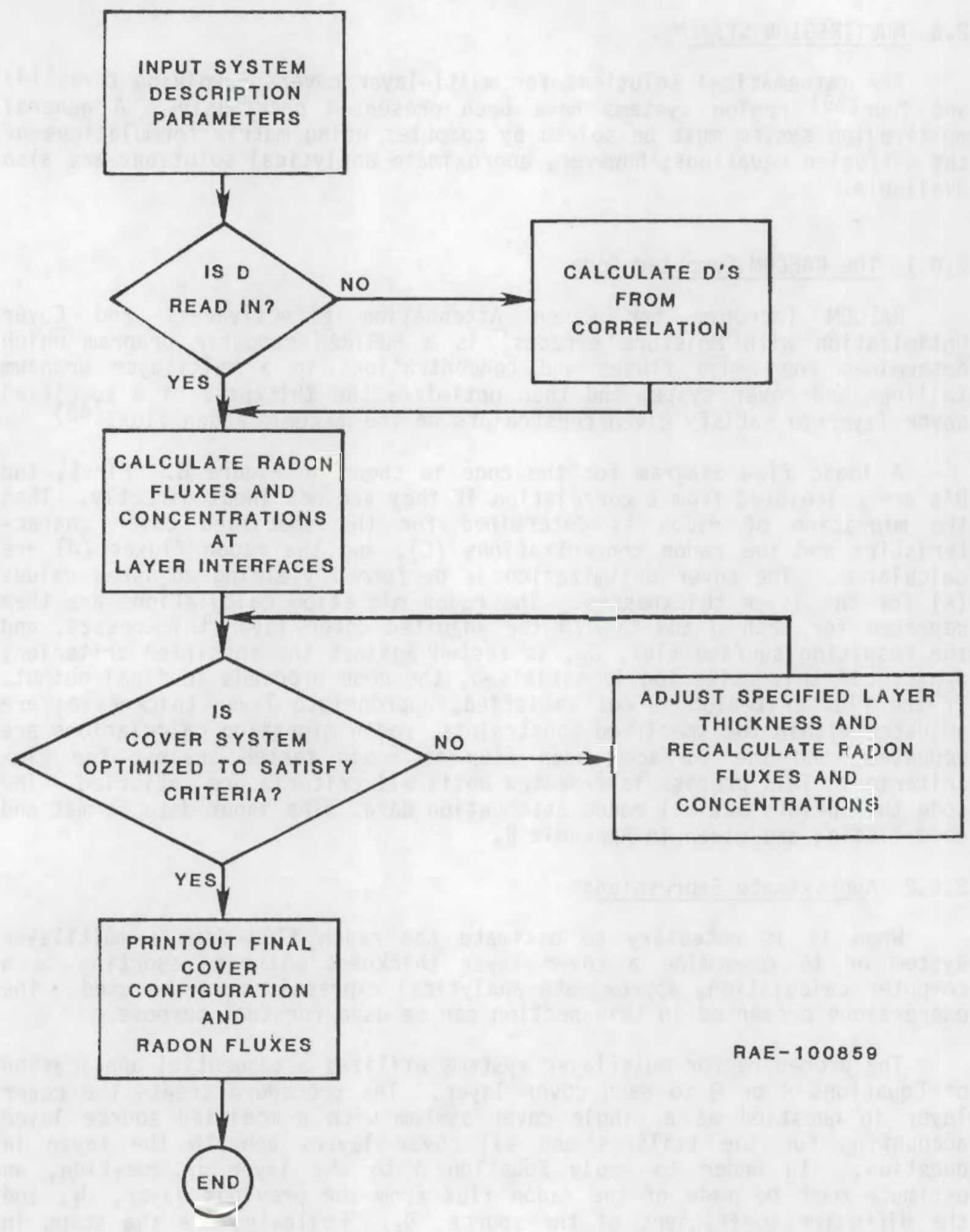

FIGURE 6. MAJOR COMPONENTS OF RAECOM MODEL. 


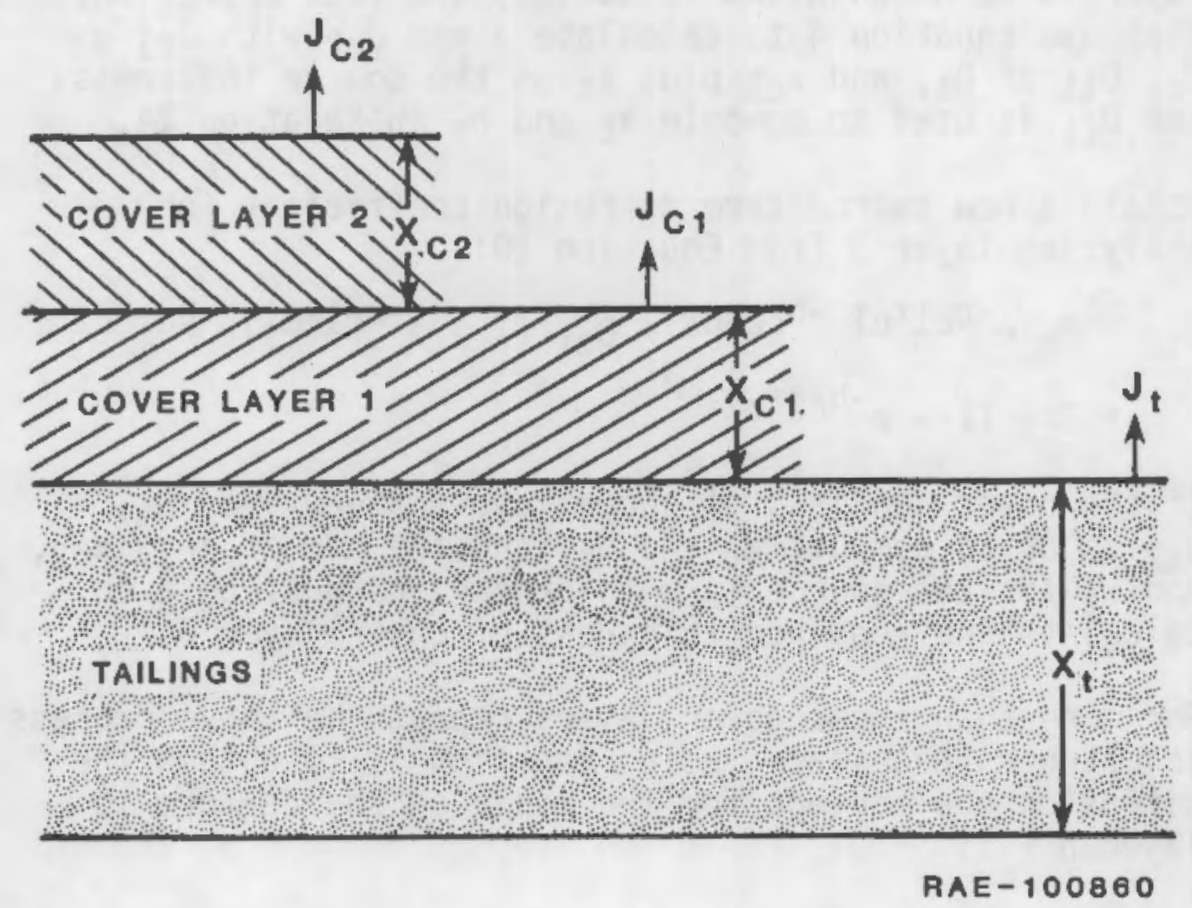

FIGURE 7. PARAMETERS FOR A MULTILAYER COVER SYSTEM. 
1. Calculate the radon flux from the first cover layer, $J_{\mathrm{Cl}}$, using Equation 4 and the tailings and first cover parameters.

2. Calculate an equivalent source diffusion coefficient, $D_{t 1}$, from Equation 9:

$$
D_{t 1}=D_{t} e^{-b_{c l} x_{c l}}+D_{c 1}\left(1-e^{-b_{c 1} x_{c 1}}\right)
$$

3. $D_{t l}$ is used in analyzing the second cover layer. If the cover consists of only two layers, use $\mathrm{J}_{\mathrm{cl}}$ as $\mathrm{J}_{\mathrm{t}}$ and $\mathrm{D}_{\mathrm{t} 1}$ as $D_{t}$ in Equation 8 to calculate the required thickness of layer 2, $x_{c 2}$. The new source term thickness is $x_{c 1}+$ $x_{t}$. The $D_{t 1}$ is used to compute $a_{t}$ and $b_{t}$ for Equation 8 .

4. If $x_{c 2}$ is specified and the thickness of a third cover layer is to be adjusted to satisfy the flux criterion, then use Equation 4 to calculate a new $J_{c 2}$ with $J_{c 1}$ as $J_{t}, D_{t 1}$ as $D_{t}$, and $x_{c 1}$ plus $x_{t}$ as the source thickness. The $D_{t l}$ is used to compute $a_{t}$ and $b_{t}$ in Equation 14.

5. Obtain a new source term diffusion coefficient for analyzing layer 3 from Equation 10:

$$
\begin{aligned}
D_{t 2} & =D_{t} e^{-b_{c} 1^{x} c 1-b_{c 2} x} c 2+D_{c 1}\left(1-e^{-b} c 1^{x} c 1\right) e^{-b} c 2^{x} c 2 \\
& +D_{c 2}\left(1-e^{-b} c 2^{x} c 2\right)
\end{aligned}
$$

6. If the cover consists of three layers use $\mathrm{J}_{\mathrm{c} 2}$ as $\mathrm{J}_{\mathrm{t}}$, $D_{t 2}$ as $D_{t}$ to compute at and $b_{t}$, and the sum of $x_{c 1}, x_{c 2}$, and $x_{t}$ for the source term thickness in Equation 8 to calculate the required thickness of cover layer 3 .

7. For more than three cover layers repeat the above process as often as necessary, using Equation 11 to obtain the diffusion coefficient for the modified source term to layer $n+1$ :

$$
\begin{aligned}
D_{t_{n}} & =D_{t} \exp \left[-\sum_{j=1}^{n} b_{c_{j}} x_{c_{j}}\right]+D_{c_{n}}\left(1-e^{-b} c^{x} c_{c n}\right) \\
+ & \sum_{j=1}^{n-1} D_{c_{j}}\left(1-e^{-b} c_{c^{x} x_{i}}\right) \exp \left[-\sum_{j=1+1}^{n} b_{c_{j} x} c_{j}\right]
\end{aligned}
$$

\subsubsection{Examples of Multiregion Calculations}

The tailings pile described in the first example is to be covered with 0.5 meter of a good quality clay and sufficient overburden to achieve a 
surface flux of $20 \mathrm{pCi} / \mathrm{m}^{2} \mathrm{~s}$. What thickness of overburden should be used? The basic material parameters are:

\begin{tabular}{lcccc} 
& \multicolumn{1}{c}{} & $\underline{\mathrm{P}}$ & $\frac{\mathrm{M}}{\mathrm{m}}$ & $\frac{\mathrm{m}}{\text { tailings }}$ \\
clay & $0.013 \mathrm{~cm}^{2} / \mathrm{s}$ & 0.44 & 11.7 & 0.4 \\
overburden & $0.022 \mathrm{~cm}^{2} / \mathrm{s}$ & 0.37 & 5.3 & 0.4
\end{tabular}

First, the bare tailings flux is the same as before:

$$
J_{t}=198 \mathrm{pCi} / \mathrm{m}^{2} \mathrm{~s}
$$

Then, calculate the attenuation through the clay component using Equation 4.

$$
\begin{aligned}
& \mathrm{J}_{\mathrm{Cl}}=\frac{2(198)(0.440)}{2.893-(0.173)} \\
& \mathrm{J}_{\mathrm{Cl}}=64.1 \mathrm{pCi} \mathrm{m}-2 \mathrm{~s}-1
\end{aligned}
$$

Now, determine the diffusion coefficient for the source term to the overburden (the source is now the tailings and clay) using Equation 9.

$$
\begin{aligned}
& D_{t 1}=D_{t} \exp \left(-b_{1} x_{1}\right)+D_{1}\left[1-\exp \left(-b_{1 \times 1}\right)\right] \\
& D_{t 1}=(0.013)(0.440)+(0.0078)(1-0.44) \\
& D_{t 1}=0.0101 \mathrm{~cm}^{2} / \mathrm{s}
\end{aligned}
$$

The value of $D_{t 1}$ is then substituted for $D_{t}$ and $J_{c 1}=64.1$ is substituted for $J_{t}$ in Equation 8 , giving

$$
\begin{aligned}
& x_{2}=102 \ln \left[\frac{6.41}{1.475+0.051}\right] \\
& x_{2}=146 \mathrm{~cm}=\text { overburden thickness }
\end{aligned}
$$

The total cover thickness is therefore $146 \mathrm{~cm}+50 \mathrm{~cm}=196 \mathrm{~cm}$. In this calculation the effective source thickness is assumed to be large enough so that tanh $a_{t} x_{t}$ is unity. 
The parameters specified in the above example were also used to construct the input to the RAECOM program as specified in Appendix B. The RAECOM calculations, shown in Table 2, yield an overburden thickness of $149 \mathrm{~cm}$. Thus, the approximate procedure gives a result that is $3 \mathrm{~cm}$ less than the exact calculation, well with in acceptable uncertainty limits.

\subsection{COVER SOURCE CONSIDERATIONS}

The example calculations of the previous sections did not consider any surface radon flux contribution from radium in the covers. The cover source term was set equal to zero. For soil cover materials containing background values of radon, the effect of the radon from the covers is very small and is approximately additive, so that the component of the radon flux from radium in the cover material does not appreciably alter the component of the radon flux from radium in the tailings. Furthermore, the linearity assumption for tailings plus cover fluxes is conservative; that is, the surface flux due only to the tailings is slightly less with a cover source term than without the cover source term. 
TABLE 2

RAECOM CALCULATION OF MULTIREGION EXAMPLE

RAECOM CALCULATION OF YULTIREGION EXAKPLE

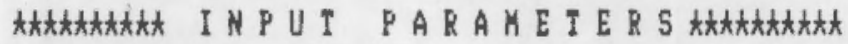

NUMBER OE LAYERS :

3

RADON FLUX INTO LAYER 1 ;

$0.000 \quad \mathrm{pCi} / \mathrm{m} 2 / \mathrm{sec}$

SURFACE RADON CONCENTRATION :

0.000

$\mathrm{pC} \mathrm{C} / \mathrm{l}$ iter

LAYER 3 ADJUSTED IO MEET Jcrit :

$20.0+/-0.100 \mathrm{E}-02 \mathrm{pCi} / \mathrm{m} 2 / \mathrm{sec}$

BARE SOURCE FLUX (Jo) FROM LAYER 1 : $198.4 \mathrm{pCi} / \mathrm{m} 2 / \mathrm{seC}$

$\begin{array}{cccccc}\text { LAYER IHICKNESS } & \begin{array}{c}\text { DIFE COEFF } \\ \text { (ca) }\end{array} & \begin{array}{c}\text { POROSITY } \\ \text { (cm2/sec) }\end{array} & \begin{array}{c}\text { SOURCE } \\ \text { (pCi/cm3/sec) }\end{array} & \begin{array}{c}\text { MOISTURE } \\ \text { (dry } \\ \text { wt. percent) }\end{array} \\ \frac{1}{2} & 500 . & 1.3000 \mathrm{E}-02 & 0.4400 & 5.7300 \mathrm{E}-04 & 11.70 \\ 3 & 50 . & 7.8000 \mathrm{E}-03 & 0.3000 & 0.0000 \mathrm{E}-01 & 6.30 \\ 3 & 100 . & 2.2000 \mathrm{E}-02 & 0.3700 & 0.0000 \mathrm{E}-01 & 5.40\end{array}$

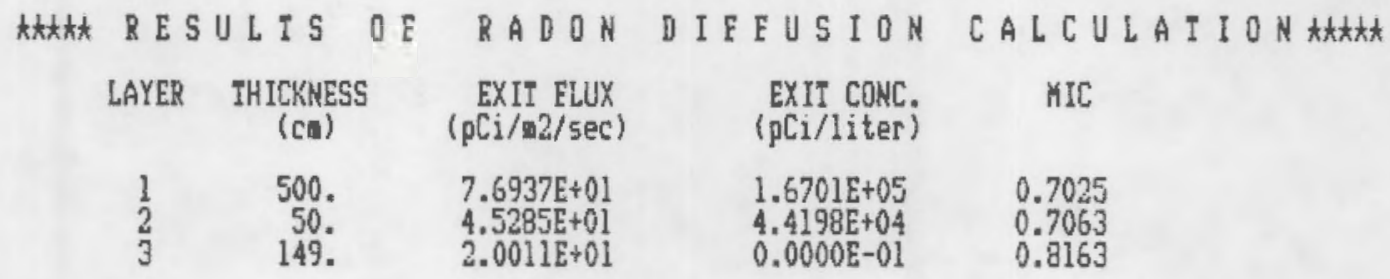

Notation: $\quad .5000+003=0.5 \times 10^{3}$

$\mathrm{pCi} / \mathrm{sqm}^{\star} \mathrm{sec}=\mathrm{pCi} \mathrm{m} \mathrm{m}^{-2} \mathrm{~s}-1$ 



\section{MEASUREMENT OF THE RADON DIFFUSION COEFFICIENT}

The degree of radon flux reduction provided by a tailings cover depends on the time required for the radon to diffuse through the cover, and thus to partially decay in it. Therefore, the diffusion coefficient of the soil is of central importance to determine the required cover thickness to achieve a given radon flux reduction. It is therefore advantageous to know as accurately as possible the $D$ of the candidate cover material. The diffusion coefficient is most accurately determined by direct measurement. The measurable quantities in determining $D$ are the radon flux and the radon concentration. Utilizing the appropriate equations, $D$ can be calculated from any combination of two measurements of flux and concentration which directly involve the source and the cover.

The three most common pairs of measurements to determine $D$ are: a) the source flux and the flux through the cover; b) the source flux and the equilibrium concentration at the bottom of the cover; and c) the concentration at the bottom of the cover and at the top of the cover within a sealed system. Variations on these methods have also been used. Radon diffusion coefficients can be measured either in the laboratory or in the field. Field measurements offer the advantage of exposure to actual wind, sun, rain and other significant environmental parameters which may affect the soil moisture content and its diffusion coefficient. However higher variability complicates the interpretation of field data. Laboratory measurements of $D$ provide better control over the soil and diffusion conditions. The expense of testing soils in the laboratory is also generally less than for field tests, as are the time requirements for the tests.

This chapter summarizes the three main methods for measuring $D$. Advantages and disadvantages of each method are presented, along with the variations of each method which have been used to calculate D. The final section presents a sensitivity analysis of each of the three main procedures.

\subsection{LABORATORY MEASUREMENTS}

\subsubsection{Bare Flux and Covered Flux}

The $D$ of a cover can be calculated from the measurements of the radon flux from the bare tailings and from the covered tailings placed in a tall column. $(21,22,26)$ This procedure requires a two-step calculation. The $D$ of the tailings is first calculated from bare flux measurements using Equation 3. That information is then used in Equation 4 with measured values of the flux from the covered tailings to calculate the D of the cover. The radon flux can be measured using either activated charcoal or accumulator cans. $(49,50)$ Additional quantities which must be measured or estimated are the radium content, emanating power, dry bulk density, and the porosity of the tailings. The porosity of the cover should also be measured or estimated. 
An advantage of the flux-flux method is that it provides a direct measurement of the cover effectiveness which is consistent with its field application. Various layers can also be combined to simulate desired cover designs. A disadvantage is that large columns and volumes of tailings and soil are required making the preparation cumbersome. The one-month delay times necessary to allow for radon equilibration in the source and cover are also a disadvantage.

\subsubsection{Bare Flux and Covered Source Concentration}

The $D$ of a cover material in a short column can be determined from measurements of the bare flux from the radon source and the radon concentration at the base of the cover after the cover system has equilibrated.(31-33) Additional quantities which must be known or estimated are the D of the source and the dry porosity of the cover soil.

An advantage of measuring the bare flux and the covered source concentration is the improved sensitivity for measurements when the radon does not decay significantly within the cover.(32) The smaller samples required also allow greater control of moistures and densities. A disadvantage is the poor sensitivity for low diffusion coefficients.

\subsubsection{Transient Radon Concentration Above A Cover}

If a test cover is sealed on one side and its other side is suddenly exposed to a high constant radon concentration, the concentration of radon at the sealed surface will increase with time until it reaches some steadystate concentration. Measurements of the increase with time, or transient radon concentration at the sealed surface provide a sensitive measure of the diffusion coefficient of the material. Although a comparison of the steady-state concentration with the source concentration may also sometimes allow calculation of a diffusion coefficient, the calculations from the transient radon concentration curve are usually most sensitive.(26)

For the transient diffusion measurements the radon source provides a high constant concentration of radon which is suddenly introduced to the entrance of the diffusion tube containing the soil. By monitoring the variation in alpha activity with time at the other end of the tube, a unique activity curve is measured which is characteristic of the diffusion coefficient of the test material. Figure 8 illustrates measured and expected curves for various values of $D$.

Major advantages of this method are the short time requirement, the freedom from atmospheric pressure variations, the small amount of sample required, and the possibility for moisture control in the sealed system. The preparation can be completed within a few hours, and the data collection can often be completed within a few days or less. This method can also combine the sensitivity of transient measurements for high $D$ with the sensitivity of steady-state measurements for low D. A comparison of D's measured with this apparatus has shown the results to be not only internally consistent but also consistent with steady-state 


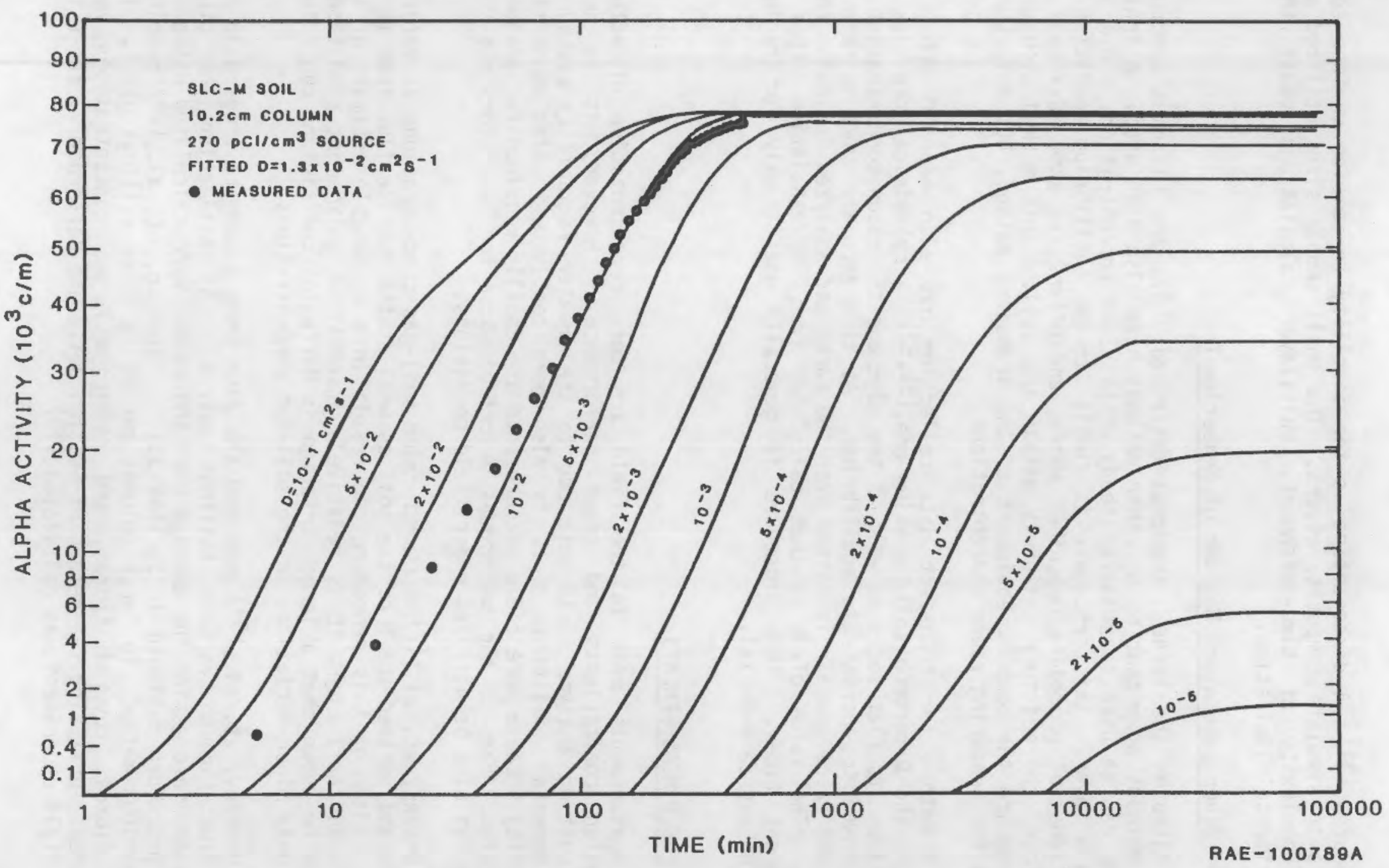

FIGURE 8. TRANSIENT ALPHA ACTIVITY CURVES FOR MEASURING RADON DIFFUSION COEFFICIENTS. 
procedures. (34) A disadvantage is the inability to combine various soil layers to simulate composite covers. The small sample sizes utilized and the complexity of time-dependent, multilayer calculations cause this experimental limitation.

\subsubsection{Other Laboratory Methods of Measuring D}

Although the three procedures described above are the most commonly used methods of measuring $D$, other methods have also been used. A sealed column can be used to measure steady-state radon concentrations above and below a cover. This procedure is similar to the equilibrium condition of the transient procedure described above, and offers the same advantage of retaining the moisture uniformly within the soil. This method also does not require the complex equipment of the transient method, but only Lucas cells for measuring radon concentrations.

A method for transient data collection has also been utilized to measure the $D$ through solid uranium ore. $(51,52)$ A cylindrical ore disk is sealed on its flat faces as well as the edge and the radon concentration is is allowed to increase to equilibrium. At time zero the seal is removed from the faces and air is passed over the faces and analyzed for radon content. The value of $D$ is then calculated from the exhalation rates at different times. This procedure is generally useful only for radiumbearing source material.

\subsection{FIELD MEASUREMENTS}

Measurements made in the field are more representative of actual diffusion coefficients and cover performance. However, it is more difficult to analyze field data due to the greater variability caused by environmental conditions. It is also more costly and often more time consuming because more field measurements are usually required for adequate precision. Many of the techniques described above for laboratory measurements can also be utilized under field conditions.

Kraner, et. a1.,(7) measured radon soil-gas concentrations at various depths and derived the $D$ of the soil as well as the surface flux from these data. Although this procedure can result in a reasonable estimate of the diffusion coefficient it is relatively insensitive under most conditions. It can be shown that a large variation in diffusion coefficient can result from only minor variations in the soil-gas concentrations.

Hartley, et. al.,(53) measured the flux from a bare tailings pile and the flux through various tailings covers. By estimating the other necessary information the average $D$ of the covers were calculated using the same procedure outlined in Section 3.1.1. Nielson, et. al., $(36)$ combined the various methods in large columns buried in three tailings piles. The bare fluxes, covered fluxes, and radon soil gas concentrations were measured. Utilizing the method of Section 3.1 .2 and Reference 7, the D for each field experiment was calculated.(36) 


\subsection{ANALYSIS OF UNCERTAINTIES}

An important factor in selecting a method to measure the diffusion coefficient of a soil is its ability to provide a precise and accurate result. Thus, it is helpful to examine the uncertainties associated with the various methods to determine the range of diffusion coefficients to which each is best suited. The magnitude of the relative uncertainty in $D$, shown in Figure 9, is determined for each method using representative values for the measurement systems described in Section 3.1. As shown in the figure, the uncertainties are a function of the term (bx). Furthermore, the transient diffusion instrumentation provides for the lowest overall relative uncertainties in $D$. When bx exceeds 1.8 , the steady-state concentrations corresponding to the plateaus in Figure 8 can be used to obtain the relative uncertainties shown for the concentration concentration method in Figure 9. When bx is less than 1.8, the transient method clearly exhibits the lowest uncertainty of the four methods.

\subsection{VALUES OF MEASURED DIFFUSION COEFFICIENT}

Diffusion coefficients for radon have been measured in a wide variety of earthen materials under several research projects $(26,34-36)$ over the past two years. The measurements have generally been aimed at determining the suitability of the materials as tailings covers. A data base of radon diffusion coefficients was recently assembled from the results of the various measurements and was used to evaluate the overall ranges and typical values of diffusion coefficients of earthen materials. $(39,54)$ The data base includes the dry densities and moisture contents of the soils and thus allows examination of variations with moisture and compaction. Much of the recent data also include sieve analyses, water drainage characteristics, and other soil parameters used in later studies on the effects of moisture, compaction and soil texture on diffusion coefficients.

The diffusion coefficient data base contains nearly 200 elements, a representative sample of which is shown in Figure 10. The data were mostly measured by the time-dependent technique, but also include many steadystate and some field measurements. The diffusion coefficients are relatively constant at absolute dryness, averaging $0.061 \pm 0.006 \mathrm{~cm}^{2} / \mathrm{s}$ for the dry soils tested. It is well known that increasing moisture causes lower diffusion coefficients.

The variation in diffusion coefficients at intermediate moistures can be largely attributed to varying pore size distributions; however, the variation at high moistures $(m=0.9-1.0)$ cannot. Instead, this variation results from the very steep variation in diffusion coefficients with moisture as $m$ approaches unity. This causes large apparent errors in diffusion coefficients to result from relatively small errors in sample moisture content, density, or specific gravity estimates from which the saturation, $\mathrm{m}$, is estimated. The large variation near saturation in Figure 10 is therefore attributed to uncertainties in the degree of moisture saturation of the soil samples. 


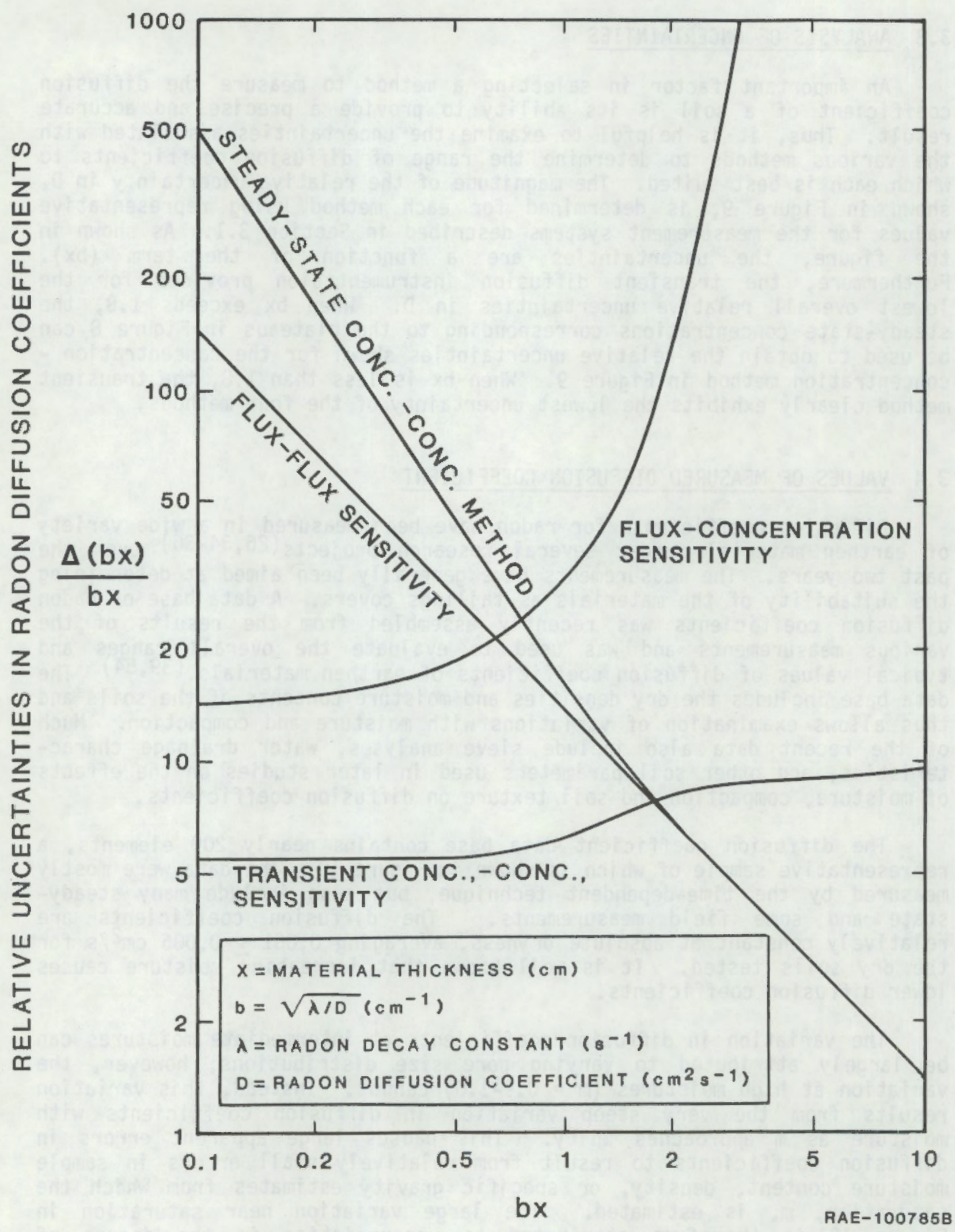

FIGURE 9. RELATIVE UNCERTAINTIES FOR FOUR METHODS OF DETERMINING THE DIFFUSION COEFFICIENT. EACH CURVE ASSUMES A $10 \%$ UNCERTAINTY IN INDIVIDUAL RADON MEASUREMENTS. 


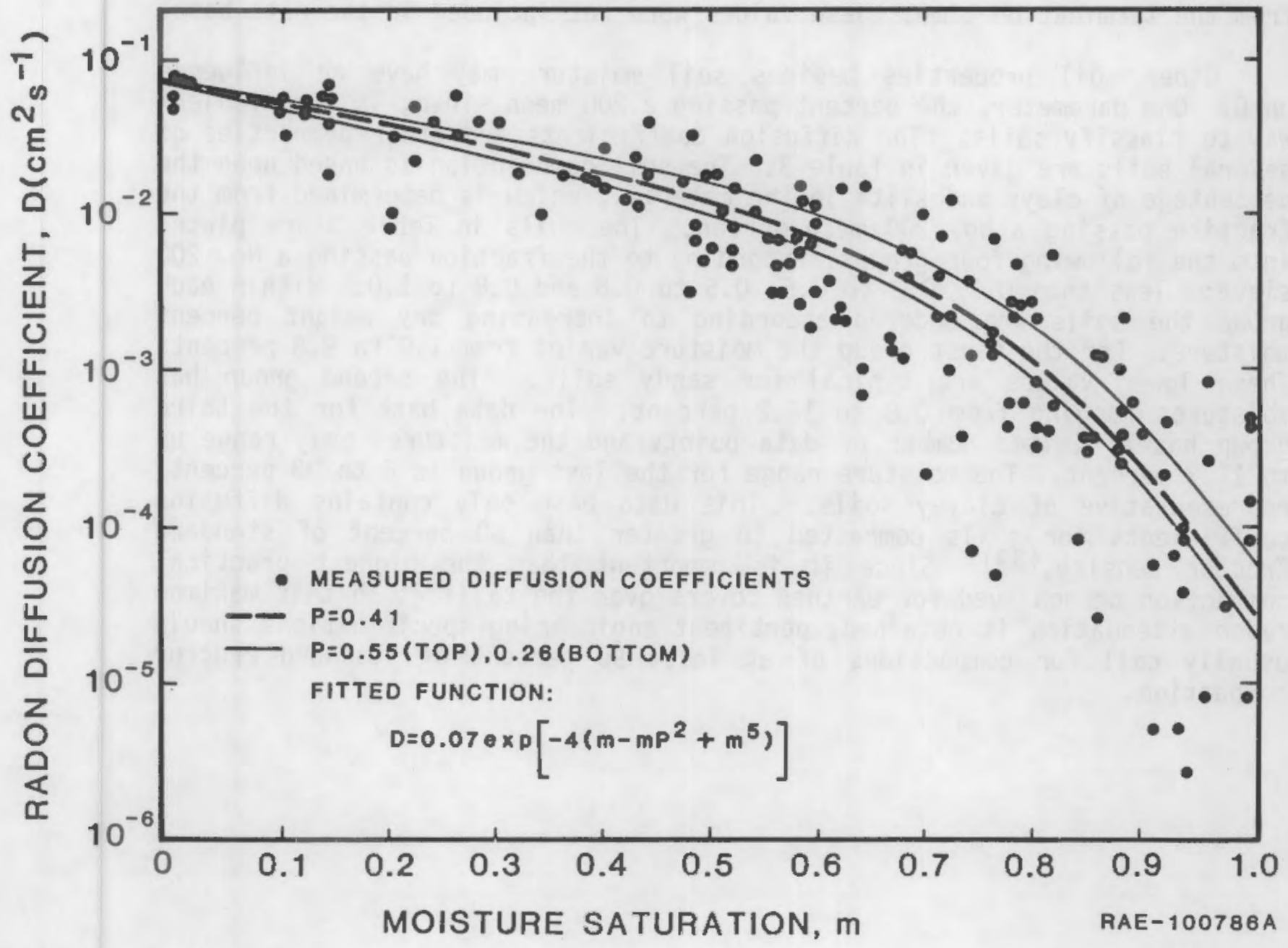

FIGURE, 10. COMPARISON OF MEASURED RADON DIFFUSION COEFFICIENTS WITH A SIMPLE CORRELATION FUNCTION ASSUMING DIFFERENT POROSITIES. 
A bias is noted in comparing the diffusion coefficients at saturation in Figure 10 with the expected value of $6 \times 10^{-6} \mathrm{~cm}^{2} / \mathrm{s}$, the diffusion coefficient for completely saturated soils. This is due to difficulty in completely saturating a sample, and also to truncation of the lower part of the distribution of these coefficients. The truncation occurs because diffusion coefficients of $>10^{-5} \mathrm{~cm}^{2} / \mathrm{s}$ require about seven days for detection of the radon gas front and measurements were often terminated before this time. Although upper limits such as $<10^{-5} \mathrm{~cm}^{2} / \mathrm{s}$ were estimated from the termination time, these values were not included in the data base.

Other soil properties besides soil moisture may have an influence on $D$. One parameter, the percent passing a 200 mesh sieve, is a convenient way to classify soils. The diffusion coefficients and other properties of several soils are given in Table 3. The soil description is based upon the percentage of clays and silts in the material, which is determined from the fraction passing a No. 200 mesh screen. The soils in Table 3 are placed into the following four groups, according to the fraction passing a No. 200 sieve: less than $0.3,0.3$ to $0.5,0.5$ to 0.8 and 0.8 to 1.0 . Within each group the soils are ordered according to increasing dry weight percent moisture. For the first group the moisture varies from 1.0 to 9.8 percent. These lower values are typical for sandy soils. The second group has moistures ranging from 0.8 to 18.2 percent. The data base for the third group has a limited number of data points and the moistures only range up to 11.7 percent. The moisture range for the last group is 6 to 38 percent, representative of clayey soils. This data base only contains diffusion coefficients for soils compacted to greater than 90 percent of standard Proctor density.(39) Since it is important that the highest practical compaction be achieved for earthen covers over the tailings so that maximum radon attenuation is obtained, pertinent engineering specifications should usually call for compactions of at least 90 percent of standard Proctor compaction. 
TABLE 3

MEASURED RADON DIFFUSION COEFFICIENTS FOR EARTHEN MATERIALS

Percent D

Percent M $\rho$ Diffusion Percent

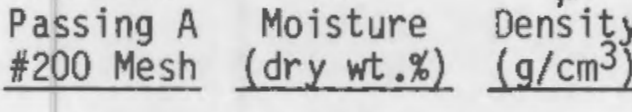
$0-30 \%$

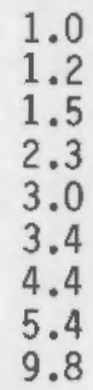

1.81

1.87

1.83

1.83

1.72

1.79

1.83

1.78

1.82

1.86

1.72

1.82

1.68

1.76

1.70

1.62

1.63

1.80

1.68

1.80

1.73

1.82

1.60

1.64

1.62

1.64

1.81

1.69

1.69

1.80

1.80
Coefficient $\left(\mathrm{cm}^{2} / \mathrm{s}\right)$

$$
\begin{aligned}
& 0.030 \\
& .062 \\
& .023 \\
& .031 \\
& .028 \\
& .024 \\
& .056 \\
& .036 \\
& .0056
\end{aligned}
$$

0.020

.039

.035

.016

.030

.038

.017

.061

.037

.028

.036

.027

.031

.045

.025

.018

.011

.0029

.014

.0091

.0018

.00081
Percent M $\# 200$ Mesh

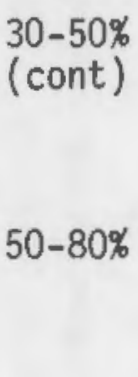

$80-100 \%$
Moisture (dry wt. . )

17.5

17.9

17.9

18.2

1.6

2.4

3.1

5.1

10.6

11.7

6.0
6.0

8.5

9.1

10.0

11.0

11.3

11.6

13.7

13.8

15.0

16.0

21.0

23.0

23.0

24.5

25.5

27.6

27.7

38.0 $\rho$ Density $\left(\mathrm{g} / \mathrm{cm}^{3}\right)$

\subsection{0}

1.80

1.81

1.80

1.61

1.93

1.76

1.68

1.72

1.55

1.84

1.30

1.45

1.93

1.79

1.68

1.35

1.81

1.89

1.90

1.65

1.37

1.36

1.36

1.31

1.35

1.38

1.30

1.37

1.30
D

Diffusion Coefficient $\left(\mathrm{cm}^{2} / \mathrm{s}\right)$

0.000040

.000079

.000079

.000032

0.029

.039

.026

.024

.017

.022

0.012

.036

.054

.0015

.020

.030

.037

.0042

.0013

.0022

.0010

.038

.0142

.0150

.0047

.0134

.0122

.0052

.0067

.00010 



\section{ESTIMATING DIFFUSION COEFFICIENTS}

Radon diffusion coefficients for earthen materials have traditionally been determined from laboratory measurements with the subject soil at a prescribed moisture content and compaction. However, it is often desirable to estimate the diffusion coefficient of materials under varying conditions for which measured values are not available. This can be done with either complex models based upon physical characteristics of the soil, or upon empirical correlations based upon measured values of $D$. Both approaches are discussed in this chapter, and the advantages and disadvantages of each are given. Because soil moisture and compaction are important factors in the value of $D$ for a given soil, they are also examined in detail in this chapter.

In order to predict the diffusion coefficient of radon from physical properties of an earthen material without conducting radon measurements, empirical correlations have generally been used. One of the earlier correlations is the correlation with moisture $(55)$ which was used in the GEIS on uranium milling. (46) Another is a correlation with the air-filled porosity of the soil.(23) Although these correlations permit estimation of diffusion coefficients from soil properties rather than diffusion measurements, their basis is still a series of measured values of diffusion coefficients.

\subsection{DIFFUSION COEFFICIENT MODEL}

Recently, a theoretical model has been developed for estimating radon diffusion coeffifients without relying on fitted parameters to radon diffusion data.(41) The formalism considers the detailed composition of the pore fluid as well as a statistical definition of the pore structure of the material. As illustrated in Figure 11, the pore fluid is modeled as a two-phase mixture of air and water, with radon diffusion occurring in both phases, and with radon exchange occurring between the air and water. The pore structure is modeled from the measured pore size distribution of the soil, and is described by the weighted average of all combinations of single and composite pores. The soil parameters required to estimate a radon diffusion coefficient are thus the moisture, the packing density and the pore size distribution.

Agreement between the model calculations and measured $D$ values is generally within the experimental uncertainties in the data. A typical result is shown in Figure 12.(54) For the calculations, the pore size distribution was deduced both from water drainage curves and from particle size distributions. (54)

\subsection{DIFFUSION COEFF ICIENT CORRELATIONS}

Empirical correlations for estimating $D$ have the advantage of being simple and easy to use, with a minimal amount of information needed. One 


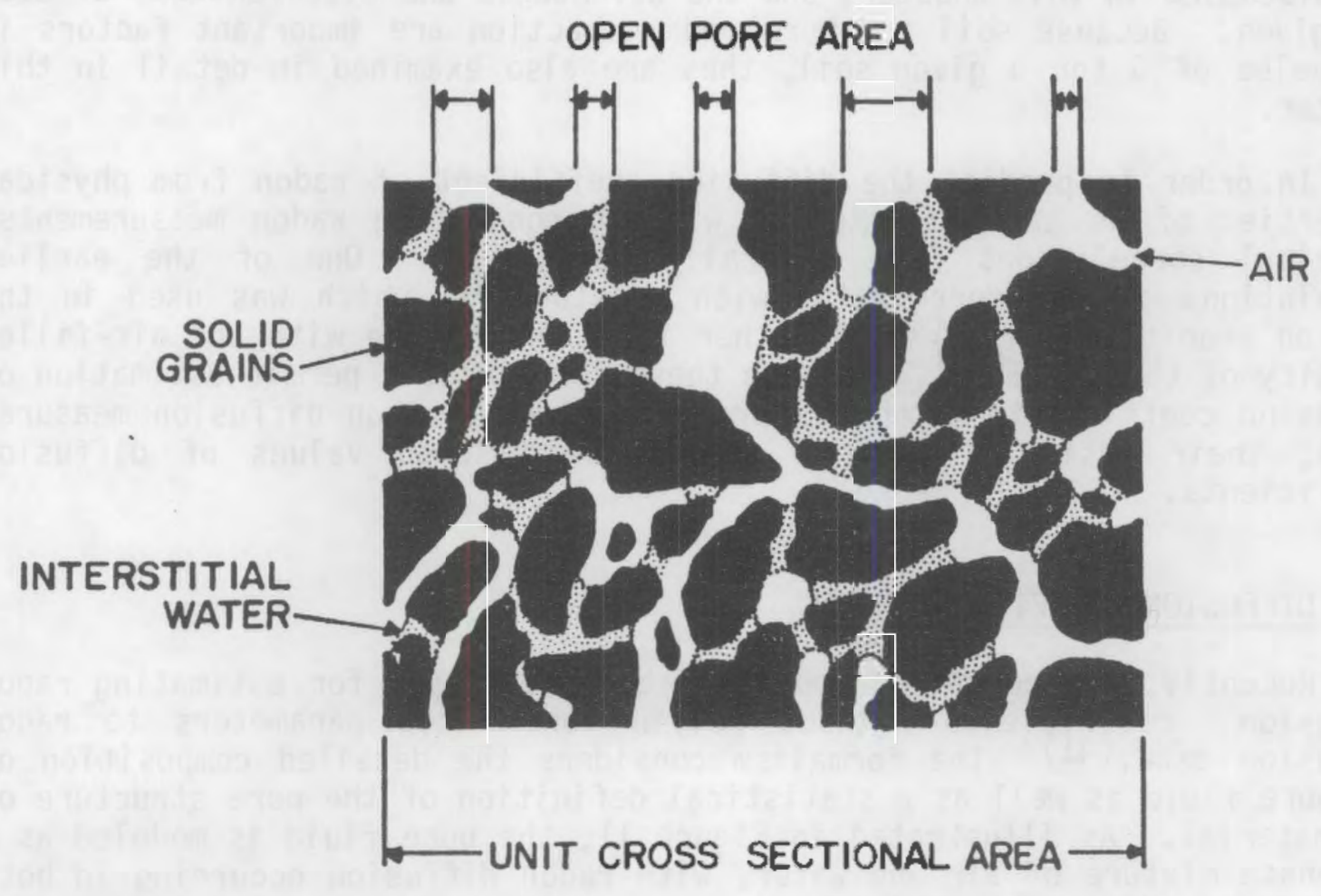

RAE -100169

FIGURE 11. REFERENCE VOLUME OF UNSATURATED POROUS MATERIAL 


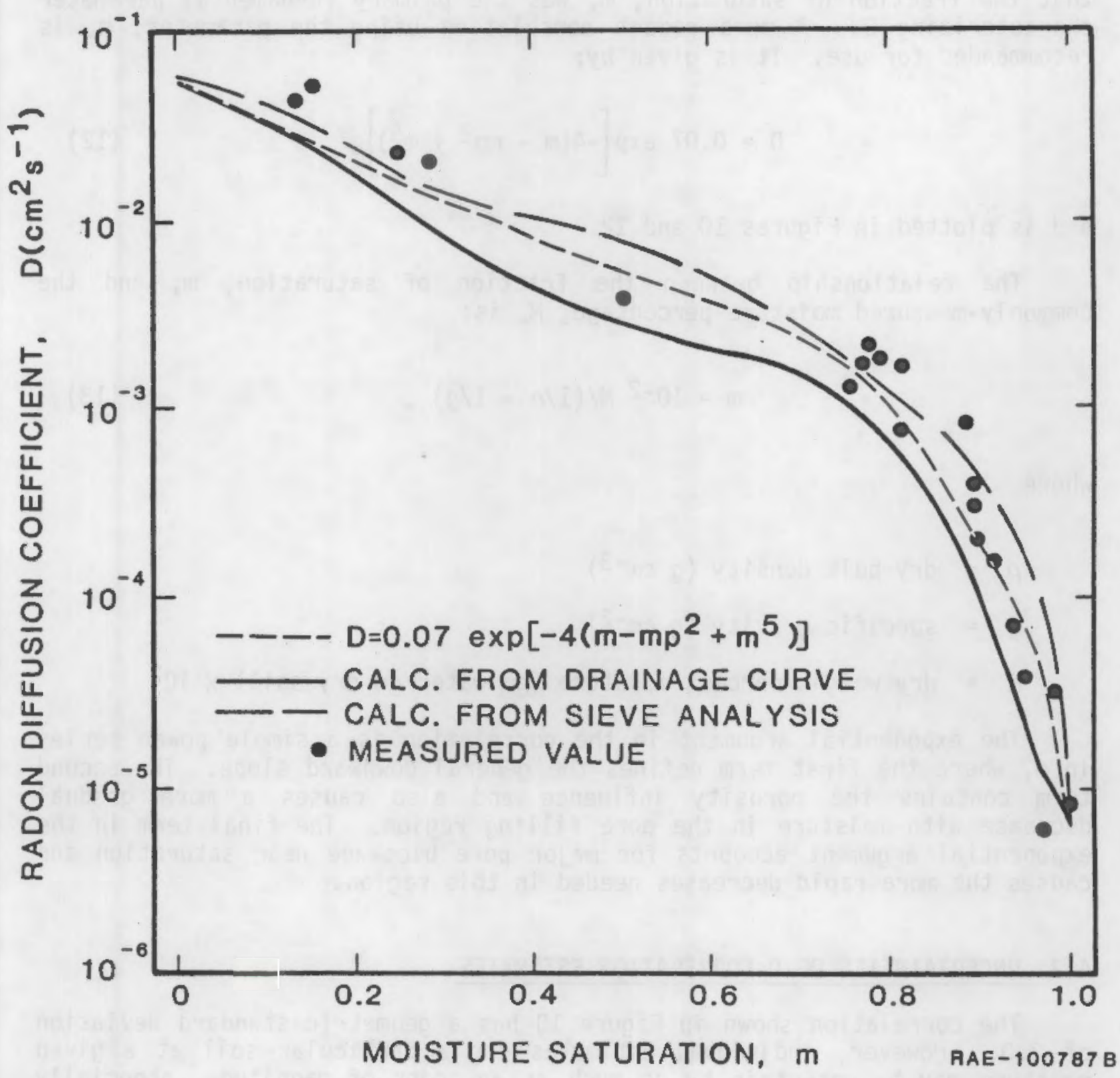

FIGURE 12. COMPARISON OF RADON DIFFUSION COEFFICIENTS AND MODEL CALCULATION FOR RIVERTON, WYOMING SOIL. 
of the early correlations related $D$ with the wet weight-percent moisture in the soil.(55) Subsequently, the development of the model for $D$ revealed that the fraction of saturation, $m$, was the primary fundamental parameter characterizing D. A more recent correlation using the parameter, $m$, is recommended for use. It is given by:

$$
D=0.07 \exp \left[-4\left(m-m p^{2}+m^{5}\right)\right] \text {, }
$$

and is plotted in Figures 10 and 12 .

The relationship between the fraction of saturation, $m$, and the common ly-measured moisture percentage, $M$, is:

$$
m=10^{-2} \mathrm{M} /(1 / \rho-1 / \mathrm{g}),
$$

where

$$
\begin{aligned}
& \rho=\text { dry bulk density }\left(\mathrm{g} \mathrm{cm}^{-3}\right) \\
& \mathrm{g}=\text { specific gravity }(\mathrm{g} \mathrm{cm}-3) \\
& M=\text { dry weight percent moisture (gm water/gm dry soil) } \times 10^{2}
\end{aligned}
$$

The exponential argument in the correlation is a simple power series in $\mathrm{m}$, where the first term defines the general downward slope. The second term contains the porosity influence and also causes a more gradual decrease with moisture in the pore filling region. The final term in the exponential argument accounts for major pore blockage near saturation and causes the more rapid decreases needed in this region.

\subsection{UNCERTAINTIES OF D CORRELATION ESTIMATES}

The correlation shown in Figure 10 has a geometric standard deviation of 2.0. However, individual estimates for a particular soil at a given moisture may be uncertain by as much as an order of magnitude, especially for higher values of $\mathrm{m}$.

A reduction can be achieved in the error associated with a $D$ value from the correlation if just one measurement is made with the candidate soil. In general, if the $D$ at a given $m$ for a specific soil is higher than the correlation, it will remain higher for other values of $m$. As seen in Figure 13, this is also true if the measured $D$ is lower than the correlation. Values for the four soils shown in the figure also indicate the fact that materials with a wide range of particle sizes have lower $D$ values. Therefore, by normalizing the correlation to a measured value for the $D$ of a specific soil at a given $m$, more accurate estimates can be made for the $D$ 


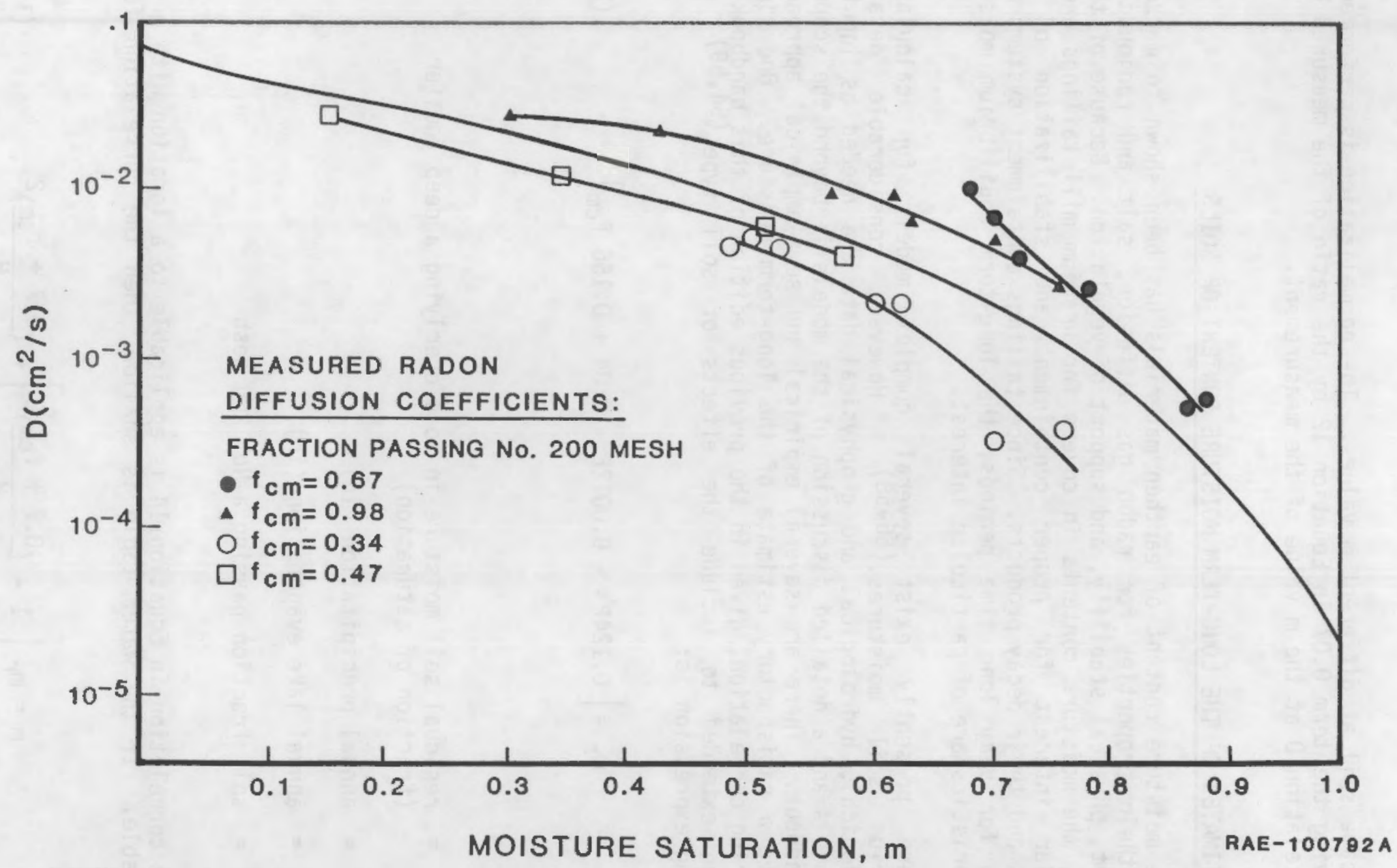

FIGURE 13. PARTICLE SIZE DISTRIBUTION EFFECTS ON D. 
of the same soil at different $m$ values. The normalization is performed by multiplying the term 0.07 in Equation 12 by the ratio of the measured $D$ to the correlation $D$ at the $m$ value of the measurement.

\subsection{ESTIMATES OF THE LONG-TERM MOISTURE CONTENT OF SOILS}

The moisture content of earthen materials has been shown to markedly affect their properties for radon gas diffusion, salt and radionuclide transport, physical stability, and support of vegetation. Because of these effects, the moisture contents in covers for uranium mill tailings are of particular interest for proper containment and stabilization of the tailings and their decay products. Since tailings containment systems must function for very long time periods, the long-term equilibrium moisture characteristics are of particular interest.

There presently exist several complex models for calculating equilibrium soil moistures. $(56-58)$ However, considerable detailed meteorological, hydrological and geophysical data are needed as input to these models and a detailed discussion of the models is beyond the scope of this handbook. There are several empirical and semi-empirical approaches that give a satisfactory estimate of the long-term moisture. One simple engineering correlation, given in the previous edition of this handbook, (1) has been extended to include the effects of soil type. $(54,59)$ The resulting expression is:

$$
m_{r}=\left[0.124 p^{\frac{1}{2}}-0.0012 E-0.04+0.156 f_{c m}\right] \text {, }
$$

where

$$
\begin{aligned}
m_{r} & =\begin{array}{l}
\text { residual soil moisture in soil overlying a deep aquifer } \\
\text { (fraction of saturation) }
\end{array} \\
P & =\text { annual precipitation }(\text { in) } \\
E & =\text { annual lake evaporation (in) } \\
f_{C m}= & \text { soil fraction passing a No. } 200 \text { mesh }
\end{aligned}
$$

The correlation in Equation 14 is applicable to a location with a deep water table. If the water table is shallow, then the correlation for $m$ becomes:

$$
\left.m=m_{r}\left[1-\left(\frac{0.7+f_{C m}}{H}\right)^{2}\right]+\frac{0.7+f_{C m}}{H}\right)^{2},
$$


where

$H=$ depth to the water table $(f t)$

Equation 14 can also be expressed in the form to estimate the dryweight percent soil moisture: $(59)$

$$
M=3.1 p^{\frac{1}{2}}-0.03 E+3.9 f_{c m}-1.0
$$

where $M$ is the dry weight percent soil moisture.

\subsection{COMPACTION EFFECTS ON DIFFUSION COEFFICIENTS}

Compaction of the cover materials generally reduces the equilibrium $D$ value. The dominant effect is from the increase in the equilibrium $\mathrm{m}$; however, for some soils, D also decrease with greater compaction at a fixed m. For soils with higher compactions, such as represented by the data in Table 3, systematic biases from the correlation are observed for certain types of soils.

The soil description in Table 3 is based upon the percentage of clays and silts in the material, which is determined from the fraction passing a No. 200 mesh screen. As stated previously, the soils are placed into four groups, according to the fraction passing a No. 200 sieve.

Diffusion coefficients from the first group are an average of 20 percent lower than the correlation, and those from the second group are 50 percent lower. Those in the third group are within one percent of the correlation, on the average, and the fourth group averages 30 percent higher than the correlation. These biases should be applied to the correlation in Equation 12 if it is used to obtain an estimate of $D$. For example, for a so $i l$ with $f_{\mathrm{cm}}$ less than 0.3 , the $\mathrm{D}$ obtained from Equation 12 can be divided by 1.2 to obtain a more accurate estimate of $D$.

The biases are consjstent with predictions from the diffusion coefficient computer model. (41) A material with a high clay-silt content is not as effective in attenuative radon as a material with a wide range of particle sizes, for a given saturation percentage. These characteristics should be considered when selecting cover materials.

A significant increase in the lower limit of the volumetric water content, $\theta$, also occurs for many soils at higher compactions. The increase was particularly significant for densities exceeding $1.5 \mathrm{~g} / \mathrm{cm}^{3} .(26,60)$ Examination of the relationship between $m, \theta$ and porosity, $p$, is helpful in explaining the increases

$$
m=\theta / p
$$


The volumetric moisture, $\theta$, increases because the pore size decreases, and additional moisture is retained in the pores due to their smaller radius, and hence their increase suction. In addition, the porosity decreases with increasing compaction. In some cases m more than doubles in magnitude for density increases of 30 percent.

The dual effect of increasing compaction on $D$ is illustrated in Figure 14. This we 11-graded soil has 25 percent passing a No. 200 mesh. Increasing the bulk density by eight percent increases the equilibrium $m$ by about 0.12 . It also results in a value of $D$ that is about a factor of four less than the correlation value of $D$ at the same value of $m$. The effect of compaction on equilibrium soil moistures has also been demonstrated in field tests. (38)

\subsection{SUMMARY}

A simple correlation can be used to estimate $D$ for many soils. The uncertainty associated with the correlation can be reduced by removing the variability associated with the soil type. This can be accomplished by normalizing the correlation to a data point for the soil under investigaton. The moisture content of the soil greatly influences D, thus, it is important to consider the moisture when estimating or measuring $D$. Finally, a higher compacted soil generally has a higher equilibrium moisture content and a lower $D$ than the same soil at a lower compaction. 


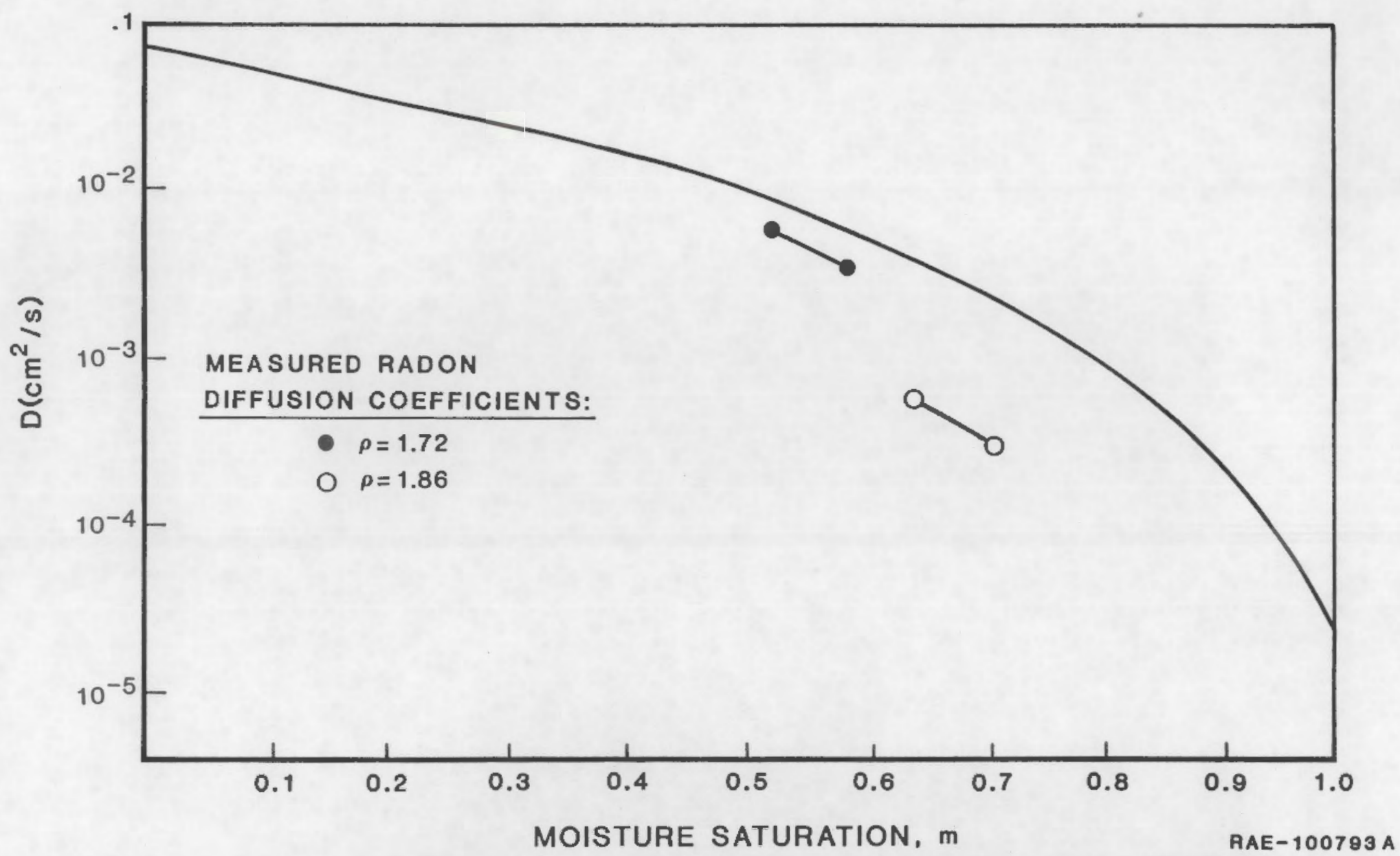

FIGURE 14. COMPACTION EFFECTS ON D FOR A WELL GRADED SOIL $\left(f_{\mathrm{cm}}=0.25\right.$ ) 



\section{OTHER FACTORS INFLUENCING RADON MIGRATION}

Three other factors influencing radon migration warrant consideration. They are the source term (the tailings), the effects of defects in the cover, and the effects of advection.

\subsection{RADON SOURCE TERM}

Characterization of the source term is a major step in performing the design analysis of an adequate cover system. As given by Equation 3 , the key parameters for the source term are the radium concentration, the dry bulk density, the emanating power, and the diffusion coefficient.

Values for the radium concentration, $R$, of tailings can be measured directly from tailings samples by the radon equilibrium method, and by direct ganma spectroscopy. $(26,61)$ If a radium analys is is not available, it can be estimated quite accurately from the uranium concentration of the ore as specified by the ore grade, using the following equation:

$$
R=K_{a} G
$$

where

$$
\begin{aligned}
G & =\text { ore grade }\left(w t \% U_{3} 0_{8}\right) \\
K_{a} & \left.=2812 \mathrm{pCi}\left({ }^{226} 6_{R a}\right) \text { per gram soil/ ( } w t \% U_{3} 0_{8}\right)
\end{aligned}
$$

This equation presumes equilibrium between the uranium and radium in the ore and all radium being contained in the tailings.

The bulk density, $\rho$ b, of the solid tailings material is a relatively easy measurement to perform. In the absence of measured data a typical value of $1.5 \mathrm{~g} / \mathrm{cm}^{3}$ can be used for the bulk dry density. The density of most tailings piles will be within 35 percent of this value.

The emanating power, E, for uranium tailings is the fraction of the radon generated that is free to diffuse in the pore spaces. It has been shown recently $(62)$ that $E$ varies with moisture. As shown in Figure $15, E$ can vary considerably for different tailings piles. (59) However, for most practical applications with uranium tailings, a value of 0.2 is a reasonable estimate of $E$. The data shown in Figure 15 are based upon a few grab samples per pile.

\subsection{SOURCE TERM IMPACTS ON RECLAMATION DESIGN}

The utilization of source term information can have beneficial impacts 


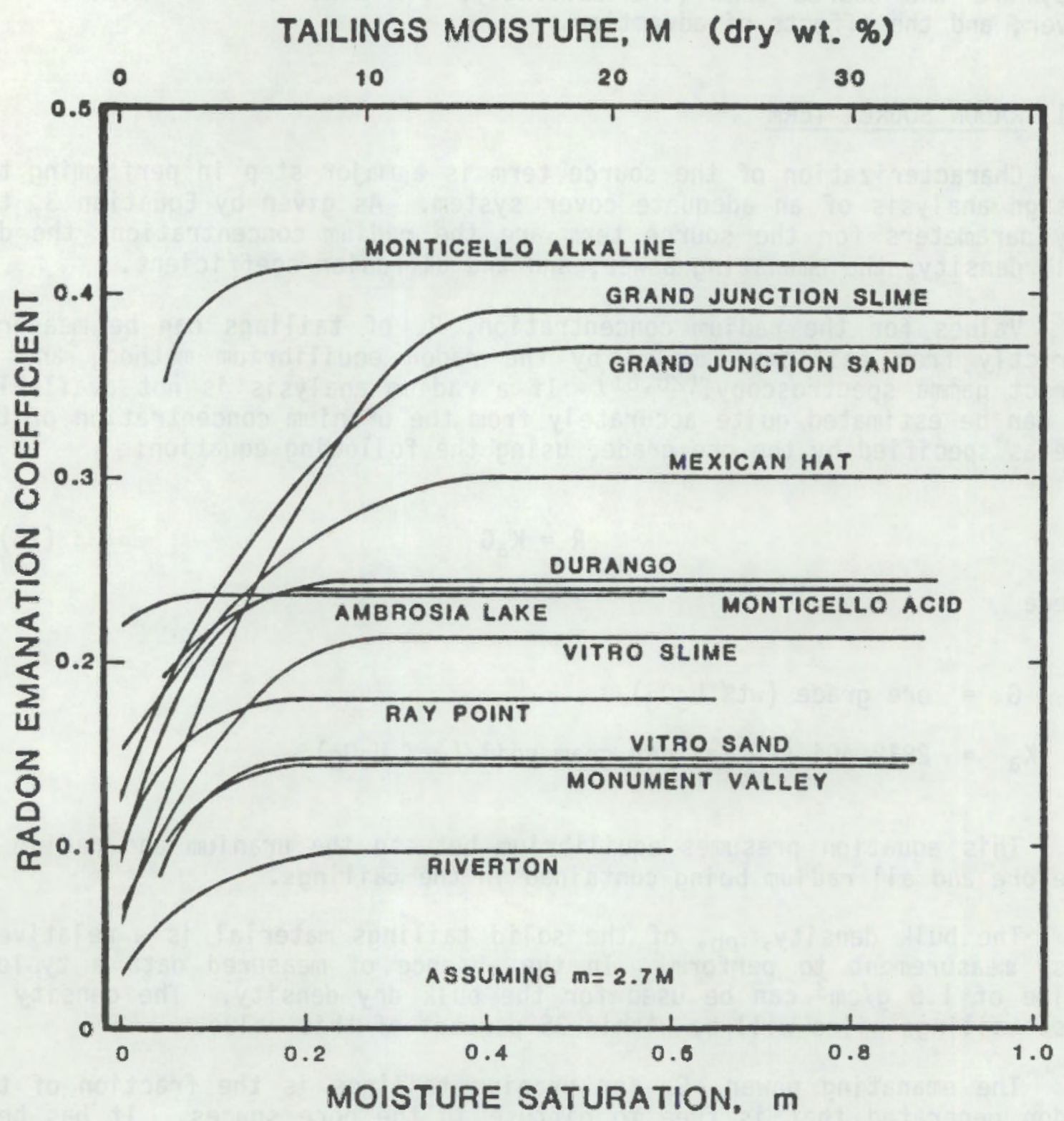

RAE $-100809 B$

FIGURE 15. RADON EMANATION COEFFICIENTS FOR TAILINGS SAMPLES. 
on remedial action design concepts. For example, the sand component of tailings can be effective as a bottom layer of a tailings cover. As an illustration, the original pile configuration consists of a central core of slimes surrounded by an outer ring of sands. The slimes occupy 40 percent of the pile and the sands comprise 60 percent of the tailings. Other key parameters used in the radon calculations for this example are given in Table 4. The example is for a warm, dry climate with a dry, sandy material used for the cover. The volume average radium content for the pile is $660 \mathrm{pCi} / \mathrm{g}$, yielding an average bare tailings flux of $557 \mathrm{pCi} / \mathrm{m}^{2} \mathrm{~s}$. The calculated cover thickness required to reduce the average surface flux to $20 \mathrm{pCi} / \mathrm{m}^{2} \mathrm{~s}$ is $494 \mathrm{~cm}$. Some savings in cover costs can be realized by covering the slimes portion of the pile with sand tailings. The sand tailings are not as effective as the cover material because they have elevated radium concentrations; however, their use as a lower cover layer result in a net decrease in the amount of clean cover material required, so that using a sand tailings layer of $122 \mathrm{~cm}$, the clean cover thickness required is reduced from $494 \mathrm{~cm}$ to $410 \mathrm{~cm}$.

A series of calculations were also performed for varying thicknesses of the sand tailings layer, and a sand tailings cover efficiency for the example was generated. It is defined as the fraction of clean cover that can be replaced by sandy tailings to yield the same radon attenuation through the system. As shown in Figure 16, the sand tailings are nearly as effective as the clean cover. The cover efficiency varies from 60 percent to 80 percent, decreasing with increasing sand tailings layer thickness. A cover efficiency of 70 percent means that one meter of sand tailings as cover is equivalent to $0.7 \mathrm{~m}$ of a clean cover soil with the same $D$ value.

\subsection{LONG-TERM INTEGRITY OF TAILINGS COVERS}

A major consideration in determining the radon release from a tailings cover system is the long-term condition and integrity of the tailings and cover system itself. Even though an effective cover may be placed initially over the tailings, there are many mechanisms that can disrupt a cover, and, because radon generally takes the path of least resistance, these mechanisms can render a significant part of the cover less effective in attenuating radon. The diffusion and advection mechanisms responsible for the transport of radon through porous materials can cause radon to migrate significant distances from its point of origin if there are defects in the material. Three of these mechanisms which can disrupt a cover are vegetation, cracking and animal burrowing. The growth of vegetation in the cover may affect the cover integrity in several ways. First, the occurrence of plants will remove moisture from the cover soil due to plant transpiration. This loss of moisture can dramatically reduce the covers' effectiveness in attenuation radon. For example, if a cover, which contains a 12 percent dry-weight moisture, reduces the flux to $2 \mathrm{pCi} / \mathrm{m}^{2} \mathrm{sec}$, them the same cover with a 7 percent moisture content and the same total porosity only reduces the flux to $17 \mathrm{pCi} \mathrm{m}^{2} \mathrm{sec}$. A decrease to five percent would yield a surface flux of about $25 \mathrm{pCi} / \mathrm{m}^{2} \mathrm{sec}$. Second, if the plant dies or lapses into a dormant or semidormant state during periods of 


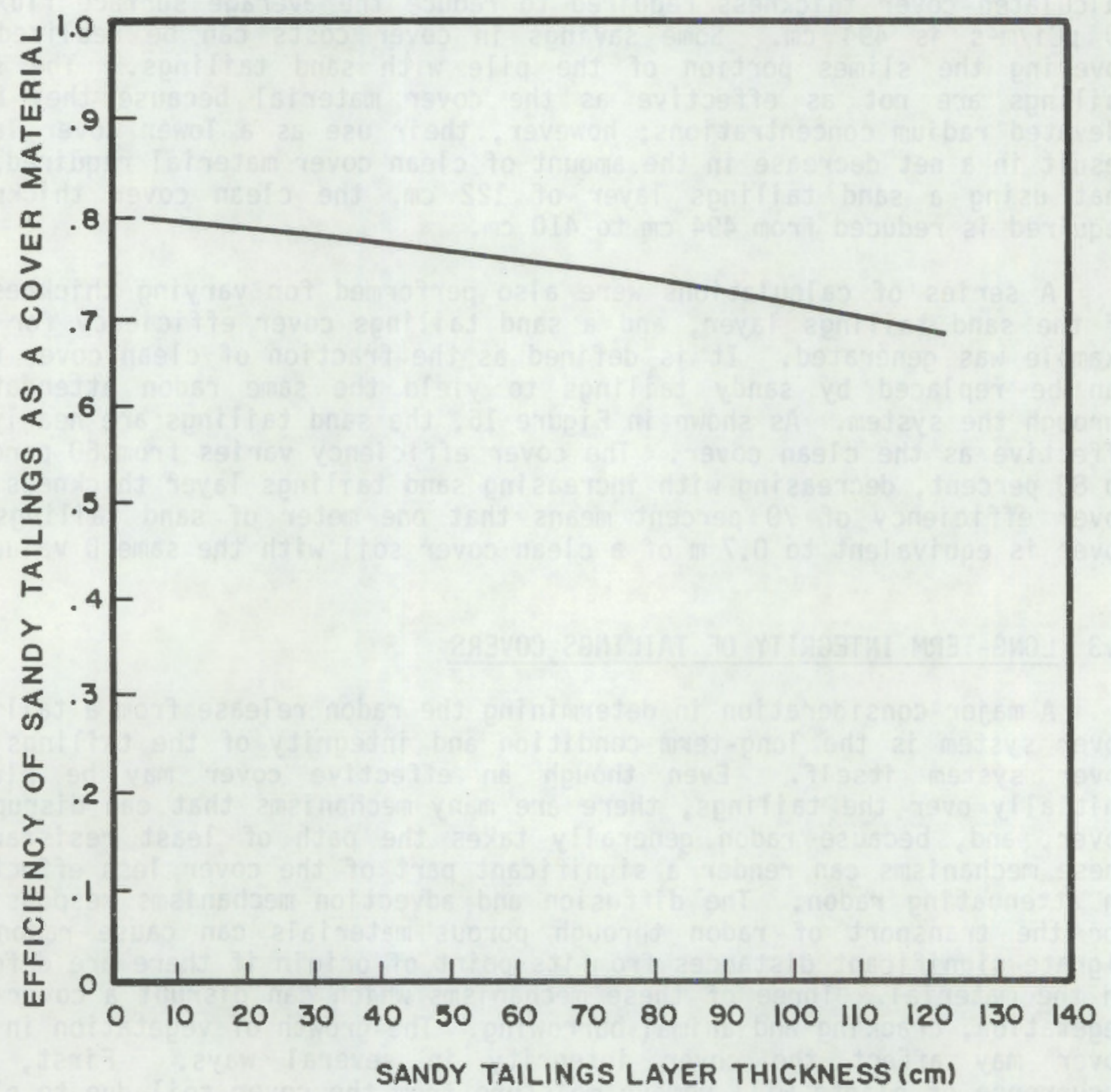

RAE $-100004 \mathrm{~A}$

FIGURE 16. COVER EFFICIENCY FOR SANDY TAILINGS. 
TABLE 4

KEY PARAMETERS FOR SOURCE CALCULATION EXAMPLE

Parameter

Radium Content

Density

Porosity

Emanation Coefficient

$\mathrm{D}_{\mathrm{t}}$

$\mathrm{D}_{\mathrm{C}}$
Value For

slimes

$600 \mathrm{pCi}$

$1.6 \mathrm{~g} / \mathrm{cm}^{3}$

0.38

0.4

$0.01 \mathrm{~cm}^{2} / \mathrm{s}$

$0.035 \mathrm{~cm}^{2} / \mathrm{s}$
Value For Sands

200 pCi

$1.6 \mathrm{~g} / \mathrm{cm}^{3}$

0.38

0.3

$0.02 \mathrm{~cm}^{2} / \mathrm{s}$

$0.035 \mathrm{~cm}^{2} / \mathrm{s}$

reduced precipitation, then air channels surrounding the roots may develop in the cover soil due to the reduction in size of roots. This dormant state can occur repeatedly for a significant fraction of each year.

A series of three-dimensional radon diffusion calculations have been performed for tailings cover systems with cracks and with holes from burrowing animals and vegetation. (43) Although the results of calculations depend somewhat upon the particular geometry of the cover penetrations, and other diffusion properties, the cover degradation with penetration magnitude can generally be approximated by the correlation shown in Figure 17. This correlation was obtained from the results of the series of 3-D computer calculations applied to various penetration geometries and sizes.(43) The abscissa of Figure 17 is the percentage area occupied by the disruption (cracks or holes). The ordinate is the percentage effective loss of cover effectiveness to the depth of the disruption. For example, a disruption that opens four percent of the area can result in a 50 percent loss of the effectiveness of the portion of the cover affected by the disruption. If the roots extend five feet, then the top five feet of cover has the effectiveness of only 2.5 feet of original cover. However, cracks in properly designed tailings covers are generally relatively shallow and have only a minor effect on the surface radon flux.

In other work on the effects of cover defects, $(44,45)$ multidimensional diffusion theory calculations suggest that a collection of cover defects which enhance radon flux by a factor of two or more will be easily recognized, e.g., cracks at least $2 \mathrm{~cm}$ wide, spaced less than $1 \mathrm{~m}$ apart and penetrating $75 \%$ of the cover thickness. 


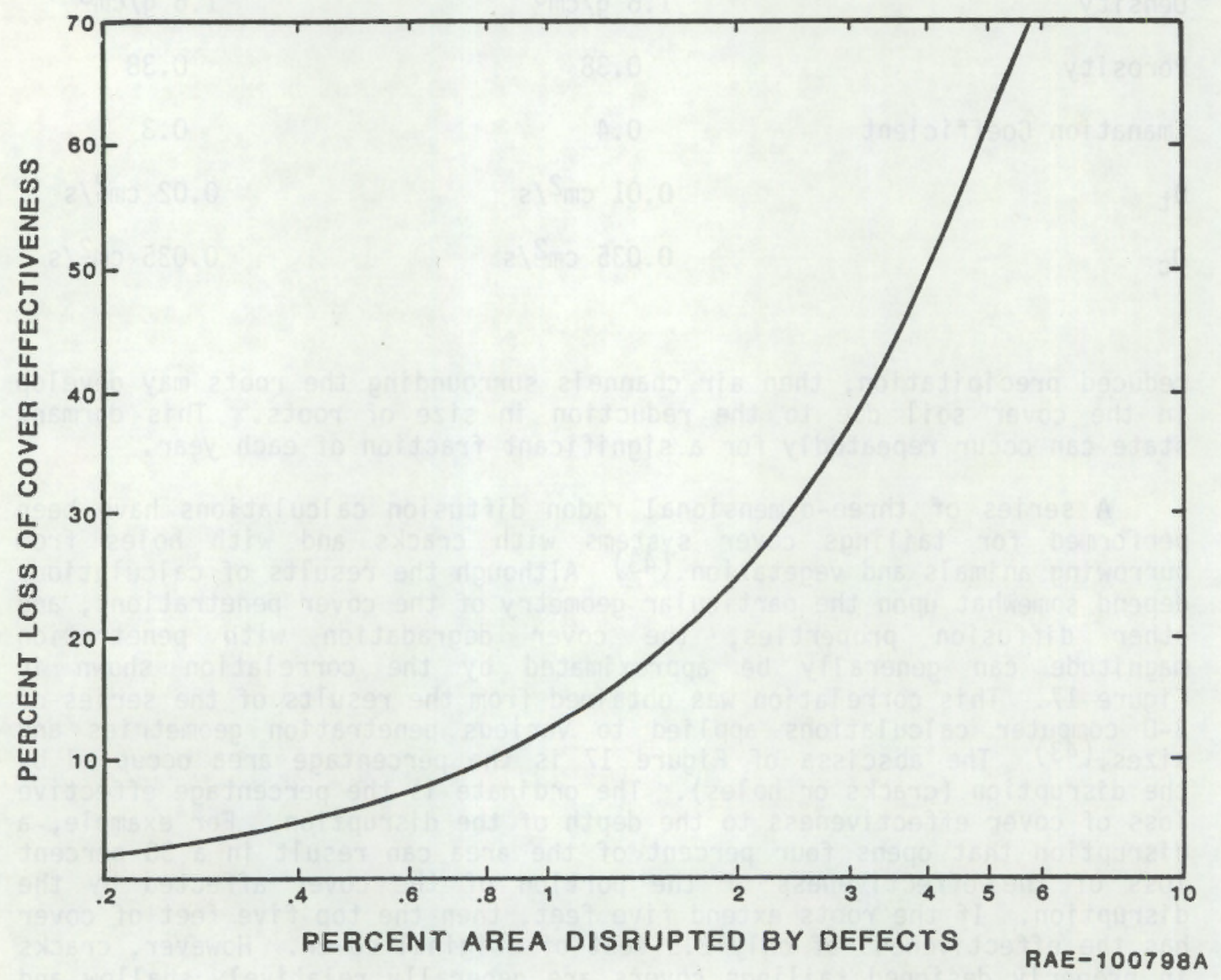

FIGURE 17. LOSS IN RADON ATTENUATION EFFECTIVENESS DUE TO CRACKS AND OTHER COVER DEFECTS. 
defects: $(45)$

The following techniques are recommended to avoid the formation of

1. Avoid soils that form shrinkage cracks. These include soils that are rich in smectites, i.e., aluminosilicate clays which form wide and deep shrinkage cracks. They can be detected by standard soil shrinkage tests or by a variety of tests that characterize clays.

2. Avoid soils that are eroded easily by precipitation runoff. These include sodic soils, i.e., soils containing unusually high concentrations of leachable sodium ion. They can be identified by their sodium adsorption ratios being greater than 15.

3. Use care in the design and application of the cover.

In summary, several techniques are available for maintaining cover integrity. If cracks develop the percentage loss of cover effectiveness in the crack depth zone is approximately equal to twelve times the percent of the surface area disrupted by cracks (Figure 17).

\subsection{RADON TRANSPORT BY ADVECTION}

Over the last several years there has been growing evidence presented to suggest enhanced radon transport in the environment. Measured radon releases from the earth's surface have been associated with radium and uranium sources that are sufficiently removed from the earth's surface to preclude normal diffusional processes from being the dominant mechanism by which the radon is transported to the surface. An example of this is the enhancement of the surface radon flux that occurs prior to earthquake activity and the enhanced surface radon flux halo associated with deep hydrocarbon deposits. These phenomena suggest that radon is also transported in the geosphere by convective or advective mechanisms. Such mechanisms may also influence the long-term radon transport through the covers of uranium mill tailings, resulting in long-term average radon releases that are significantly enhanced over the releases predicted with simple diffusion theory.

Most phenomena, including other diffusional processes, that can potentially influence radon advection couple into the radon transport equation by the time- and position-dependent velocity term. The magnitude and cyclic frequency of the advective velocity, $v(x, t)$ and the depth over which it occurs are critical factors in determining the degree of enhancement of the radon flux over its diffusive value. Hence, it is important to ascertain the form of $v(x, t)$ in order to estimate the flux enhancement from the advective velocity. For example, water evaporation from a tailings cover is generally a cyclic phenomenon. If most of the water evaporation from the soil occurs within a distance of $20 \mathrm{~cm}$ of the 
surface, then no significant radon flux enhancement will occur, eyen if the evaporation rates produce relatively high advective velocities. (42)

It has been shown that by defining a diffusive velocity as $2 \sqrt{\lambda D}$, the flux enhancement can be estimated quantitatively with relatively simple expressions, enabling many insights to be gained about radon advection. Three important parameters determine the long-term magnitude of flux enhancement from advection--the peak advection velocity, the depth over which the advection applies, and the time period of the advection. In general advection has only a minor long-term effect on the radon flux until the advective velocity is significantly greater than the diffusive velocity.

The effect of advection from cyclical mechanisms on the long-term average radon flux can be estimated by measuring $J_{\max }$, the flux at the maximum point of the cycle and $J_{\min }$, the flux at the minimum point of the cycle. The total long-term average flux, $J_{a}$, is just the arithmetic average of $J_{\max }$ and $J_{\min }$. Furthermore, the ratio of total average flux to the simple diffusion flux, $J_{d}$, can be obtained from Figure 18 by forming the ratio $\mathrm{K}=\mathrm{J}_{\max } / J_{\min }$. The ratio of the maximum amplitude, $v_{0}$, of the advective velocity to the diffusive velocity, $v_{d}$, is also given in the figure. For example, if a series of flux measurements on a tailings pile yield a $J_{\max }$ of $63 \mathrm{pCi} \mathrm{m}-2 \mathrm{~s}^{-1}$ and a $J_{\min }$ of $5 \mathrm{pCi} \mathrm{m}-2 \mathrm{~s}^{-1}$, then $\mathrm{K}$ is equal to 12.6, and from Figure 18, the flux enhancement, $J_{a} / J_{d}$, is 1.9 . The long-term total flux, $J_{a}$, is $(68) / 2=34 \mathrm{pCi} \mathrm{m-2s}-1$; therefore, the diffusive flux, $J_{d}$, would be $18 \mathrm{pCi} \mathrm{m}-2 \mathrm{~s}^{-1}$. The ratio of the maximum amplitude of the advective velocity to the diffusive velocity is $v_{0} / v_{d}=1.6$. A common value for the diffusive velocity is $3 \times 10^{-4} \mathrm{~cm} \mathrm{~s}^{-1}$. Therefore, the maximum magnitude of the advective velocity is about $5 \times 10^{-4} \mathrm{~cm} \mathrm{~s}-1$. This is a much larger value than is generally found around present uranium milling environments; therefore, advection is generally not an important effect for semi-arid regions. Because the diffusive velocity is significantly lower for humid areas, advection may be more prominant in comparison. 


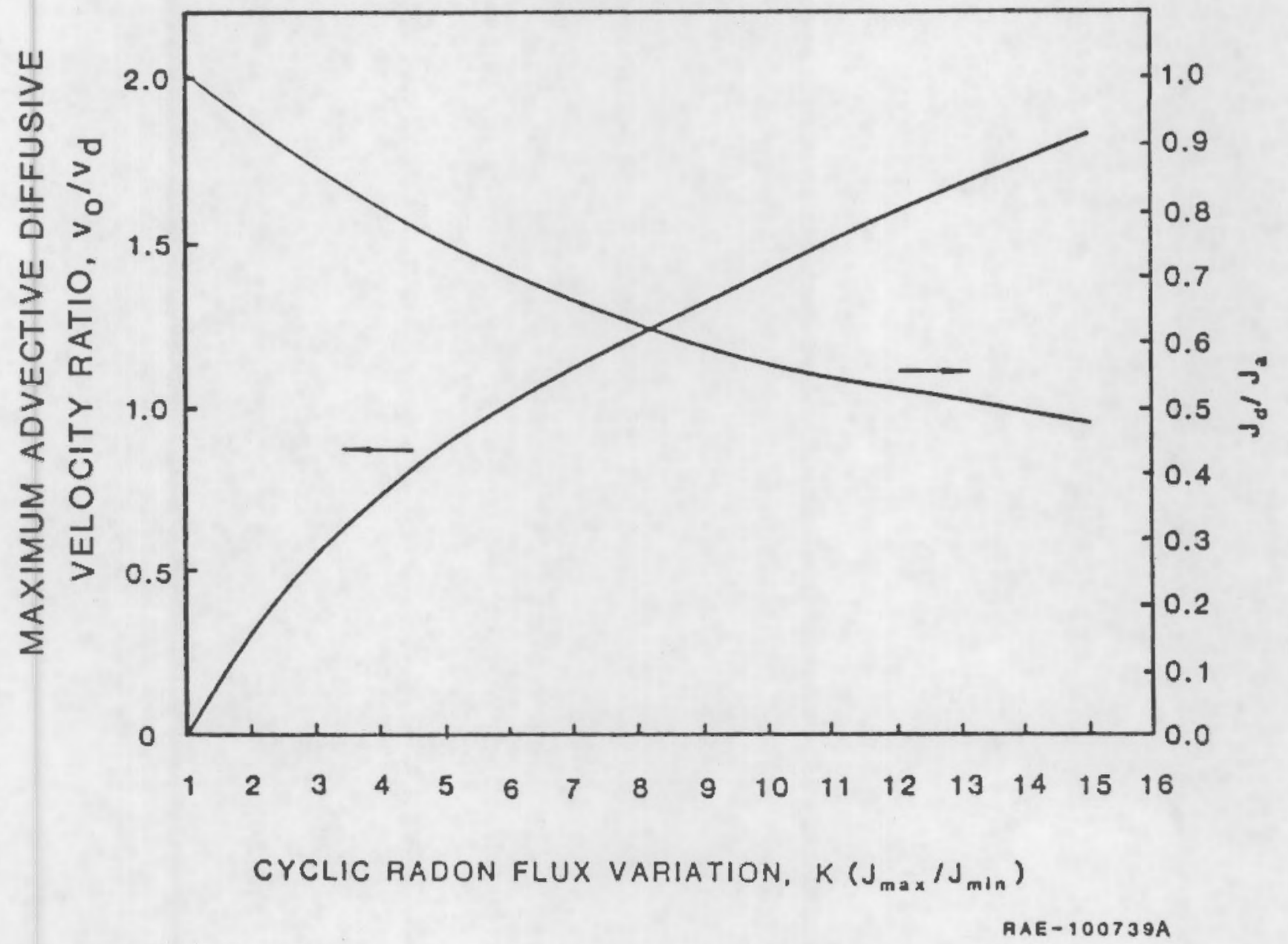

FIGURE 18 . ESTIMATION OF THE RATIOS $v_{0} / v_{d}$ AND $J_{d} / J_{a}$ FROM THE CYCLIC RADON FLUX RATIO K. 



\section{SUMMARY AND APPLICATION}

The radon releases from bare and covered tailings can be estimated using diffusion theory, if appropriate diffusion coefficients are used. The procedures for calculating the thickness of an adequate cover system are straight-forward and the calculations can be performed by hand or by computer programs such as the RAECOM code. A procedural checklist for the hand calculations is given in Table 5 .

As shown in the table, Step 1 is the calculation of all source parameters. Step 2 is the calculation of the cover parameters. These parameters are input to RAECOM for a determination of the required cover thickness and surface flux. If a hand calculation is performed, Step 3 is the calculation of over attenuation parameters and bare tailings flux. In Step 4, the required cover thickness is calculated. If the system consists of a multilayer cover, the surface flux from the first layer is calculated in Step 4 and the diffusion coefficient for the effective source term is calculated in Step 5. Repeat steps 4 and 5 until the top layer is calculated. The following example(63) illustrates the use of this procedure:

The values used for computing the bare tailings flux are as follows:

\section{Step 1}

$$
\begin{aligned}
R & =231.8 \mathrm{pCi} \mathrm{g}^{-1} \\
\rho & =1.6 \mathrm{~g} \mathrm{~cm}^{-3} \\
\mathrm{E} & =0.2 \\
D_{\mathrm{t}} & =0.013 \mathrm{~cm}^{2} \mathrm{~s}^{-1}
\end{aligned}
$$

The value of $D_{t}$ was obtained from Equation 12, using a tailings residual moisture of $M=11.5$ dry-weight percent, which yields a value of $\mathrm{m}=0.45$ using Equation 13.

\section{$\underline{\text { Step } 2}$}

The cover system consists of two feet of well-graded earthen material, covered with random fill or overburden, and one-half foot of top soil. The $D$ for the well graded material is estimated to be $0.0083 \mathrm{~cm}^{2} \mathrm{~s}^{-1}$ based upon an $\mathrm{m}$ value of 0.55 , and the $D$ for the overburden and topsoil is estimated to be $0.02 \mathrm{~cm}^{2} \mathrm{~s}^{-1}$ based upon an $\mathrm{m}$ value of 0.35 .

\section{Step 3}

Substitution of the above values into Equation 3 yields for the bare tailings flux: 


$$
\begin{aligned}
J_{t}= & \left(231.8 \mathrm{pCi} \mathrm{g}^{-1}\right)\left(1.6 \mathrm{~g} \mathrm{~cm}^{-3}\right)(0.2) \times\left(2.1 \times 10^{-6} \mathrm{~s}^{-1} \times 0.013 \mathrm{~cm}^{-2} \mathrm{~s}^{-1}\right)^{\frac{1}{2}} \\
& \times 1 \times 10^{4} \mathrm{~cm}^{2} \mathrm{~m}^{-2}=123 \mathrm{pCi} \mathrm{m}-2 \mathrm{~s}^{-1}
\end{aligned}
$$

The values of all needed parameters are:

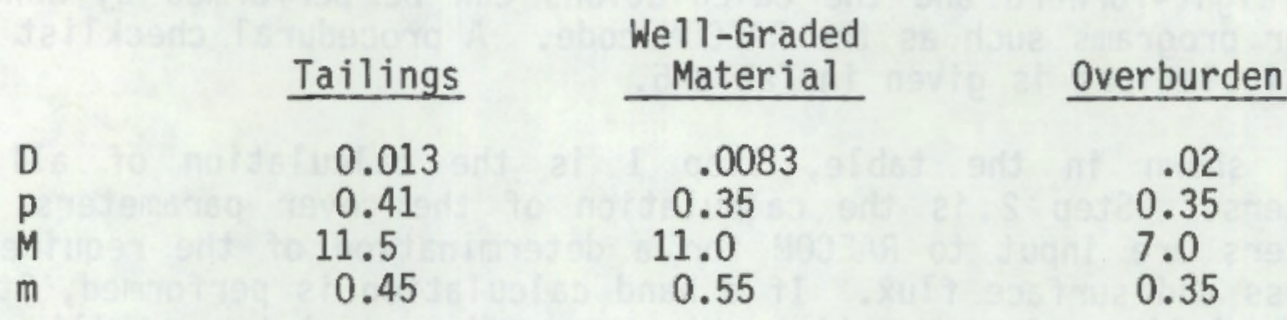

\section{$\underline{\text { Step } 4}$}

Using these values, the previously calculated bare tailings radon flux, and assuming the porosities are equal for all materials yields $\mathrm{J}_{1}=36.4 \mathrm{pCi} \mathrm{m}^{-2} \mathrm{~s}^{-1}$.

The next step (Step 5) is to calculate the $D$ of the effective source term. This composite diffusion coefficient is computed by Equation 9 . Thus, the composite $\mathrm{D}_{\mathrm{t} 1}$ is computed as:

$$
D_{t 1}=D_{t} \exp \left(-b_{1} x_{1}\right)+D_{c 1}\left[1-\exp \left(-b_{1} x_{1}\right)\right]
$$

where

$$
\begin{aligned}
D_{t} & =0.013 \mathrm{~cm}^{2} \mathrm{~s}^{-1} \\
D_{\mathrm{c} 1} & =0.0083 \mathrm{~cm}^{2} \mathrm{~s}^{-1} \\
\mathrm{x}_{1} & =61 \mathrm{~cm} \\
\mathrm{~b}_{1} & =\left(2.1 \times 10^{-6} \mathrm{~s}^{-1} / 0.0083 \mathrm{~cm}^{2} \mathrm{~s}^{-1}\right)^{\frac{1}{2}} \\
\mathrm{~b}_{1} & =0.016 \mathrm{~cm}^{-1}
\end{aligned}
$$

then

$$
D_{t 1}=0.013(0.379)+0.00515=0.0101 \mathrm{~cm}^{2} \mathrm{~s}^{-1}
$$

Step 4 is then repeated. Equation 8 yields the depth of overburden-topsoil in addition to the clay layer by using the following quantities: 


$$
\begin{aligned}
& D_{\mathrm{t}}=0.0101 \mathrm{~cm}^{2} \mathrm{~s}^{-1} \\
& x_{t}=\text { more than } 10 \mathrm{~m}
\end{aligned}
$$

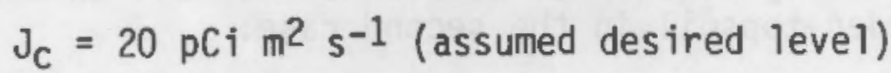

$$
\begin{aligned}
& J_{t}=36.4 \mathrm{pCi} \mathrm{m}^{-2} \mathrm{~s}^{-1} \\
& x_{c}=97.6 \ln \left[\frac{3.64}{1.569+0.130}\right]=74 \mathrm{~cm}
\end{aligned}
$$

Thus, the total cover needed to achieve a radon flux of $20 \mathrm{pCi} \mathrm{m} \mathrm{m}^{-2} \mathrm{~s}^{-1}$ is:

$$
\begin{aligned}
& 61 \mathrm{~cm} \text { clay } \\
& +74 \mathrm{~cm} \text { overburden-topsoil } \\
& 135 \mathrm{~cm} \text { total cover }
\end{aligned}
$$

It is also of interest to calculate the cover thickness required to meet a flux criterion of $20 \mathrm{pCi} \mathrm{m}-2 \mathrm{~s}^{-1}$ if only overburden-topsoil is placed over the tailings.

Using Equation 8 with the values,

$$
\begin{aligned}
& \mathrm{J}_{\mathrm{C}}=20 \mathrm{pCi} \mathrm{m}-2 \mathrm{~s}^{-1} \\
& \mathrm{~J}_{\mathrm{t}}=123 \mathrm{pCi} \mathrm{m} \mathrm{s}^{-1} \\
& \mathrm{D}_{\mathrm{t}}=0.013 \mathrm{~cm}^{2} \mathrm{~s}^{-1} \text { (the diffusion coefficient of the tailings) } \\
& \mathrm{D}_{\mathrm{C}}=\underset{\substack{\text { topsoi1) } \\
\text { to }}}{0.02 \mathrm{~cm}^{2} \mathrm{~s}^{-1} \text { (the diffusion coefficient of the overburden- }} \\
& \mathrm{a}_{\mathrm{t}} / \mathrm{a}_{\mathrm{C}}=0.850
\end{aligned}
$$

gives

$$
x_{C}=97.6 \ln \left[\frac{12.3}{1.850+0.004}\right]=185 \mathrm{~cm}
$$

The above calculations were performed by hand. The approximations associated with these cover-thickness equations are accurate to within 
$3 \mathrm{~cm}$. If the RAECOM code is used, items 1 and 2 of Table 5 provide sufficient information to prepare a complete data set in the format given in Appendix B. A RAECOM calculation for this example yields a cover thickness of $61 \mathrm{~cm}$ clay plus $77 \mathrm{~cm}$ overburden-topsoil in the first case and $184 \mathrm{~cm}$ of overburden-topsoil in the second case. 


\section{TABLE 5}

PROCEDURAL CHECKLIST FOR CALCULATING ADEQUATE COVER THICKNESS

\section{Step}

1. Determine Source Term Parameters, R, E, $\rho_{t}, P_{t}, a_{t}$

\section{Default values, $R=2,812 \mathrm{G}$}

$\rho_{\mathrm{t}}=1.5, \mathrm{p}_{\mathrm{t}}=0.35, \mathrm{gt}_{\mathrm{t}}=2$

2. Determine Cover Material Parameters, $D_{C}, P_{C}, \rho_{c}$

3. Calculate Cover Attenuation Parameters and Calculate or Estimate Bare Tailings Flux

4. Calculate Surface Flux or Cover Thickness

Oefault values, $P_{c}=0.35$, $g_{c}=2.7$

$$
\begin{aligned}
& m_{t}=10^{-2} m_{t}\left[\frac{1}{\rho_{t}}-\frac{1}{g_{t}}\right]^{-1} \\
& D_{t}=0.07 \exp \left[-4\left(m-m p^{2}+m^{5}\right)\right] \\
& a_{t}=p_{t}^{2} D_{t}\left[1-0.74 m_{t}\right]^{2} \\
& m_{c}=10^{-2} m_{c}\left[\frac{1}{\rho_{c}}-\frac{1}{g_{c}}\right]^{-1} \\
& D_{c}=0.07 \exp \left[-4\left(m-m p_{c}^{2}+m^{5}\right)\right] \\
& J_{t}=R \rho_{t} E\left(\lambda D_{t}\right)^{\frac{1}{2}} \\
& b_{c}=\left(\lambda / D_{c}\right)^{\frac{1}{2}} \\
& a_{c}=P c^{2} D_{c}\left[1-0.74 m_{c}\right]^{2} \\
& J_{c}=\frac{2 J_{t} \exp \left(-b_{c} x_{c}\right)}{\left[1+\left(a_{t} / a_{c}\right)^{\frac{1}{2}} \tanh b_{t} x_{t}\right]+\left[1-\left(a_{t} / a_{c}\right)^{\frac{1}{2}} \tanh b_{t} x_{t}\right] \exp \left(-2 b_{c} x_{c}\right)} \\
& x_{c}=\frac{1}{b_{c}} \ln \left[\frac{2 J_{t} / J_{c}}{\left(1+\sqrt{\left.a_{t} / a_{c}\right)} \tanh b_{t} x_{t}\right)+\left(1-\sqrt{\left.a_{t} / a_{c}\right)} \tanh b_{t} x_{t}\right)\left(J_{c} / J_{t}\right)^{2}}\right]
\end{aligned}
$$

5. For Multiple Layer Cover, Calculate Effective Source $\mathrm{D}_{\mathrm{sm}}$

6. Repeat For Multiple Layer Covers

Calculate Item 4 for the first cover layer, then calculate Item 5 for the second cover layer, then calculate

Item 4 for the second cover layer, and so on until Item 4 is calculated for the top layer 


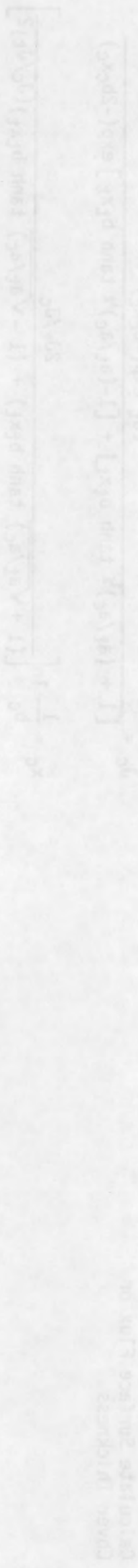




\section{REFERENCES}

1. V.C. Rogers and K.K. Nielson, "A Handbook for the Determination of Radon Attenuation Through Cover Materials," U.S. Nuclear Regulatory Commission, NUREG/CR-2340, December 1981.

2. G.E. Harrison, "The Diffusion of Radon Gas Mixtures," University of Birmingham, 1938.

3. E.M. Kovach, "Meteorological Influences Upon the Radon-Content of Soil-Gas," Transactions of the American Geophysical Union, 26, 241, 1945.

4. B.J. Giletti and J.L. Kulp, "Radon Leakage From Radioactive Minerals," Columbia University, 1954.

5. S.L. Jaki and V.F. Hess, "A Study of the Oistribution of Radon, Thoron, and Their Decay Products Above and Below the Ground," J. Geophys. Res. $63,370-390,1958$.

6. H.B. Evans, "Factors Influencing Permeability and Diffusion of Radon In Synthetic Sandstones," University of Utah, 1959.

7. H.W. Kraner, G.L. Schroeder, and R.D. Evans, "Measurements of the Effects of Atmospheric Variables on Radon 222 Flux and Soil-Gas Concentration," The Natural Radiation Environment, J.A.S. Adams and W.M. Lowder, Eds., University of Chicago Press, 1964.

8. Allen B. Tanner, "Radon Migration in the Ground: A Review," The Natural Radiation Environment, J.A.S. Adams and W.M. Lowder, Eds., University of Chicago press, 1964, p. 161-190.

9. M.H. Wilkening and J.E. Hand, "Radon Flux at the Earth-Air Interface," J. Geophys. Res. $65,3367-3370,1960$.

10. W. Jost, Diffusion in Solids, Liquids, Gases, Academic Press, New York, 1960.

11. A.S. Serdyukova and Yu. T. Kapitanov, "Radon Isotopes and Short-Lived Products of Their Disintegration in Nature," Atomizdat, Moskva, (Translated from Russian TT72-51014, 1978), 1969.

12. M.H. Wilkening, W.E. Clements and D. Stanley, "Radon-222 Flux Measurements in Widely Separated Regions," The Natural Radiation Environment II, J.A.S. Adams and W.M. Lowder, Eds., The University of Chicago Press, 1975.

13. H.W. Kraner, G.L. Schroeder and R.D. Evans, "Annual Progress Report to AEC," MIT-952-4, 1967. 
14. M.V.J. Culot, H.G. 01son and K.J. Schiager, "Effective Diffusion Coefficient of Radon in Concrete Theory and Method for Field Measurements," Health Physics, 30, p. 263, March 1976.

15. K.J. Schiager, "Analysis of Radiation Exposures On Or Near Uranium Mill Tailings Piles," Radiation Data and Reports, 15, 411, 1974.

16. M.V.J. Culot, H.G. 0lson and K.J. Schiager, "Radon Progeny Control in Buildings," Colorado State University, Fort Collins, Colorado, May 1973.

17. J.C. Franklin, J.C. Kerkering and K.D. Weyerstad, "Effects of Moisture on Radon Emanation," U.S. Bureau of Mines Technical Progress Report, 1978.

18. R.C. Bates and J.E. Edwards, "Radon Emanation Relative to Changing Barometric Pressure and Physical Constraints," Second Conference on Uranium Mining Technology, Reno, Nevada, November 1978.

19. A.B. Tanner, "Radon Migration in the Ground--A Supplementary Review," The Natural Radiation Environment III, T.F. Gesell and W.M. Lowder, Eds., CONF-780422, 1980.

20. K.K. Nielson, B.J. Thamer, K.M. Putzig, "The Effects of Moisture on Radon Emanation and Diffusion," Salt Lake City: Ford Bacon \& Davis Report to U.S. Bureau of Mines, FBDU-315-1, January 1980.

21. P.J. Macbeth, C.M. Jensen, V.C. Rogers and R.F. Overmyer, "Laboratory Research on Tailings Stabilization Methods and Their Effectiveness in Radiation Containment," U.S. Department of Energy Report GJT-21, April 1978.

22. V.C. Rogers, R.F. Overmyer, K.M. Putzig, C.M. Jensen, K.K. Nielson and B.W. Sermon, "Characterization of Uranium Tailings Cover Materials For Radon Flux Reduction," U.S. Nuclear Regulatory Commission, NUREG/CR-1081, March 1980.

23. R.W. Nelson, G.W. Gee and C.A. Oster, "Radon Control by Multilayer Earth Barriers," Uranium Mill Tailings Management - III, Ft. Collins: Colorado State University, p. 79-88, 1980.

24. M.H. Momeni, W.E. Kisieleski, S. Tyler, A. Zielen, Y. Yuan and C.J. Roberts, "Radiological Impact of Uranium Tailings and Alternatives For Their Management," Proceedings of the Health Physics Society 12th Mid-Year Topical Symposium, "Low-Level Radioactive Waste Management," U.S. EPA 520/3-79-002, CONF-790209-7, February 1979.

25. W.B. Silker and P.G. Heasler, "Diffusion and Exhalation of Radon From Uranium Tailings," U.S. Nuclear Regulatory Commission, NUREG/CR-1138, October 1979. 
26. K.K. Nielson, V.C. Rogers, D.C. Rich, F.A. Nederhand, G.M. Sandquist and C.M. Jensen, "Laboratory Measurements of Radon Diffusion Through Multilayered Cover Systems For Uranium Tailings" U.S. Department of Energy Report UMT/0206, 1981.

27. B.J. Thamer, K.K. Nielson, V.C. Rogers, R.F. Overmyer, B.W. Sermon and P.J. Macbeth, "Radon Diffusion and Cover Material Effectiveness for Uranium Tailings Stabilization," Salt Lake City: Ford Bacon \& Davis Utah Report to U.S. Department of Energy, FBDU-258, May 1980.

28. J. Pohl-Ruling, F. Stienhauser and E. Pohl, "Investigation on the Suitability of Various Materials as Rn-222 Diffusion Barriers," Health Physics, 39, p. 299, 1980.

29. V.C. Rogers, B.J. Thamer, R.F. Overmyer and B.W. Sermon, "A New Laboratory Technique For Measuring Diffusion Coefficients of Mill Tailings Covers," Trans. Am. Nuc. Soc., 34, 132, 1980.

30. G.L. Schroeder, H.W. Kraner and R.D. Evans, "Diffusion of Radon in Several Naturally Occurring Soils," J. Geophys. Res., 70, 471-474, 1965.

31. B.L. Cohen, "Laboratory Measurements of Diffusion Constants for Mill Tailings Covers and Its Application," Trans. Amer. Nuc. Soc., 33, p. 173,1979 .

32. B.L. Cohen, "Methods For Predicting the Effectiveness of Uranium Mi11 Tailings Covers," Nuc1. Inst. Meth. 164, 595-599, 1979.

33. W.B. Silker, "A Radon Attenuation Test Facility," U.S. Nuclear Regulatory Commission, NUREG/CR-2243, September 1981.

34. K.K. Nielson, D.C. Rich, V.C. Rogers and D.R. Kalkwarf, "Comparison of Radon Diffusion Coefficients Measured by Transient Diffusion and Steady-State Laboratory Methods," U.S. Nuclear Regulatory Commission, NUREG/CR-2875, November 1982.

35. W.B. Silker and D.R. Kalkwarf, "Radon Diffusion in Candidate Soils For Covering Uranium Mill Tailings," U.S. Nuclear Regulatory Commission, NUREG/CR-2924, 1983.

36. K.K. Nielson, V.C. Rogers and D.C. Rich, "Small Scale Field Test of Simple Earthen Covers For Uranium Mill Tailings," U.S. Department of Energy Report, UMTRA-DOE/AL0-19, 1983.

37. E.A. Lepel, W.B. Silker, V.W. Thomas and D.R. Kalkwarf, "Comparison of Field-Measured Radon Diffusion Coefficients With Laboratory Measured Coefficients," U.S. Nuclear Regulatory Commission, NUREG/CR-2769, April 1983.

38. J.N. Hartley, G.W. Gee, E.G. Baker and H.D. Freeman, "1981 Radon Barrier Field Test at Grand Junction Uranium Mill Tailings Pile," U.S. Department of Energy Report DOE/UMT-0213, April 1983. 
39. V.C. Rogers, K.K. Nielson and G.B. Merre11, "Engineering Guides For Est imating Cover Materials Thickness and Volume," U.S. Department of Energy Report, UMTRA-DOE/AL0-193, November 1982.

40. V.C. Rogers and K.K. Nielson, "A Complete Description of Radon Diffusion in Earthen Materials," Symposium of Uranium Mill Tailings Management - IV, Ft. Collins: Colorado State University, p. 247-263, 1981.

41. K.K. Nielson and V.C. Rogers, "A Mathematical Model For Radon Diffusion In Earthen Materials," U.S. Nuclear Regulatory Commission Report, NUREG/CR-2765, 1982.

42. V.C. Rogers, K.K. Nielson and G.B. Merre11, "The Effects of Advection on Radon Transport Through Earthen Materials," U.S. Nuclear Regulatory Commission Report NUREG/CR-3409, 1983.

43. V.C. Rogers and G.M. Sandquist, "Long-Term Integrity of Uranium Mi11 Tailings Covers," Salt Lake City: RAE Corp. Report to U.S. Nuclear Regulatory Commission, RAE-21-1, July 1981.

44. D.R. Kalkwarf and D.W. Mayer, "Influence of Cover Defects on the Attenuation of Radon With Earthen Covers," U.S. Nuclear Regulatory Commission Report, NUREG/CR-3395, 1983.

45. D.W. Mayer and D.A. Zimmerman, "Radon Diffusion Through Uranium Mill Tailings and Cover Defects," U.S. Nuclear Regulatory Commission Report NUREG/CR-2457, 1981.

46. Final Generic Environmental Impact Statement on Uranium Milling, U.S. Nuclear Regulatory Commission Report NUREG-D706, September 1980.

47. K.K. Nielson and V.C. Rogers, "Radon Flux Through Multi-Layered Covers Over Uranium Mill Tailings," Trans. Amer. Nuc. Soc., 34, p. 131, 1980.

48. V.C. Rogers, G.M. Sandquist and K.K. Nielson, "Radon Attenuation Effectiveness and Cost Optimization for Uranium Mill Tailings and Composite Covers," U.S. Department of Energy Report, UMTRA-D0E/ALO 165, July 1981.

49. V.C. Rogers, K.K. Nielson, G.M. Sandquist and D.C. Rich, "Radon Flux Measurement and Computationa 1 Methodologies," Salt Lake City: RAE Corp. Report to Bendix Field Eng., RAE-38-1, February 1984.

50. J.A. Young, V.W. Thomas and P.0. Jackson, "Recommended Procedures For Measuring Radon Fluxes From Disposal Sites of Residual Radioactive Materials," U.S. Nuclear Regulatory Commission, NUREG/CR-3166, March 1983.

51. B.J. Thamer, K.K. Nielson and K.M. Felthauser, "The Effects of Moisture on Radon Emanation," Denver, Colorado: U.S. Bureau of Mines Open File Report 184-82, 1982. 
52. R.C. Bates, "Time-Dependent Rn-222 Loss From Small Samples," Health Physics, 39, pp. 799-801, 1980.

53. J.N. Hartley, G.W. Gee, H.D. Freeman, J.F. Cline, P.F. Beedlow, J.L. Buelt, J.R. Relyea and T. Tamura, "Uranium Mill Tailings Remedial Action Project Cover and Liner Technology Development Program," Int. Symp. on Mgmt. of Wastes From Uranium Mining and Milling, IAEA-SM-262/39, Albuquerque, New Mexico, May 1982

54. V.C. Rogers, K.K. Nielson, D.C. Rich, G.M. Sandquist and M.L. Mauch, "Radon Attenuation With Earthen Covers, Annual Report," Salt Lake City: RAE Corp. Report to DOE-UMTRAP, RAE-33-14, October 1982.

55. V.C. Rogers, R.F. Overmyer and K.K. Nielson, "Radon Attenuation Through Cover Materials, "Uranium Mill Tailings Management - II, Ft. Collins: Colorado State University, p. 145-156, November 1979.

56. C.S. Simmons and G.W. Gee, "Simulation of Water Flow and Retention in Earthen Cover Materials Overlying Uranium Mill Tailings," U.S. Department of Energy Report UMT/0203, September 1981.

57. M.W. Grant, G.B. Merre11, V.C. Rogers and K.K. Nielson, "Performance and Cost of Uranium Mill Tailings Containment Systems - The PACUTS Computer Program," U.S. Department of Energy Report UMTRA-DOE/ALO-35, 1983.

58. S.K. Gupta, K.K. Tanji, D.R. Nielson, J.W. Biggar, C.S. Simmons and J.L. Macintyre, Field Simulation of Soil-Water Movement With Crop Water Extraction, Water Science and Engineering Papers No. 4013, Department of Land, Air, and Water Resources, University of California, Davis, California, 1978.

59. V.C. Rogers, K.K. Nielson, G.B. Merre11, "Radon Attenuation With Earthen Covers - 1983 Annual Report," RAE Report to Department of Energy - UMTRAP, RAE-36-3, October 1983.

60. J.E. Box and S.A. Taylor, "Influence of Soil Bulk Density on Matric Potential," Soil Sci. 93, 119, 1962.

61. S.R. Austin and R.F. Droullard, "Radon Emanation From Domestic Ores Determined by Modifications of the Closed-Can, Gamma-Only Assay Method," Denver, Colorado: U.S. Bureau of Mines Report RI-8264, 1978.

62. K.K. Nielson, V.C. Rogers, M.L. Mauch, J.N. Hartley and H.D. Freeman, "Radon Emanation Characteristics of Uranium Mill Tailings," Uranium Mill Tailings Management - V, Ft. Collins: Colorado State University, p. 355-367, December 1982.

63. Environmental Assessment Related to the Operation of Hansen Uranium Mill Project, U.S. Nuclear Regulatory Commission Report NUREG-0749, January 1981 . 


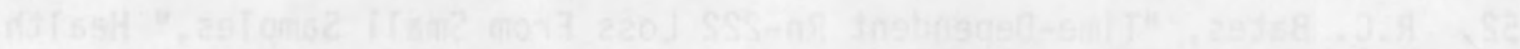
(3)

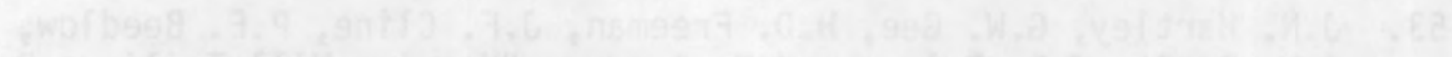

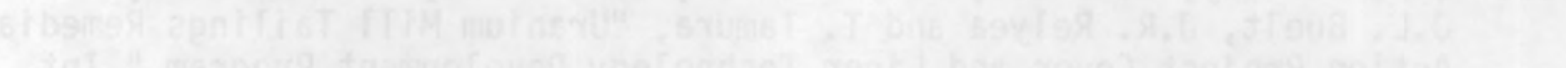

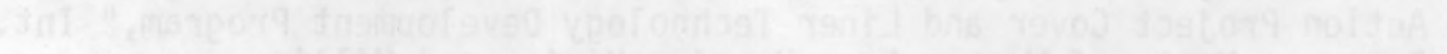

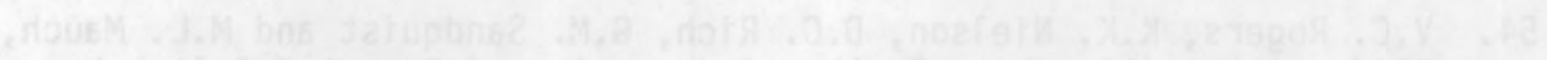

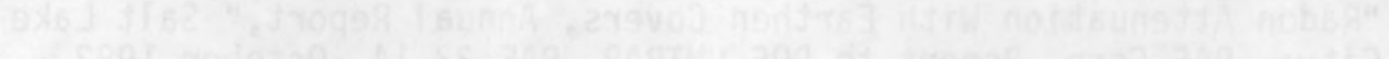

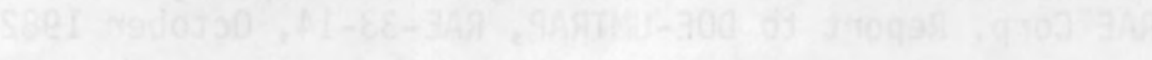




\section{APPENDIX A}

\section{MATHEMATICAL BASIS FOR RADON DIFFUSION}

The radon diffusion equation for, a porous, multiphase system, given in Equation 1, is derived in this Appendix in order to obtain expressions for the equivalent $D$ descriving the radon diffusion through the system. Since the basic diffusion relationship pertained to a single medium, two coupled diffusion equations serve as the starting point for the derivation. These equations apply to the diffusion in the air-space and in the water-space of the multiphase system. It has been shown previously $(40,41)$ that radon diffusion through a two-phase medium in the pore spaces of earthen materials can be characterized by the following diffusion equations:

$$
\begin{array}{r}
D_{a} \frac{d^{2} C_{a}}{d x^{2}}-\lambda C_{a}+\frac{R \rho \lambda E_{a}}{p(1-m)}+\frac{T_{w a}}{p(1-m)}=0 \\
D_{w} \frac{d^{2} C_{w}}{d x^{2}}-\lambda C_{w}+\frac{R \rho \lambda E_{w}}{p m}-\frac{T_{w a}}{p m}=0
\end{array}
$$

where

$$
\begin{aligned}
& \mathrm{D}_{\mathrm{a}}=\text { diffusion coefficient in the air-filled pore space }\left(\mathrm{cm}^{2} \mathrm{~s}^{-1}\right) \\
& D_{W}=\text { diffusion coefficient in the water-filled pore space }\left(\mathrm{cm}^{2} \mathrm{~s}^{-1}\right) \\
& \mathrm{C}_{\mathrm{a}}, \mathrm{C}_{\mathrm{w}}=\text { radon concentrations in the respective air- and water- } \\
& \text { filled pore space }\left(\mathrm{pCi} / \mathrm{cm}^{3}\right) \\
& p=\text { porosity } \\
& m=\text { volume fraction of moisture saturation of the pore space } \\
& A=\text { radon decay constant } \\
& \mathrm{R}=\text { radium concentration in material } \\
& \rho=\text { bulk density of dry material } \\
& E_{a}=\text { radon emanation power coefficient for the air-filled } \\
& \text { pore spaces } \\
& E_{W}=\text { radon emanation coefficient for the water-filled pore } \\
& \text { spaces } \\
& T_{\text {wa }}=\text { radon transfer rate from water to the air }
\end{aligned}
$$


The sum of $E_{a}$ and $E_{w}$ yields the total emanation coefficient, $E$, of the earthen material.

The radon concentration in the total pore space is given by:

$$
C=C_{a}(1-m)+C_{w} m
$$

Combining Equations $\mathrm{A}-1, \mathrm{~A}-2$ and $\mathrm{A}-3$ yields

$$
D \frac{d^{2} C}{d x^{2}}-\lambda C+R \rho \lambda E / p=0
$$

where

$$
D=\frac{D_{a}(1-m)+D_{w} m k}{1-(1-k) m},
$$

and

$$
k=\underset{\left(k=0.26 \text { at } 20^{\circ} \mathrm{C}\right)(41)}{\text { radon distributiont, }} \mathrm{C}_{\mathrm{w}} / \mathrm{C}_{\mathrm{a}} \text {, for water/air }
$$

Equation $A-4$ is the radon diffusion equation traditionally
used $(1,9,46)$ and is identical to Equation 1 . The diffusion coefficient D pertains to the total pore space in the material.

\section{A.1 BARE TAILINGS FLUX}

One parameter needed for estimating cover thicknesses over uranium mill tailings is the radon source term; thus it is desirable to obtain an expression for the flux from an uncovered tailings pile. Solution of Equation A-4 for the boundary conditions:

$$
\begin{aligned}
& \frac{d C}{d x}\left(x=x_{t}\right)=0 \\
& C(x=0)=0
\end{aligned}
$$

yields the following expression for the bare tailings flux 


$$
J_{t}=10^{4} R_{\rho} E{\sqrt{\lambda D_{t}}} \tanh \left[\sqrt{\lambda / D_{t}} x_{t}\right],
$$

where $x_{t}$ is the thickness of the tailings and the subscript $t$ refers to the tailings.

\section{A.2 COVERED TAILINGS}

The solution of the diffusion equation for a two-region problem applies to a tailings pile covered with a homogeneous material. For simplicity, the source term in the cover and the radon concentration at the surface of the cover are assumed to be zero. The origin is assumed to be at the interface. It is also assumed that there is continuity of flux, radon concentration in air, and radon concentration in water across the interface. The latter two continuity conditions can be combined into the following interface condition:

$$
\frac{C_{t}}{1-(1-k) m_{t}}=\frac{C_{c}}{1-(1-k) m_{c}} \text {, }
$$

where $C_{t}$ and $C_{c}$ are defined by Equation $A-3$.

Continuity of flux across the interface gives:

$$
D_{t} p_{t} \frac{d C_{t}}{d x}=D_{c} p_{C} \frac{d C_{C}}{d x}
$$

It is convenient to group the parameters comprising the source term in such a way that the grouped parameter has a physical meaning. This grouping is the same as the expression for the radon flux at the surface of the bare tailings.

Solution of Equation A-4 using the boundary and interface conditions in Equations $A-6, A-7, A-9$ and $A-10$ yields for the surface flux:

$$
J\left(x_{c}\right)=\frac{2 J_{t} e^{-b_{c} x_{c}}}{\left(1+\sqrt{\frac{a_{t}}{a_{c}}} \tanh \left(b_{t} x_{t}\right)\right)+\left(1-\sqrt{\frac{a_{t}}{a_{c}}} \tanh \left(b_{t} x_{t}\right)\right) e^{-2 b_{c} x_{c}}}
$$

where

$$
\begin{aligned}
& x_{c}=\text { cover thickness } \\
& b_{i}=\sqrt{\lambda / D_{i}}(i=c \text { or } t) \\
& a_{i}=p_{i}^{2} D_{i}\left[1-(1-k) m_{i}\right]^{2}
\end{aligned}
$$





\section{APPENDIX B \\ RADIATION ATTENUATION EFFECTIVENESS \\ AND COVER OPTIMIZATION WITH MOISTURE EFFECTS}

THE RAECOM CODE

The one-dimensional, steady-state radon diffusion code, RAECO, (48) has been modified and updated. The updated code, RAECOM, is a FORTRAN program which determines the radon fluxes and concentrations in multilayer uranium tailings and cover systems using the mathematical formulation given in Appendix A, and then optimizes the cover thickness to satisfy a given flux constraint. The numerical method of solution in RAECOM is identical to that in RAECO.

In proceeding through a calculation, first, the D's are calculated from a correlation if they are not input directly. Then the migration of radon is determined for the specified cover characteristics and the radon concentrations (C) and the radon fluxes (J) are calculated. The cover optimization is performed yielding adjusted values ( $t$ ) for the layer thicknesses. The radon migration calculations are then repeated for each $J$ and $C$ with the adjusted cover layer thicknesses, and the resulting surface

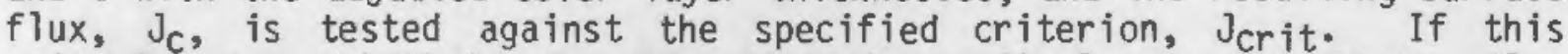
criterion is satisfied, the code proceeds to final output. If the flux criterion is not satisfied, appropriate layer thicknesses are adjusted within the specified constraints, radon migration calculations are repeated, and the surface radon flux is again tested against the flux criterion. This process is repeated until all criteria are satisfied. The code then outputs all radon attenuation data. If additional cover systems are to be evaluated, the RAECOM code will re-initialize and perform the complete analysis for the subsequent cover systems. Any number of cover systems can be analyzed by stacking data sets.

\section{B.1 MODIFICATIONS}

Modifications to RAECO that are incorporated in RAECOM include:

1. Soil moistures (dry weight percent) are read in to calculate the $D$ of any layer not input, using Equation 12.

2. The radon concentration interface condition includes the effects of soil moisture (Appendix A).

3. The diffusion coefficient of the pore space, D, and the pore space radon source term, $Q=R \rho E \lambda / P$, are read in directly instead of the bulk parameters $D_{e}=p D$ and $Q_{e}=p Q$. 
4. The optimization routine does not depend upon cost parameters.

5. If desired, the program will estimate the entrance radon flux into layer 1, assuming an infinitely thick subsoil underneath layer 1.

\section{B.2 INPUT DATA FORMAT FOR RAECOM}

All input data is free format. The following input is needed for program operation.

Card Set Number

1

2

$3,1-\mathrm{N}$
Card Description

Site Designation Card - One card with up to 80 characters which designates the tailings cover system and run identification.

Boundary Conditions and Cost Control Parameters One card containing six parameter values, each separated by commas in the following order:

(1) N, Number of distinct tailings cover layers: positive integer, presently limited to 99.

(2) F01, Entrance radon flux to layer $1, \mathrm{pCi} / \mathrm{m}^{2} \mathrm{~s}$. If F01 equals -1 ., then FO1 is computed internally for an infinitely thick subsoil.

(3) CN1, Surface radon concentration at top of system, $\mathrm{pC} i / 1$.

(4) ICOST, Integer Cover Optimization Flag, $I C O S T=0$ if no optimization is to be performed, otherwise, ICOST equals the layer number to be optimized. ICOST cannot equal 1.

(5) CRITJ, Surface Flux Constraint for optimization, $\mathrm{pCi} / \mathrm{m}^{2} \mathrm{~s}, \mathrm{CRITJ}=0$ for no constraint.

(6) ACC, Surface Flux Convergence Criterion, fraction.

Individual Cover Layer Data Cards - One card for each tailings or cover layer. Each card is composed of four parameters:

(1) DX, The layer thickness in $\mathrm{cm}$. 
(2) D, Layer radon diffusion coefficient, $\mathrm{cm}^{2} \mathrm{~s}^{-1}$.

(3) p, Layer porosity.

(4) Q, Layer radon source term in $\mathrm{pCi} \mathrm{cm}^{-3} \mathrm{~s}^{-1}$.

(5) M, Moisture content as dry wt percent.

\section{B.4 SAMPLE PROBLEM}

The output and input for the example problem described in Table 2 of the Handbook is given below:

\section{RAECOM CALCULATION OF MULTIREGION EXAMPLE}

RAECOM CALCULAIION OF MULTIREGION EXAKPLE

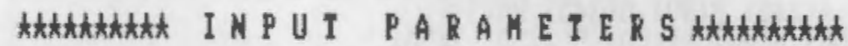

MUHBER OE LAYERS :

3

RADON FLUX IMTO LAYER 1 :

$0.000 \quad \mathrm{pCi} / \mathrm{p} 2 / \mathrm{sec}$

SUREACE RADON CONCENTRATION :

0.000

pCi/liter

LAYER 3 ADJUSTED TO KEET Jcrit :

$20.0+/-0.100 \mathrm{E}-02 \mathrm{pCi} / \mathrm{n} 2 / \mathrm{sec}$

BARE SOURCE ELUX (Jo) FROM LAYER $1: 198.4$ pCi/n $2 / \mathrm{sec}$

\begin{tabular}{|c|c|c|c|c|c|}
\hline LAYER & $\underset{\text { (cu) }}{\text { IHICKNESS }}$ & $\begin{array}{l}\text { DIFF COEFF } \\
(\mathrm{c} 2 / \mathrm{sec})\end{array}$ & POROSITY & $\begin{array}{c}\text { SOURCE } \\
(\mathrm{pCi} / \mathrm{c} \| 3 / \mathrm{sec})\end{array}$ & $\begin{array}{l}\text { MOISTURE } \\
\text { (dry wt. percent) }\end{array}$ \\
\hline$\frac{1}{2}$ & $\begin{array}{l}500 . \\
50 . \\
100 .\end{array}$ & $\begin{array}{l}1.3000 \mathrm{E}-02 \\
7.8000 \mathrm{E}-03 \\
2.2000 \mathrm{E}-02\end{array}$ & $\begin{array}{l}0.4400 \\
0.3000 \\
0.3700\end{array}$ & $\begin{array}{l}5.7300 \mathrm{E}-04 \\
0.0000 \mathrm{E}-01 \\
0.0000 \mathrm{E}-01\end{array}$ & $\begin{array}{r}11.70 \\
6.30 \\
5.40\end{array}$ \\
\hline
\end{tabular}

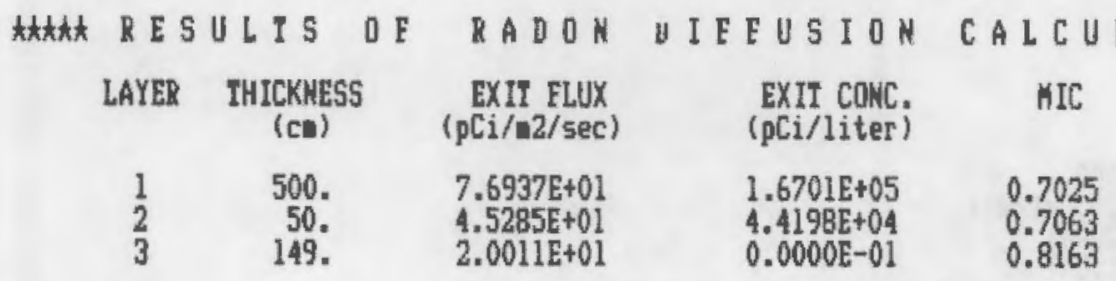

RAECOM CALCULAIION OF MULIIREGION EXAMPLE

$3,0 ., 0.3,20 ., .001$

$560 ., .013, .44, .000573,11.7$

$50 ., .0078, .30, .0, \quad 6.3$

$100 ., .022, .37, .0, \quad 5.4$ 


\section{B.4 RAECOM LISTING}

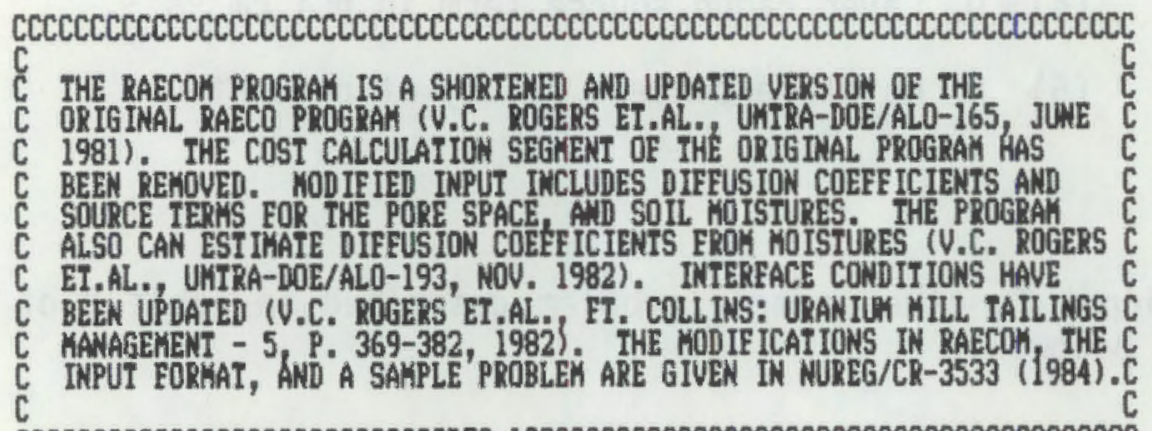

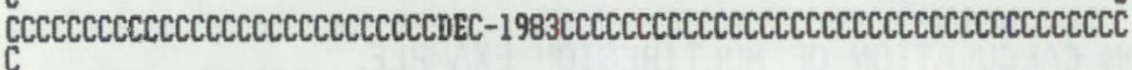

C PROGRAM RAECOH

¿ DEEINE \& INITIALIZE ARRAYS

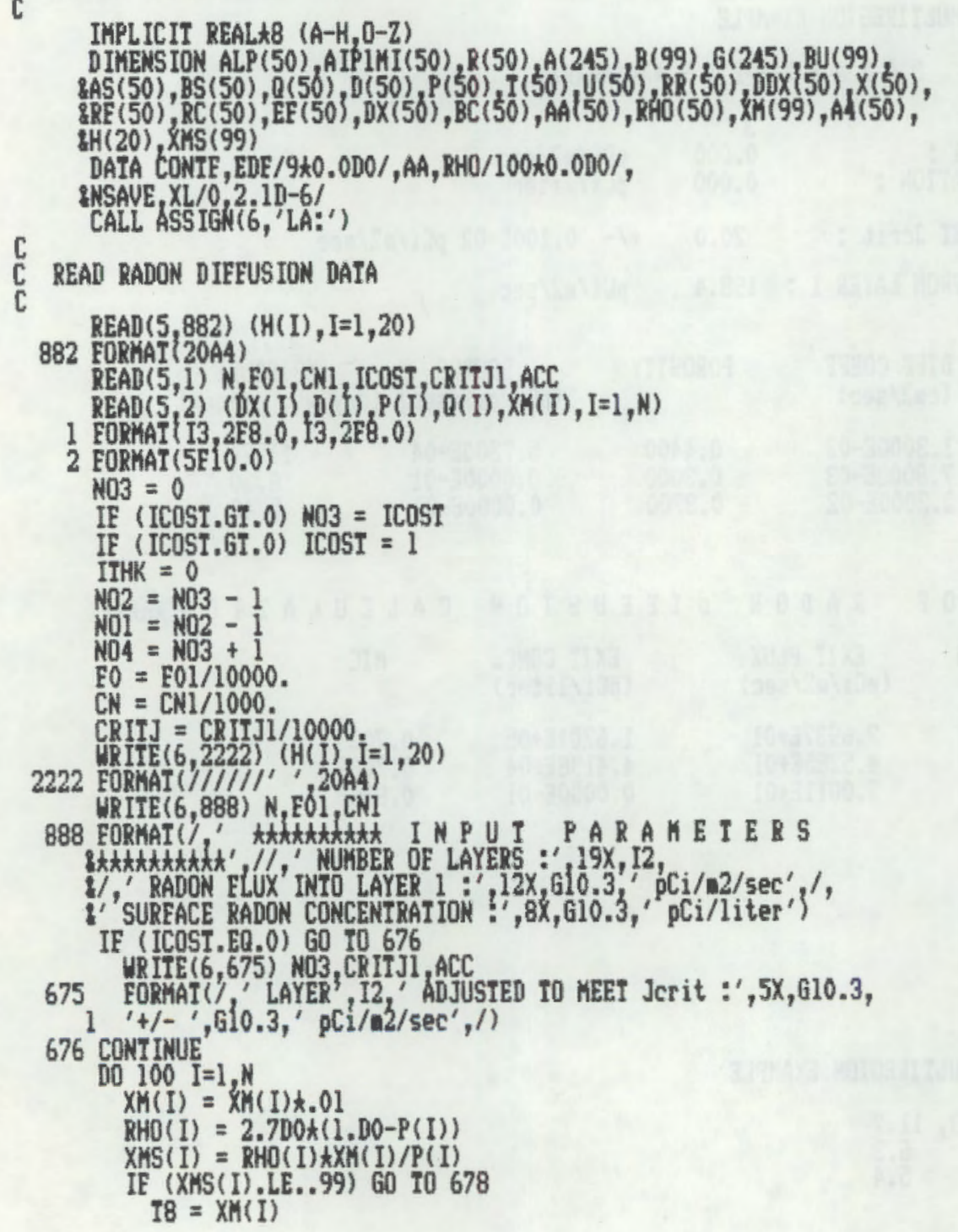




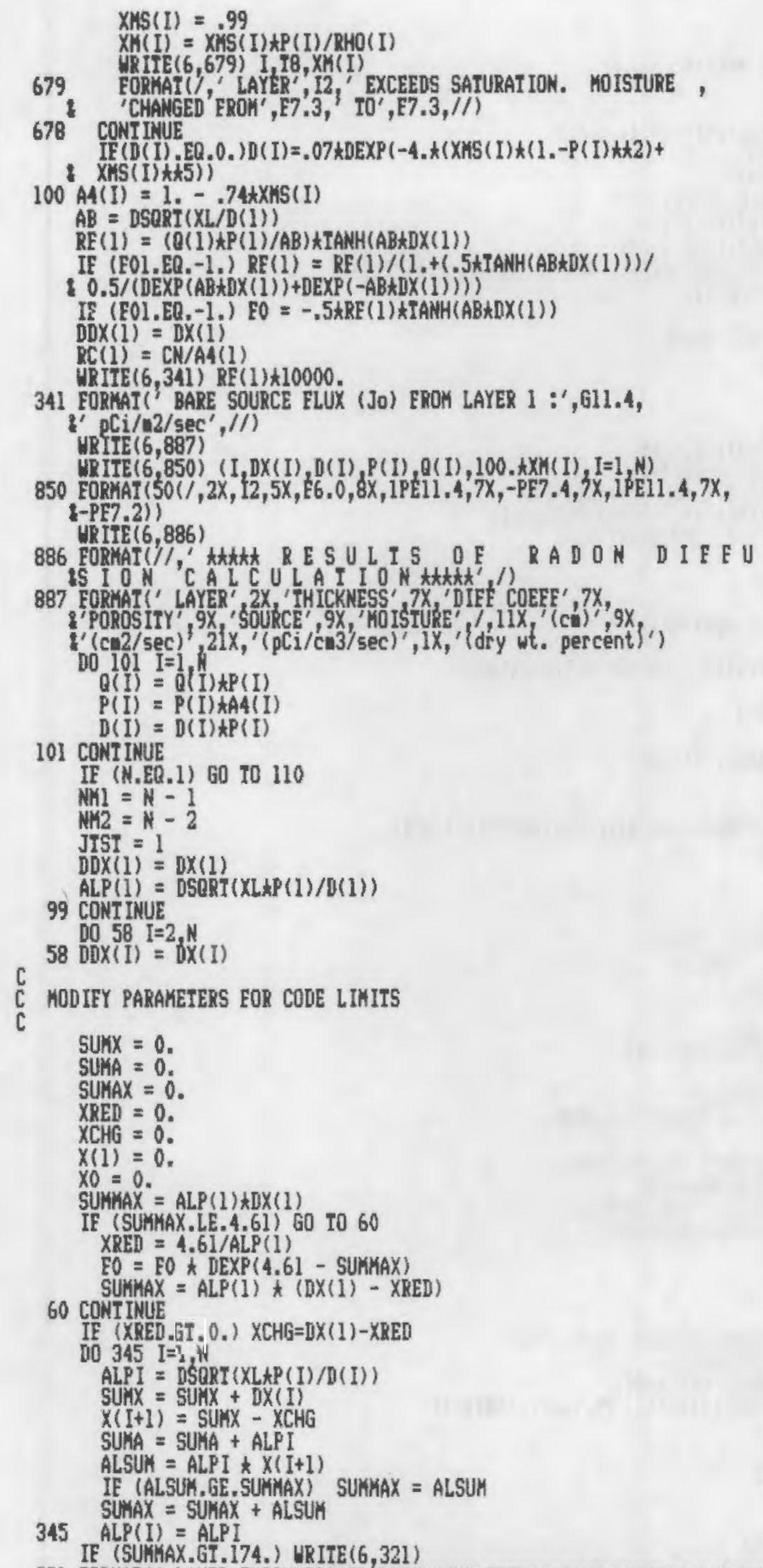

321 EORKAT(' LAYER IHICKNESS OR DIFEUSION COEFEICIENI EXCEEUS LIMITS') IF (SUHYAX.LE.87.) GO TO 500

$X O=$ SUMAX/SUKA

Dio $456 \mathrm{I}=0, \mathrm{~N}$

$X(I+1)=X(I+1)-X 0$

456 CONTINUE

500 CONTINUE 


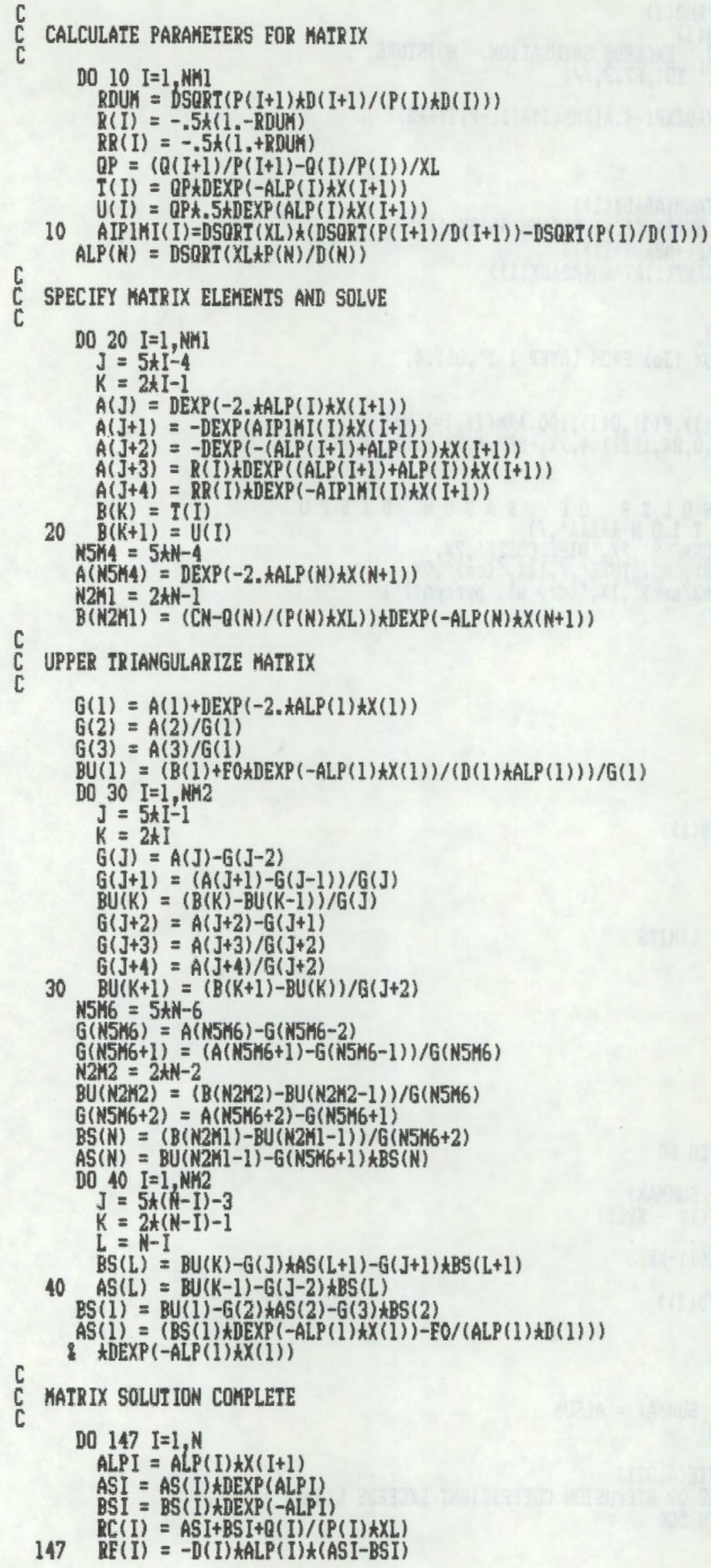




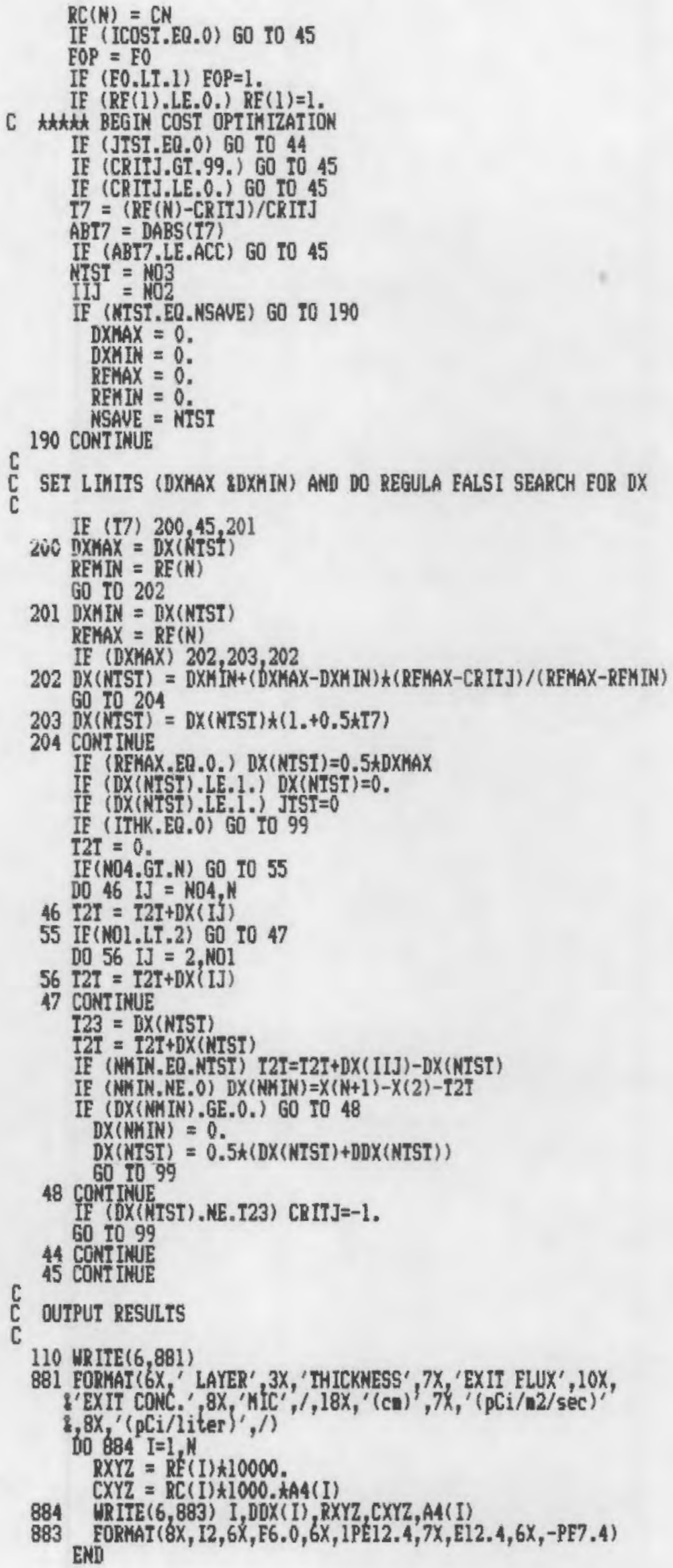



NUREG/CR-3533

PNL -4878

RAE-18-5

RU

\section{DISTRIBUTION}

No. of

$\underline{\text { Copies }}$

OFFSITE

U.S. Nuclear Regulatory Commission

Division of Technical Information and Document Control

7920 Norfolk Avenue

Bethesda, MD 20014

10 George F. Birchard

U.S. Nuclear Regulatory Commission 1130-SS

Washington, DC 20555

15 V. C. Rogers

Rogers \& Associates Eng. Corp

P. 0. Box 330

Salt Lake City, UT 84110

10 K. K. Nielson

Rogers \& Associates Eng. Corp.

P. 0. Box 330

Salt Lake City, UT 84110

M. L. Matthews

Department of Energy

Albuquerque, NM 87115

P. J. Magno

ANR 460

U.S. Environmental Protection Agency

402 M Street S.W.

Washington, DC 20460

P. T. Owen

Remedial Action Program Information Center

Oak Ridge National Laboratory

P. 0. Box X, Building 2001

Oak Ridge, TN 38830

Walter C. Barber

Jacobs Engineering Group, Inc.

5301 Central Ave., N.E., Ste. 1700

Albuquerque, NM 87108
No. of

Copies
Mark Jackson

Jacobs Engineering Group, Inc.

5301 Central Ave., N.E., St. 1700

Albuquerque, NM 87108

Ken R. Baker

Jacobs Engineering Group, Inc.

5301 Central Ave., N.E., Ste. 1700

Albuquerque, NM 87108

Peter Rafferty

Weston

5301 Central Ave., N.E., Ste. 1700

Albuquerque, NM 87108

John Nelson

Colorado State University

Fort Collins, CO 80523

Thomas Shepherd

Water, Waste \& Land Co.

1311 So. College Ave.

Fort Collins, CO 80524

John Themel is

U.S. Department of Energy

5301 Central Ave., N.E., Ste. 1700

Albuquerque, NM 87108

Victor Haw

National Uranium Tailings Program

555 Booth St.

Ottawa, Ontario

KIA OGI

Gordon M. Ritcey

Canada Centre for Mineral \&

Energy Technology

555 Booth St.

Ottawa, Ontario

KIA OGI 
NUREG/CR-3533

PNL-4878

RAE-18-5

DISTRIBUTION

$\mathrm{RU}$

No. of

Copies

Desmond M. Levins

Australian Atomic Energy Commission Research Establishment

Lucas Heights, New South Wales 2232

Australia

Kaye P. Hart

Australian Atomic Energy Commission

Research Establishment

Lucas Heights, New South Wales 2232

Australia

Hoyt Mitchell

Project Engineer

ARIX

1005 North 12th St., Suite 202

Grand Junction, CO 81501
No. of

Copies

B. W. Opitz

R. W. Perkins

S. R. Peterson

A. E. Reisenauer

T. W. Schrauf

D. R. Sherwood

J. A. Stottlemyre

R. L. Skaggs

V. W. Thomas

N. A. Wogman

Publishing Coordination (2)

Technical Information (5)

\section{ONSITE}

35 Pacific Northwest Laboratory

W. J. Deutsch

D. W. Dragnich/C. E. Elderkin

M. E. Dodson

J. L. Downs-Berg

R. M. Ecker

M. R. Elmore

R. L. Erickson

W. D. Felix

M. G. Foley

J. S. Fruchter

G. W. Gee

J. N. Hartley

P. 0. Jackson

10 D. R. Kalkwarf

C. W. Kimball

C. T. Kincaid

J. M. Latkovich

E. A. Lepe 1

M. J. Mason

W. J. Martin

T. J. Mckeon

I. C. Nelson

R. W. Nelson

J. M. Nielson 


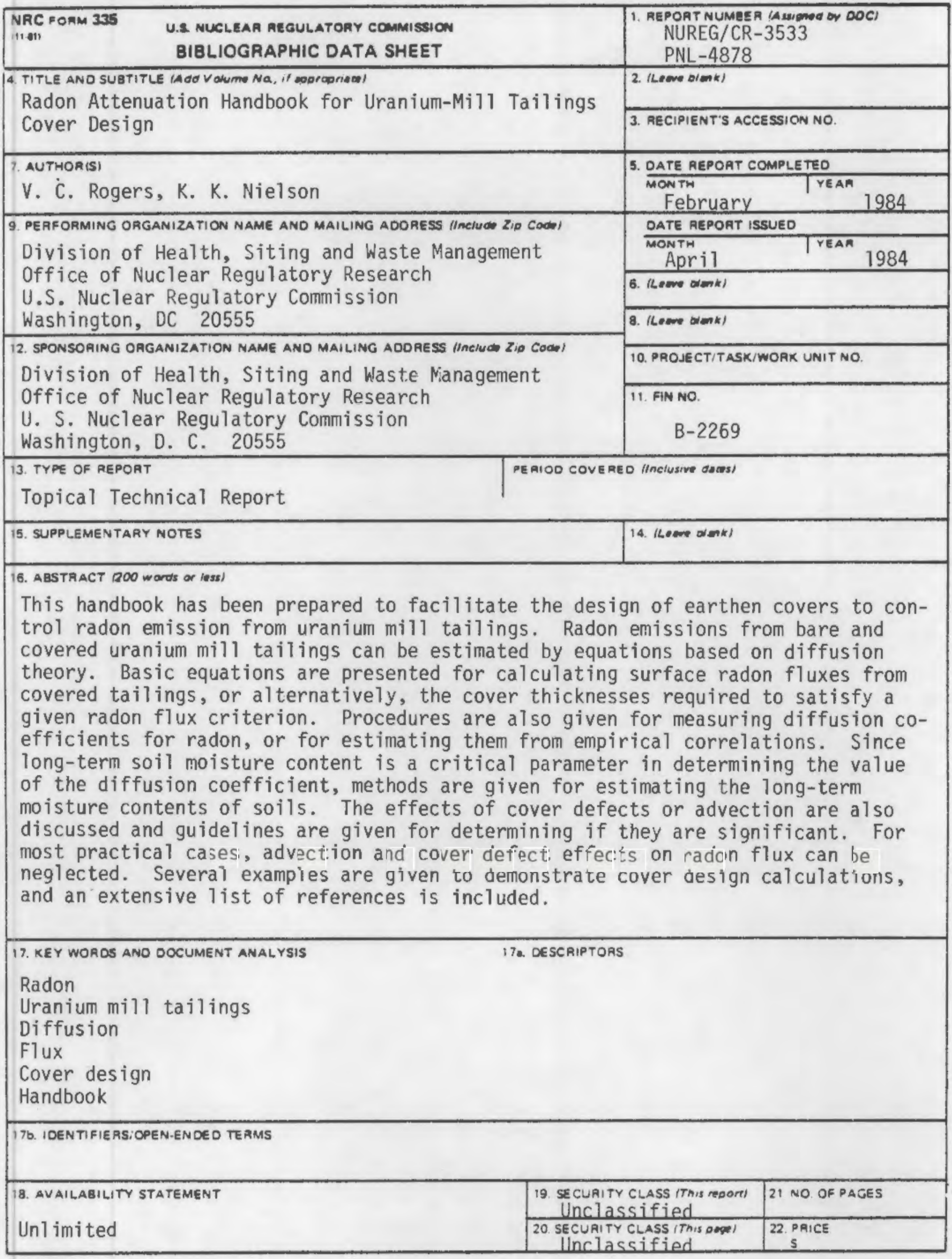


